\title{
WestVirginiaUniversity
}

THE RESEARCH REPOSITORY @ WVU

Graduate Theses, Dissertations, and Problem Reports

2012

\section{A Simplified Icing Model for Simulation and Analysis of Dynamic Effects}

Matthew A. Cunningham

West Virginia University

Follow this and additional works at: https://researchrepository.wvu.edu/etd

\section{Recommended Citation}

Cunningham, Matthew A., "A Simplified Icing Model for Simulation and Analysis of Dynamic Effects" (2012). Graduate Theses, Dissertations, and Problem Reports. 486.

https://researchrepository.wvu.edu/etd/486

This Thesis is protected by copyright and/or related rights. It has been brought to you by the The Research Repository @ WVU with permission from the rights-holder(s). You are free to use this Thesis in any way that is permitted by the copyright and related rights legislation that applies to your use. For other uses you must obtain permission from the rights-holder(s) directly, unless additional rights are indicated by a Creative Commons license in the record and/ or on the work itself. This Thesis has been accepted for inclusion in WVU Graduate Theses, Dissertations, and Problem Reports collection by an authorized administrator of The Research Repository @ WVU. For more information, please contact researchrepository@mail.wvu.edu. 
A Simplified Icing Model for Simulation and Analysis of Dynamic Effects

Matthew A. Cunningham

Thesis Submitted to the

College of Engineering and Mineral Resources

at West Virginia University

in partial fulfillment of the requirements

for the degree of

Master of Science

in

Mechanical Engineering

Mario G. Perhinschi, Ph.D., Chair

Wade Huebsch, Ph.D.

Marcello Napolitano, Ph.D.

Department of Mechanical and Aerospace Engineering

Morgantown, West Virginia

2012

Keywords: Simulation, Wing Icing, Ice Accretions 


\section{Abstract \\ A Simplified Icing Model for Simulation and Analysis of Dynamic Effects Matthew A. Cunningham}

Ice accretions on aerodynamic surfaces are a major concern during flight. In this research effort, glaze ice is being modeled and its effects on aircraft dynamics analyzed. This type of ice builds up as a clear layer on aerodynamic surfaces and other components such as antennas and intakes. Glaze icing is dangerous because as the amount of ice increases, it alters the shape and properties of the aerodynamic surface. Wind tunnel tests of this type of icing and data analysis have shown that the main effects of icing consist of decrease of lift coefficient, reduction of stall angle of attack, increase in drag coefficient, reduction of control surface effectiveness, and degradation of stability characteristics. In some instances, icing can produce significant gravimetric alterations and aerodynamic control surface lockage.

Based on these conclusions, a simplified icing model has been developed as part of a simulation package for aircraft health management instruction. The objective of this simulation package is to offer an interactive educational environment for experimentation, demonstration, and analysis of flight at both nominal and abnormal conditions. This icing model is expected to provide computationally effective tools primarily for the study of dynamic effects of ice accretions on aircraft performance, handling qualities, and pilot workload. Experimental wind tunnel data under icing conditions were used to develop regression models for the lift and drag coefficients. Linear variation with time in icing was considered for the degradation of stability and control derivatives.

The simplified icing model has been integrated with a business jet real-time simulation model since this type of aircraft is frequently subjugated to icing conditions. The impact of icing on aircraft is analyzed via simulation and observation of modal parameters. During steady state flight, linearization is performed to obtain stability matrices and their eigenvalues are used to determine and study the modal parameters on both the longitudinal and lateral-directional channels. In addition, the performance analysis studies the aircraft capabilities to maintain steady level symmetric and asymmetric flight. Also, an examination of the aircraft longitudinal and lateral-directional handling qualities compared to specifications for Class II aircraft in phase B flight conditions was considered.

Numerical simulations have revealed that the icing model behaves qualitatively as expected. While the time under icing conditions increases, the aircraft becomes much more difficult to control and a steady level flight condition can no longer be maintained after approximately three minutes when the throttle command saturates. Continued exposure to icing conditions results in approaching stall conditions and/or loss of altitude. The modal parameter analysis shows a degradation of handling qualities for both longitudinal and lateral-directional channels. The largest relative degradation is recorded for the damping ratios of the phugoid and Dutch roll. However, it is the short term oscillation that experiences a degradation by one level of handling qualities on the Cooper-Harper scale. 


\section{Acknowledgements}

First, I would like to thank my committee chair, Dr. Perhinschi, for this opportunity in furthering my education. I would also like to thank my committee members, Dr. Napolitano and Dr. Huebsch, for their time and patience in dealing with me.

I would also like to express thanks to Bonnie, without her help I would not have made it into this program or given this opportunity. To my family and friends, who have always been there with support and help. And to my love, Rivkah, without you here to keep edging me on, I never would have made it this far. 


\section{Table of Contents}

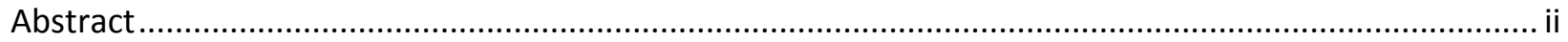

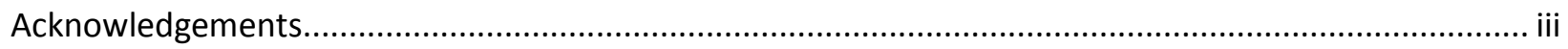

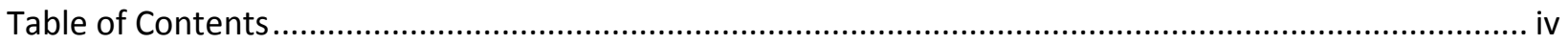

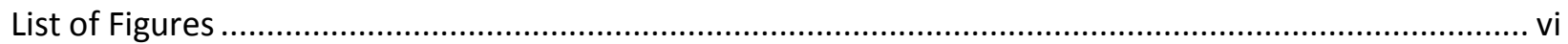

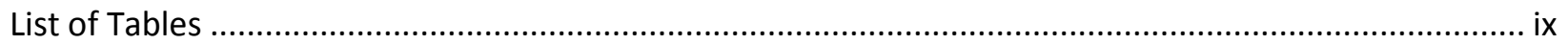

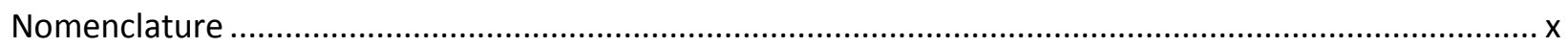

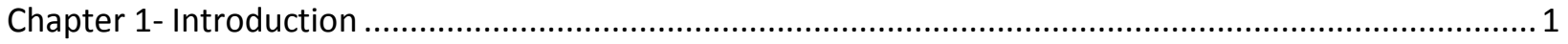

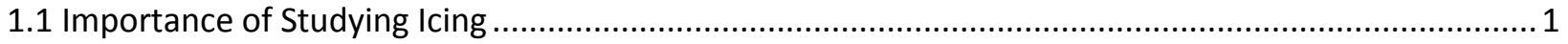

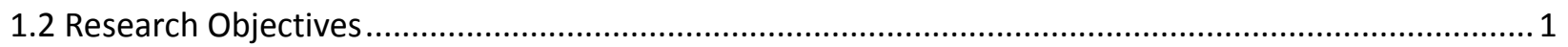

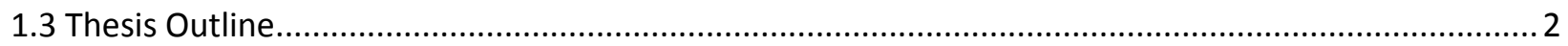

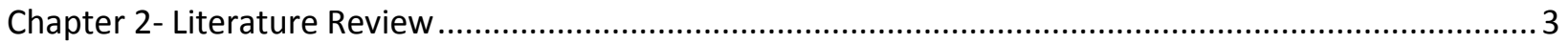

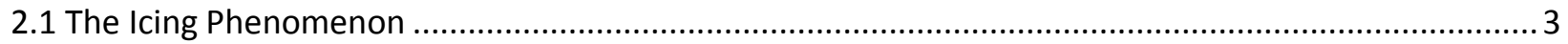

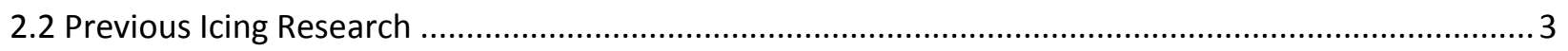

2.2.1 Computational Icing Research ................................................................................................ 4

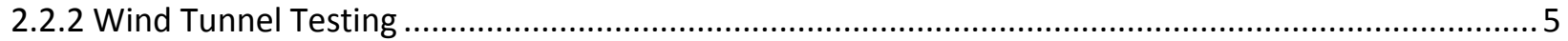

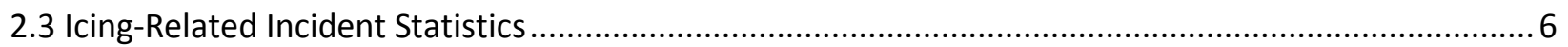

Chapter 3- Model Development Methodology ................................................................................. 7

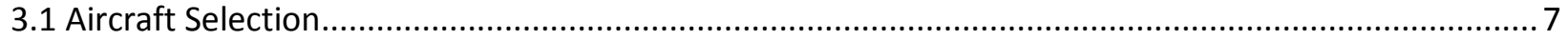

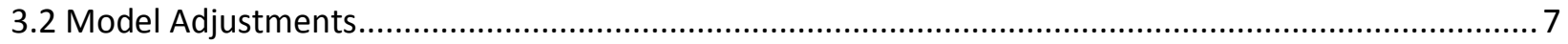

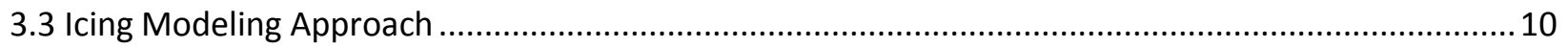

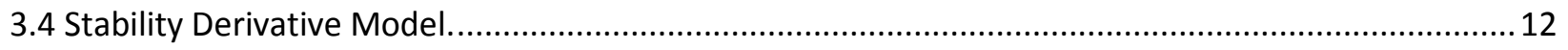

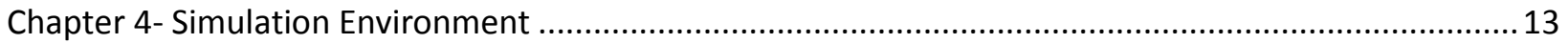

4.1 General Description of the Simulation Environment .................................................................... 13

4.2Linearizing the Model: Stability and Control Derivatives ............................................................... 15

4.3Linearizing the Model: Matrix Formulation and Eigenvalues ......................................................... 17

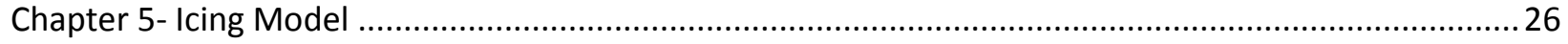

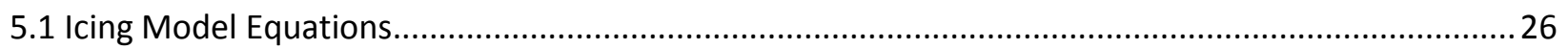

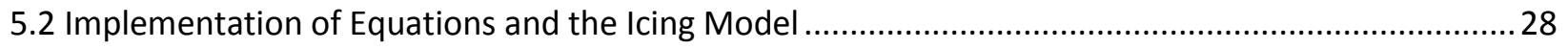

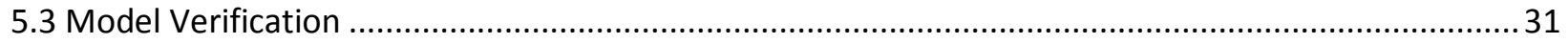

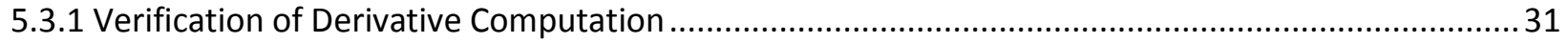

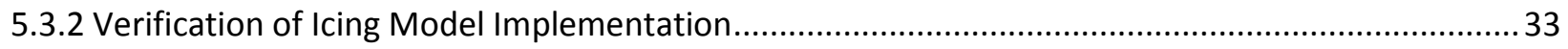




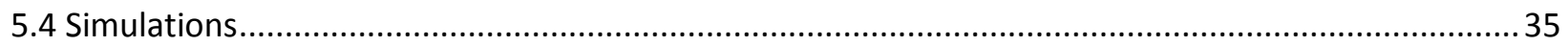

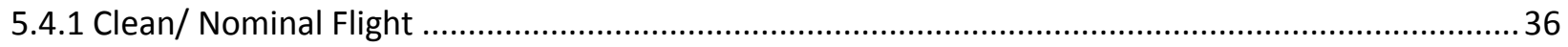

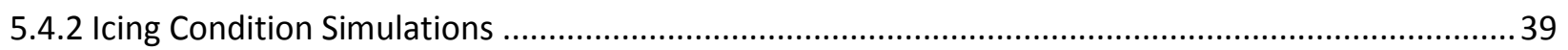

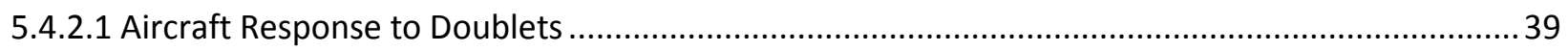

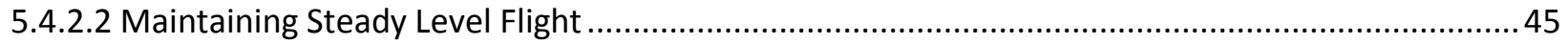

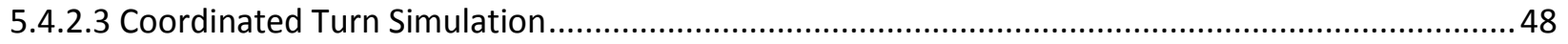

Chapter 6- Analysis of Icing Impact on Aircraft Dynamics .................................................................. 51

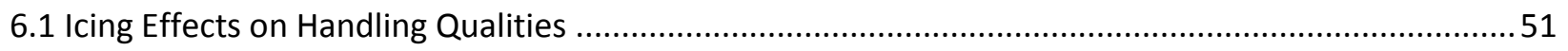

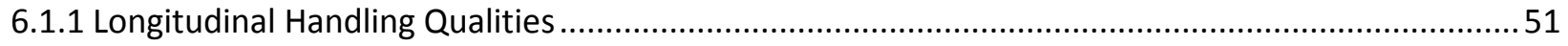

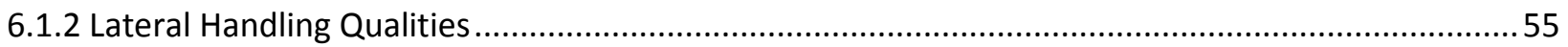

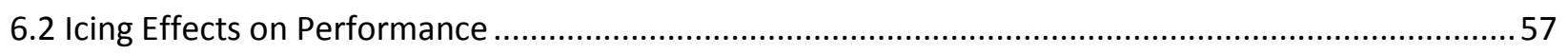

6.2.1 Trim Requirements for Horizontal Flight ............................................................................... 57

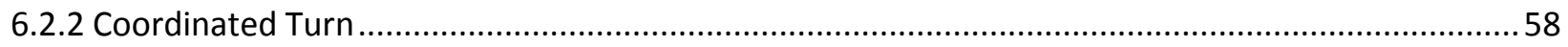

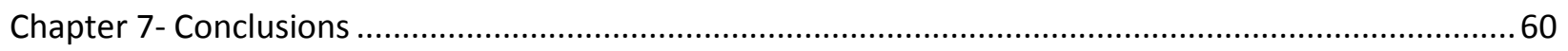

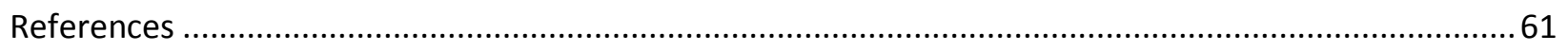

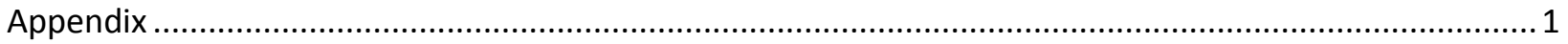

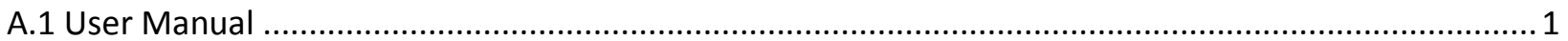




\section{List of Figures}

Figure 1: (Left) Clear ice formed on a wing. (Center) Mixed ice formed on wing in flight. (Right) Rime ice buildup. Photos courtesy of AOPA and NASA. .. 3

Figure 2: Plot of total accidents with icing conditions. Courtesy of NASA [40]...................... 6

Figure 3: General overview of business jet model......................................................... 7

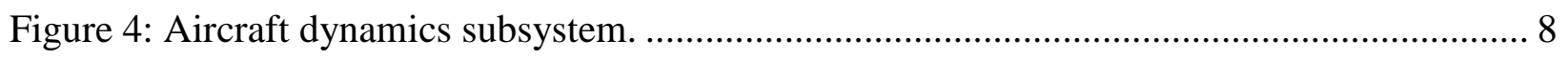

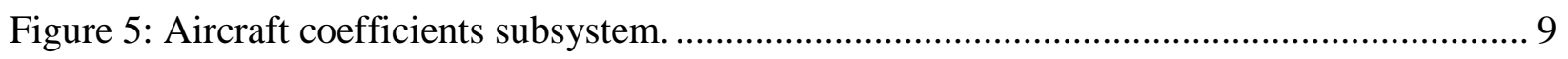

Figure 6: Landing gear, flaps, and speed brake defaults............................................... 9

Figure 7: Lift coefficient degradation over time spent in icing .......................................... 10

Figure 8: Drag coefficient degradation over time spent in icing ......................................... 11

Figure 9: Normalized drag coefficient data. ........................................................................ 11

Figure 10: Moment coefficient multiplied to $\mathrm{C}_{\mathrm{m} \alpha}$ and the stall lookup table. .......................... 12

Figure 11: Icing from blocks and the compute reference derivatives subsystem..................... 12

Figure 12: Aircraft health management portal, aircraft selection screen................................. 13

Figure 13: Pilot input menu for selecting control inputs. .................................................... 13

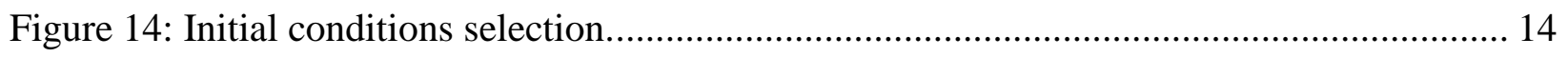

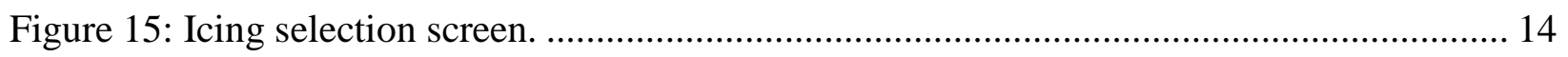

Figure 16: Screenshot of icing simulation setup............................................................. 15

Figure 17: Section of compute reference derivative subsystem used to modify variables.......... 16

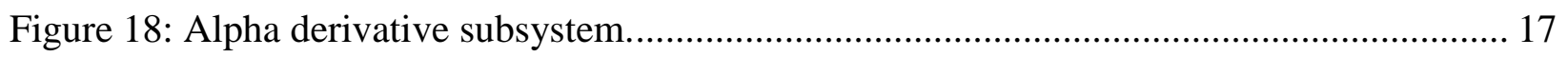

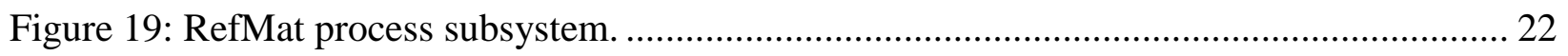

Figure 20: Compute reference matrices subsystem. ........................................................ 22

Figure 21: Building and implementation of longitudinal matrix equations.............................. 23

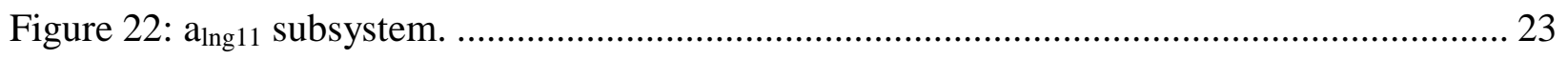

Figure 23: Construct matrices into vector to go to file....................................................... 24

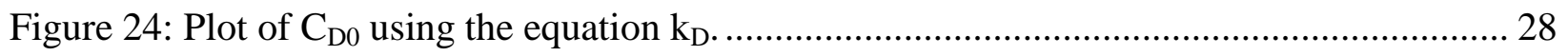

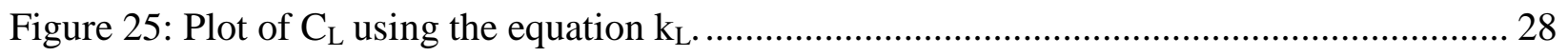

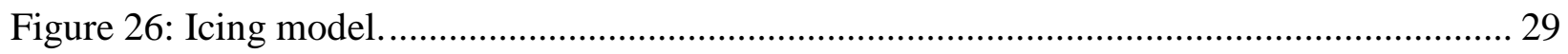

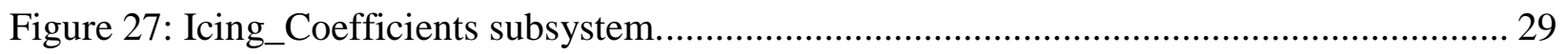

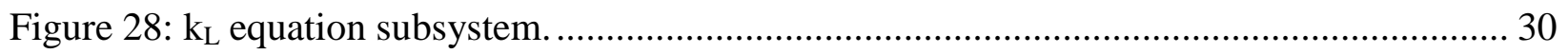

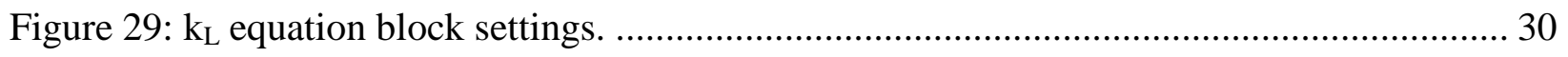

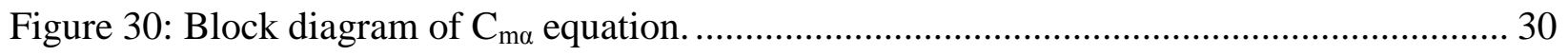

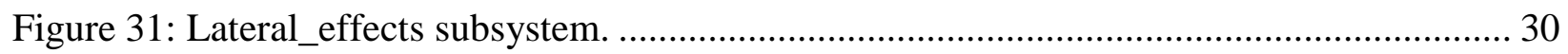

Figure 32: Lateral stability derivative icing block diagrams. ............................................... 31 
Figure 33: $\mathrm{C}_{\mathrm{za}}, \mathrm{C}_{\mathrm{ma}}, \mathrm{C}_{\mathrm{zV}}$, and $\mathrm{C}_{\mathrm{mV}}$ values calculated within the calculate derivatives subsystem. 33

Figure 34: Data presented by NASA [38] ........................................................................ 34

Figure 35: NASA data presented for drag coefficient [36] .................................................. 34

Figure 36: Plot of $\mathrm{C}_{\mathrm{L}}$ against angle of attack using icing constant equations and stall lookup

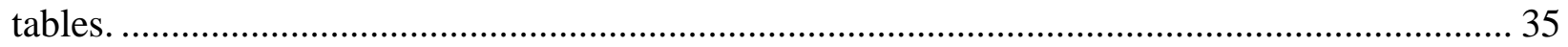

Figure 37: CD against angle of attack using the icing constant equation................................ 35

Figure 38: Elevator and roll deflections used in clean and ice simulations.............................. 36

Figure 39: Rudder deflections used for clean and ice simulations. ....................................... 36

Figure 40: Pitch rate response under nominal conditions.................................................... 37

Figure 41: First elevator control deflection doublet and pitch rate response............................. 37

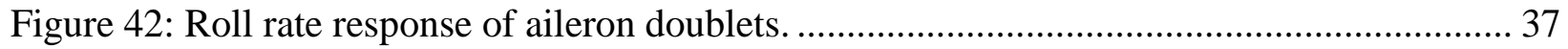

Figure 43: Second doublet from the left aileron and the roll rate response it created. ................ 38

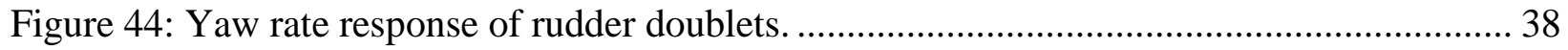

Figure 45: (Left) Third rudder doublet input. (Right) Yaw rate response to third rudder doublet.

Figure 46: Elevator inputs for icing simulation and the pitch rate responses.......................... 40

Figure 47: Pitch rate response to elevator doublet 1 (2 minutes in icing). ................................ 40

Figure 48: Pitch rate response to elevator doublet 2(4 minutes in icing). ............................... 41

Figure 49: Elevator doublet 3(6 minutes in icing) and additional commands to maintain steady

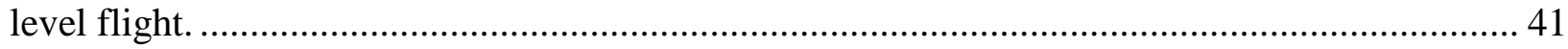

Figure 50: Pitch rate response of elevator doublet 3(6 minutes in icing) and additional steady

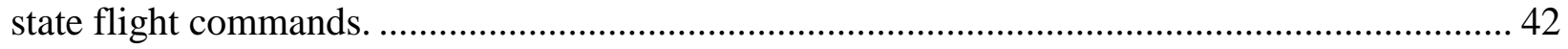

Figure 51: Left aileron doublets for icing simulation and the roll rate responses. .................... 42

Figure 52: Roll rate response to roll doublet 1 (2 minutes in icing)....................................... 42

Figure 53: Roll doublet 2(4 minutes in icing) and steady state command input shown next to the

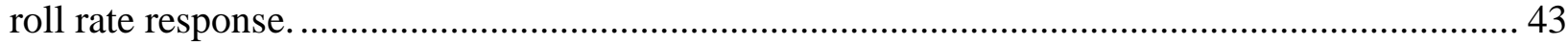

Figure 54: Roll doublet 3(6 minutes in icing) and additional steady state roll commands shown

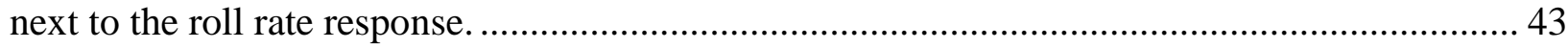

Figure 55: The three rudder doublets and their responses. .................................................... 44

Figure 56: Yaw rate response to rudder doublet 1(2 minutes in icing). ................................... 44

Figure 57: Yaw rate response to rudder doublet 2(4 minutes in icing). .................................. 44

Figure 58: Yaw rate response to rudder doublet 3(6 minutes in icing). .................................. 45

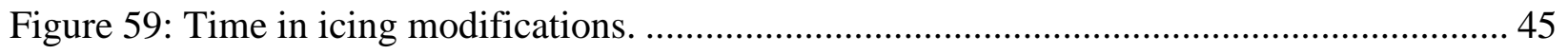

Figure 60: Elevator and throttle deflections for steady level flight. ..................................... 46

Figure 61: Aileron and rudder deflections for maintaining steady level flight......................... 46

Figure 62: Aircraft's altitude throughout simulation. ....................................................... 46 


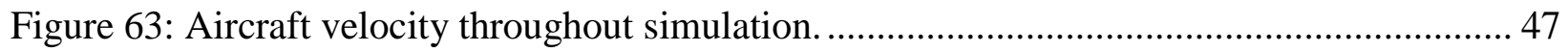

Figure 64: Aircraft's pitch rate response throughout the simulation........................................ 47

Figure 65: PID roll attitude hold controller. ..................................................................... 48

Figure 66: Aircraft roll angle for clean simulation............................................................ 48

Figure 67: Aileron control inputs (left) and throttle command (right). .................................. 49

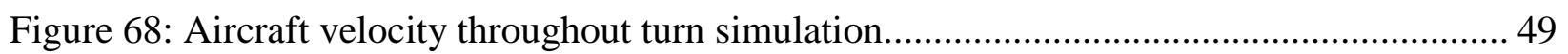

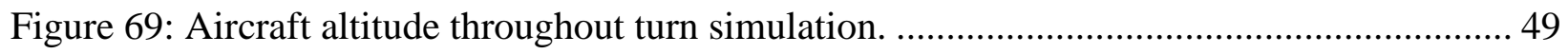

Figure 70: Aileron deflections throughout turn simulation. ............................................... 50

Figure 71: Changes in short period frequency over time................................................... 52

Figure 72: Pitch rate response of aircraft after 6 minutes in icing......................................... 52

Figure 73: Changes in short period damping over time...................................................... 53

Figure 74: Changes in phugoid frequency over time.......................................................... 53

Figure 75: Plot showing phugoid response after 3 minutes of icing...................................... 54

Figure 76: Changes in phugoid damping with time.......................................................... 54

Figure 77: Plot of short period frequency vs. gravity force/angle of attack. .......................... 55

Figure 78: Changes in Dutch roll frequency with time....................................................... 55

Figure 79: Plot of roll doublet response after 6 minutes in icing........................................... 56

Figure 80: Changes in Dutch roll damping with time......................................................... 56

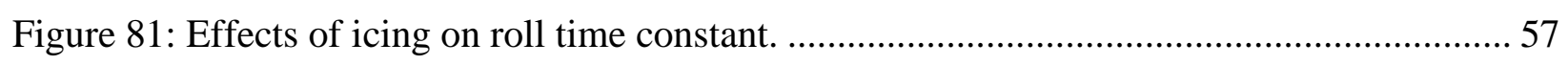

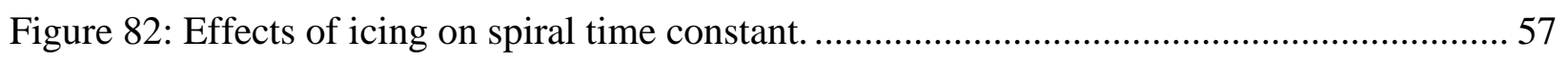

Figure 83: (Left) Altitude at four minutes in icing. (Right) Altitude at five minutes in icing...... 58

Figure 84: Aircraft roll angle under varying amounts of ice. ................................................ 59 


\section{List of Tables}

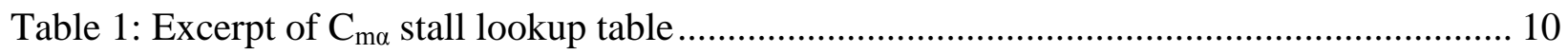

Table 2: List of stability derivatives from lookup table compared to calculated.......................... 31

Table 3: Required trim settings to maintain steady level flight................................................... 58

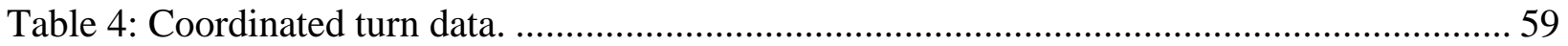




\section{Nomenclature}

\section{Variables}

\begin{tabular}{|c|c|c|}
\hline Variable & Description & Units \\
\hline A & Stability Matrix & - \\
\hline a & Stability Matrix Element; Constant & - \\
\hline B & Control Matrix & - \\
\hline $\mathrm{b}$ & Control Matrix Element; Wing Span; Constant & $\mathrm{m}$ \\
\hline $\mathrm{C}$ & Aerodynamic Coefficient & - \\
\hline $\mathrm{c}$ & Chord Length & $\mathrm{m}$ \\
\hline $\bar{c}$ & Mean Aerodynamic Chord & $\mathrm{m}$ \\
\hline D & Derivative with Respect to Time & - \\
\hline $\mathrm{g}$ & Acceleration from Gravity & $\mathrm{m} / \mathrm{s}^{2}$ \\
\hline I & Moment of Inertia; Identity Matrix & $\mathrm{Kg}-\mathrm{m}^{2} ;-$ \\
\hline $\mathrm{i}$ & Non-dimensionalized Moment of Inertia & - \\
\hline $\mathrm{j}$ & Imaginary Component & - \\
\hline $\mathrm{k}$ & Alteration Factor & - \\
\hline 1 & Half Mean Chord; Half Wing Span & $\mathrm{m}$ \\
\hline $\mathrm{m}$ & Mass & $\mathrm{Kg}$ \\
\hline $\mathrm{P}$ & Roll Rate & $\mathrm{deg} / \mathrm{sec}$ \\
\hline$\dot{p}$ & Roll Rate Derivative with Respect to Time & $\mathrm{deg} / \mathrm{sec}^{2}$ \\
\hline$\hat{\mathrm{p}}$ & Non-dimensional Roll Rate & - \\
\hline$q$ & Pitch Rate & $\mathrm{deg} / \mathrm{sec}$ \\
\hline$\dot{q}$ & Pitch Rate Derivative with Respect to Time & $\mathrm{deg} / \mathrm{sec}^{2}$ \\
\hline$\hat{\mathrm{q}}$ & Non-dimensional Pitch Rate & - \\
\hline$r$ & Yaw Rate & $\mathrm{deg} / \mathrm{sec}$ \\
\hline$\dot{r}$ & Yaw Rate Derivative with Respect to Time & $\mathrm{deg} / \mathrm{sec}^{2}$ \\
\hline$\hat{\mathrm{r}}$ & Non-dimensional Yaw Rate & - \\
\hline $\mathrm{S}$ & Wing Surface Area & $\mathrm{m}^{2}$ \\
\hline $\mathrm{s}$ & s-domain Variable & - \\
\hline $\mathrm{t}$ & Time; Time Constant & $\mathrm{sec} ; \min$ \\
\hline$t^{*}$ & Normalization Factor for Time & $1 / \mathrm{s}$ \\
\hline u & $\mathrm{x}$-velocity Component & $\mathrm{m} / \mathrm{s}$ \\
\hline$\hat{u}$ & Non-dimensionalized $\mathrm{x}$-velocity perturbations & - \\
\hline $\mathrm{V}$ & Velocity & $\mathrm{m} / \mathrm{s}$ \\
\hline$\dot{V}$ & Velocity Derivative with Respect to Time & $\mathrm{deg} / \mathrm{sec}^{2}$ \\
\hline $\mathrm{x}$ & Aircraft Stability Parameter & - \\
\hline$\dot{X}$ & State Vector & - \\
\hline \multicolumn{3}{|c|}{ Greek Variables } \\
\hline$\alpha$ & Angle of Attack & $\operatorname{deg}$ \\
\hline$\dot{\alpha}$ & $\begin{array}{c}\text { Angle of Attack Derivative with Respect to Time; Rate of } \\
\text { Change of Angle of Attack }\end{array}$ & $\mathrm{deg} / \mathrm{sec}$ \\
\hline$\beta$ & Sideslip Angle & $\mathrm{deg} ; \mathrm{rad}$ \\
\hline$\dot{\beta}$ & Sideslip Angle Derivative with Respect to Time & $\mathrm{deg} / \mathrm{sec}$ \\
\hline$\delta \mathrm{a}$ & Aileron Deflection & - \\
\hline
\end{tabular}




\begin{tabular}{|c|c|c|}
\hline$\delta \mathrm{e}$ & Elevator Deflection & - \\
\hline$\delta \mathrm{r}$ & Rudder Deflection & - \\
\hline$\zeta$ & Perturbation of Rudder Deflection; Damping Coefficient & deg; rad; - \\
\hline$\eta$ & Elevator Deflection Perturbation & deg; rad \\
\hline$\theta$ & Pitch Angle & $\mathrm{deg} ; \mathrm{rad}$ \\
\hline$\dot{\theta}$ & Pitch Angle Derivative with Respect to Time & $\mathrm{deg} / \mathrm{sec}$ \\
\hline$\lambda$ & Eigenvalue & - \\
\hline$\mu$ & Non-dimensionalized mass & - \\
\hline$\xi$ & Aileron Deflection Perturbation & $\mathrm{deg} ; \mathrm{rad}$ \\
\hline$\rho$ & Density & $\mathrm{Kg} / \mathrm{m}^{3}$ \\
\hline$\phi$ & Roll Angle & $\mathrm{deg} ; \mathrm{rad}$ \\
\hline$\dot{\phi}$ & Roll Rate Derivative with Respect to Time & $\mathrm{deg} / \mathrm{sec}$ \\
\hline$\psi$ & Yaw Angle & $\mathrm{deg} ; \mathrm{rad}$ \\
\hline$\omega$ & Frequency & $\mathrm{rad} / \mathrm{sec}$ \\
\hline \multicolumn{3}{|c|}{ Subscripts } \\
\hline Symbol & Description & Units \\
\hline 0 & Initial Condition; 0 Angle of Attack & - \\
\hline $1,2,3,4$ & Various Velocity Equations; State Space Matrix Indices & - \\
\hline $\mathrm{A}, \mathrm{B}, \mathrm{C}$ & Moment of Inertia about X,Y,Z & - \\
\hline a & Aileron & - \\
\hline $\mathrm{D}$ & Inertia about yz; Drag & - \\
\hline $\mathrm{E}$ & Inertia about $\mathrm{xz}$ & - \\
\hline $\mathrm{e}$ & Elevator & - \\
\hline $\mathrm{F}$ & Inertia about $\mathrm{xy}$ & - \\
\hline FM & Aircraft Force or Moment & - \\
\hline fa & Force of Aileron & - \\
\hline $\mathrm{fe}$ & Force of Elevator & - \\
\hline $\mathrm{fr}$ & Force of Rudder & - \\
\hline ha & Aileron Hinge Moment & - \\
\hline he & Elevator Hinge Moment & - \\
\hline $\mathrm{hr}$ & Rudder Hinge Moment & - \\
\hline $\mathrm{L}$ & Lift & - \\
\hline 1 & Rolling Moment & - \\
\hline $\operatorname{lng}$ & Longitudinal & - \\
\hline lt & Lateral & - \\
\hline $\mathrm{m}$ & Pitching Moment & - \\
\hline $\mathrm{n}$ & Yawing Moment; Natural Frequency & - \\
\hline $\mathrm{p}$ & Perturbation of Roll Rate & - \\
\hline $\mathrm{q}$ & Perturbations of Pitch Rate & - \\
\hline $\mathrm{r}$ & Perturbation of Yaw Rate; Rudder & - \\
\hline Roll,spiral & Roll, Spiral Time Constants & - \\
\hline $\mathrm{u}$ & Velocity x-component & - \\
\hline V & Velocity & - \\
\hline $\mathrm{x}$ & Forces in $\mathrm{x}$-direction; $\mathrm{x}$-direction & - \\
\hline $\mathrm{y}$ & Forces in y-direction; $y$-direction & - \\
\hline
\end{tabular}




$\begin{array}{ccc}\text { z } & \text { Forces in z-direction; z-direction } & - \\ \alpha & \text { Greek Subscripts } & - \\ \dot{\alpha} & \text { Angle of Attack } & - \\ \beta & \text { Rate of Change of Angle of Attack } & - \\ \delta \mathrm{a} & \text { Sideslip Angle } & - \\ \delta \mathrm{e} & \text { Aileron Deflection } & - \\ \delta \mathrm{r} & \text { Elevator Deflection } & - \\ \zeta & \text { Rudder Deflection } & - \\ \dot{\zeta} & \text { Perturbation of Rudder Deflection } & - \\ \eta & \text { Rate of Change of Perturbed Rudder Deflection } & - \\ \dot{\eta} & \text { Elevator Deflection Perturbation } & - \\ \xi & \text { Rate of Change of Perturbed Elevator Deflection } & - \\ \dot{\xi} & \text { Aileron Deflection Perturbation } & \end{array}$

\begin{tabular}{|c|c|c|}
\hline \multicolumn{3}{|c|}{$\underline{\text { Acronyms }}$} \\
\hline Symbol & Description & Units \\
\hline AOA & Angle of Attack & Degrees \\
\hline AOPA & Aircraft Owner and Pilots Association & - \\
\hline FAA & Federal Aviation Administration & - \\
\hline GUI & Graphical User Interface & - \\
\hline NACA & National Advisory Committee for Aeronautics & - \\
\hline NASA & National Aeronautics and Space Administration & - \\
\hline WVU & West Virginia University & - \\
\hline
\end{tabular}




\section{Chapter 1- Introduction}

\subsection{Importance of Studying Icing}

The phenomenon of aircraft wing icing is a dangerous one that has led to countless accidents [31]. The buildup of ice accretions alter the wing's profile shape, leading to alterations of the aircraft's overall lift and drag properties. As a consequence, significant changes in the aircraft's performance and handling qualities may occur. These changes can often be an early warning sign to the pilot that they have a buildup of ice on their aircraft. How do ice accretions affect the handling qualities and performance of the aircraft? To answer this question, a simulation of an aircraft icing occurrence has been developed, tested, analyzed, and discussed here, which will allow for safe and effective studies of the dynamic effects of icing. The simplified model developed within this effort can be easily implemented in motion base simulators for pilots, or in classroom applications for future engineers to learn from.

Extensive research has been done by NASA in examining the occurrence of ice accretions on an aircraft as a consequence of the importance of this phenomenon. They have also replicated the occurrence in wind tunnel tests and achieved good results. Some of their research is applied to this project [38]. NASA's research goes hand in hand with the FAA's campaign of alerting pilots to the dangers of ice accretions. The flight safety branch of the FAA has organized a safety advisor that shows statistics and warns pilots of the signs of ice accretions [1].

Currently, many different companies are working on methods of melting or dispersing the ice that builds up on an aircraft's wings. These methods include pneumatic and mechanical devices that a pilot may deploy in order to break up the ice on the wings and even some chemical treatment of the wings that can be performed by ground crews before flight [6][40].

Here at West Virginia University (WVU), a simulation package including several different aircraft has been developed for the purpose of studying aircraft dynamics under both nominal and abnormal conditions[7][35]. Abnormal conditions include; actuator failure, structural failure, engine failures, sensor failures, as well as environmental upset conditions. The simulation package has been developed for student use to study varying failures and their effects on the aircraft's performance and pilot workload. The developed icing model was added to the business jet model and integrated into the simulation package [11].

\subsection{Research Objectives}

The primary objective of this research is to develop a simplified model of aircraft icing that can be applied to the WVU Aircraft Health Management simulation package, and allow students the opportunity to observe icing effects on aircraft in flight. This will also allow for the analysis and study of the effects of ice accretions on the aircraft's stability and modal parameters. Throughout the course of this research, several milestones were set in order to ensure that all objectives were met. These milestones can be summarized as follows:

1. Select an appropriate aircraft for icing applications.

2. Find icing data applicable to selected aircraft.

3. Develop and implement a mathematical model that captures the main aerodynamic effects of icing and their variation in time.

4. Develop and implement a simulation module for the calculation of aircraft stability derivatives at pre-set time intervals during simulation.

5. Implement aircraft linear equations of motion using the calculated derivatives. 
6. Extract stability matrices at pre-set time intervals and use their eigenvalues to analyze the effects of icing on aircraft dynamics and handling qualities.

\subsection{Thesis Outline}

The remainder of this thesis will be organized with the following chapters. Chapter 2 will contain a literature review of previous studies within the field of aircraft icing. Chapter 3 will delve into the methodology of how this project was approached including why the business jet aircraft was selected and how the icing model and codes were developed. Chapter 4 will discuss the model environment, the matrix formulation, and the eigenvalue formulation. Chapter 5 will cover how the icing model itself was implemented, as well as cover its validation. The remainder of chapter 5 will contain example simulation data for a simulation of the aircraft under nominal conditions and also under icing conditions. Chapter 6 will study the results of simulations and discuss the dynamic effects of icing along both the longitudinal and lateral directions. Finally, chapter 7 will contain conclusions of the simulation and analysis. 


\section{Chapter 2- Literature Review}

\subsection{The Icing Phenomenon}

Ice accretions have been a major hazard to aircraft flight since the early days [38]. Significant research efforts have continuously focused on better understanding the icing environment and making flight in icing conditions safer [37]. Icing conditions occur at temperatures below freezing when there is moisture in the air. This moisture is in a super-cooled state and when it strikes the aircraft surfaces, it freezes instantly, creating the ice layer. Initially, ice builds up as a thin rough layer on the surface's leading edge [21]. Gradually, it continues to grow on the leading edge and alters the surface geometry and thusly its aerodynamic properties. Ice accretions will not only affect the airfoil geometry but will accrue on the entire aircraft. They can adversely affect the aircraft by: increasing drag, reducing lift, increasing weight [26], possibly inflicting a loss of power, affecting control surfaces [20], changing efficiency of brakes, interfering with the aircraft's landing gear, increasing vibrations and structural stresses, causing a reduction in pilot field of view, afflicting various aircraft sensors, and also affecting radio navigation and communication [1].

Severe icing conditions can lead to either a tail stall or a wing stall of the aircraft [7]. Tail stalls are dangerous and a pilot should be ready for them since ice can build up faster on the tail section than on the wing. Also, roll upsets may occur as a result of ice creating forces that cause the ailerons to deflect [28].

Ice accretions also come in a variety of types, such as rime, which is rough and milky white in appearance, clear (or glaze), which is the type that typically afflicts control surfaces, and mixed ice, which is a combination of the two [1]. Clear ice is properly named due to its transparent appearance and it contains air pockets that make it lumpy. As clear ice accumulates it becomes more and more irregular in shape, leading to the changes in aerodynamic properties of the surface. Figure 1 shows the different types of ice on aircraft surfaces.

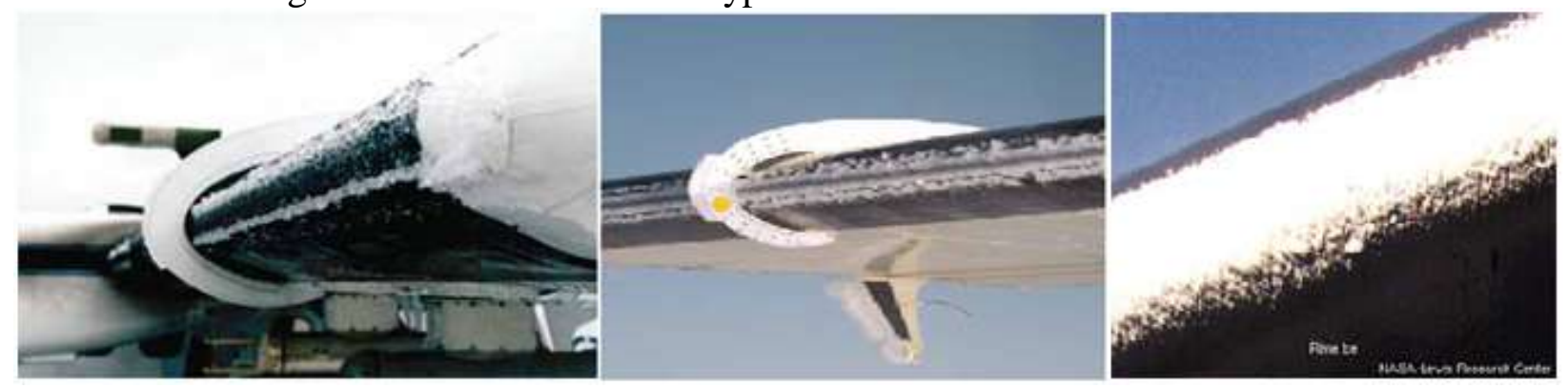

Figure 1: (Left) Clear ice formed on a wing. (Center) Mixed ice formed on wing in flight. (Right) Rime ice buildup. Photos courtesy of AOPA and NASA.

Due to the hazards of aircraft icing, aircraft certification authorities have responded by imposing strict requirements for aircraft operation within icing conditions [47]. Some of these requirements include the airplane having ice protections devices that meet special federal aviation regulations, a pilot may not take off if the airplane has frost, ice, or snow on any propeller or control surface, and no pilot may fly into known icing conditions [14].

\subsection{Previous Icing Research}

Because of the restrictions imposed on new aircraft, companies have delved into finding cost-effective methods of testing aircraft across a wide range of icing conditions. Several 
different methods have been implemented and all have managed to agree that icing significantly affects the airfoils lift and drag properties. Some of these methods have even combined both computational and wind tunnel testing approaches.

\subsubsection{Computational Icing Research}

The computation field of icing research could be divided into three areas: first, ice accretion prediction, second, the advancement of anti-icing and de-icing systems generally referred to as ice system performance, and third, analysis of icing effects on aircraft [8]. Extensive research has been performed in each of these areas.

Ice accretion prediction codes have been produced by national research centers, government agencies, and academic institutions around the world. These codes are powerful and useful tools in the design of aircraft and the testing of geometries within an icing field. Some of these codes are even qualified for the testing of aircraft for the icing condition requirements [47]. Some of these accepted codes include:

1. LEWICE, a code developed by the NASA Glenn Research Center [31].

2. CIRAMIL from the Italian Aerospace Research Center [37].

3. CANICE developed at Ecole Polytechnique de Montreal [18].

4. TRAJICE made by the Defense Evaluation and Research Agency in the United Kingdom [17].

5. ONERA created at the Office National d'Etudeset de Recherches Aérospatiales in France [24].

The codes operate using modules such as calculating the flow field or by modifying the clean geometry of the airfoil to simulate the growth of the ice. Specifically, the NASA LEWICE code operates using four modules; one being a flow field calculation, the second is particle trajectory, the third is the thermodynamic and ice growth calculation, and the fourth is the modification of the geometry for the growth of the ice [20]. These codes are also put through rigorous testing and are reviewed in order to improve their capabilities. One such review held in Italy found no clear winner as to whose code was the best; however, the Defense Evaluation and Research Agency felt that TRAJICE performed the best [37].

Some of the mentioned codes are capable of performing a thermodynamic analysis and determining the heat transfer coefficients between the geometry's surface and the moisture droplets impacting the surface. These calculations allow for the study of anti-icing and de-icing systems. De-icing systems come in a variety of forms, from heating systems to mechanical and pneumatic systems placed on the surface. Electrical systems use an electrical current to generate heat on the surface, melting the ice, while mechanical and pneumatic systems use devices that inflate or vibrate and break up the ice that has built up. Fluid types have also been developed, which are sprayed on to the surface and not only break up existing ice but remain as a protective film to prevent further ice accretions [6].

The FAA has also used numerical analysis for the study of large water droplets forming ice on airfoil shapes. This analysis uses a high-resolution full Navier-Stokes solver using a solution-adaptive unstructured grid for both iced and clean airfoil conditions [5]. This approach showed reasonable numerical data for a wide range of experimental conditions. The research also concluded that the Reynolds number effects of iced airfoils were negligible, unlike those of clean airfoils.

The study of icing effects on aircraft can be performed under safer and inexpensive conditions within a simulation environment at adequate levels of accuracy. Simulation models can also be implemented in six degree-of-freedom motion base simulator so that pilots may feel 
the dynamic effects of icing on the aircraft to better prepare them for real world icing occurrences. Several motion base simulators have been developed in order to train pilots in icing conditions without risk [43]. The problem can be approached in a couple different ways. One such way is to use data from a known aircraft to create a state-space representation at nominal conditions [28]. Icing effects for such a model can be implemented by modifying the existing stability and control derivatives (or the system matrices), which are typically provided in the form of lookup tables. In general, there are many variables to be considered when modeling icing, such as where the ice is going to form, what part of that surface will be affected, and things such as the ice shape and roughness, which are random by nature. These effects will alter different parameters affecting both the longitudinal and lateral dynamics. Through the use of the lookup tables, and the use of experimental data, alteration coefficients can be created to modify the lookup tables as necessary for the modeling of icing conditions.

Further research has been performed for the application of neural networks for ice accretion prediction. The approach could be used for: real-time ice accretion prediction, a preconditioner for other ice accretion codes, predictors for computational fluid dynamics, assistance in estimating aircraft performance degradation, or even work with codes similar to NASA's LEWICE code [33].Several different neural network architectures were tested in order to find which type works the most efficiently. This specific research found that the general regression neural network architecture worked the most efficiently. The neural network worked by first taking the airfoil shape and reducing it to a series of Fourier coefficients. Then the neural network would predict the ice accretions. Neural networks also need training, the training for this network is done by a training file containing the aircraft's flight conditions, the Fourier coefficients, and the extent of ice shapes.

\subsubsection{Wind Tunnel Testing}

The data used within simulation models, as well as validation data for ice accretion prediction codes, are most often found through wind tunnel research of icing conditions. A model of the aircraft to be simulated can be placed under static and dynamic studies within wind tunnels. These tests can assist in finding data over a large range of angles of attack and sideslip angles [3]. Some of these icing wind tunnels can reach speeds up to 200 miles per hour [27]. One icing wind tunnel in the United States is capable of speeds up to Mach 1.15 [19]. However, the temperature range for these tests is limited to atmospheric conditions, so tests must be done during winter conditions. Another icing wind tunnel at the Italian Aerospace Research Center has the ability to match weather and flight conditions for altitudes up to 7000 meters [13].

Other wind tunnel tests have made use of the numerical studies to further research various ice shapes on aircraft and their effects. These ice shapes ranged from just a thin layer that affected roughness, to runback icing, and ice buildup due to a de-icing failure. The ice shape for the failure was taken at $22.5 \mathrm{~min}$ of ice accretions, and the shape was calculated using NASA's LEWICE program [2]. 


\subsection{Icing-Related Incident Statistics}

According to the Aircraft Owners and Pilots Association's (AOPA) safety advisor, between 1990-2000 12\% of all weather related accidents were icing related. Of all the icing related incidents only $8 \%$ were from ice built up while the aircraft was still on the ground. All of the aircraft taken in the statistics were single or multi engine civilian aircraft, and $48 \%$ of the pilots involved in the accidents had over 1000 hours of total time in experience [1].

In a further study performed by NASA representatives, a statistical report was build from the NTSB Aviation Accident and Incident Data system and the FAA Accident/Incident Data System over a 19 year period [40]. The data from these sources was grouped into 4 categories from commuter/domestic aviation fields; part 121, part 135 scheduled, part 135 non-scheduled, and part 91 . Part 121 operations are for domestic flights, part 135 is similar with more stringent qualifications on the aircraft, these flights can also be scheduled or non-scheduled, and part 121 91 is for general operating and flight rules [16]. The study focused on showing the number of icing accidents within each of these categories. Of the 534 accidents in part $121,1.1 \%$ were with icing conditions. Part 135 scheduled had 203 accidents with 8.4\% in icing conditions, while the non-scheduled category had 1,057 accidents and 5.5\% in icing conditions. Part 91 had 23,055 accidents and $1.4 \%$ of which were in icing conditions. The following figure is a plot of these results which NASA had presented.

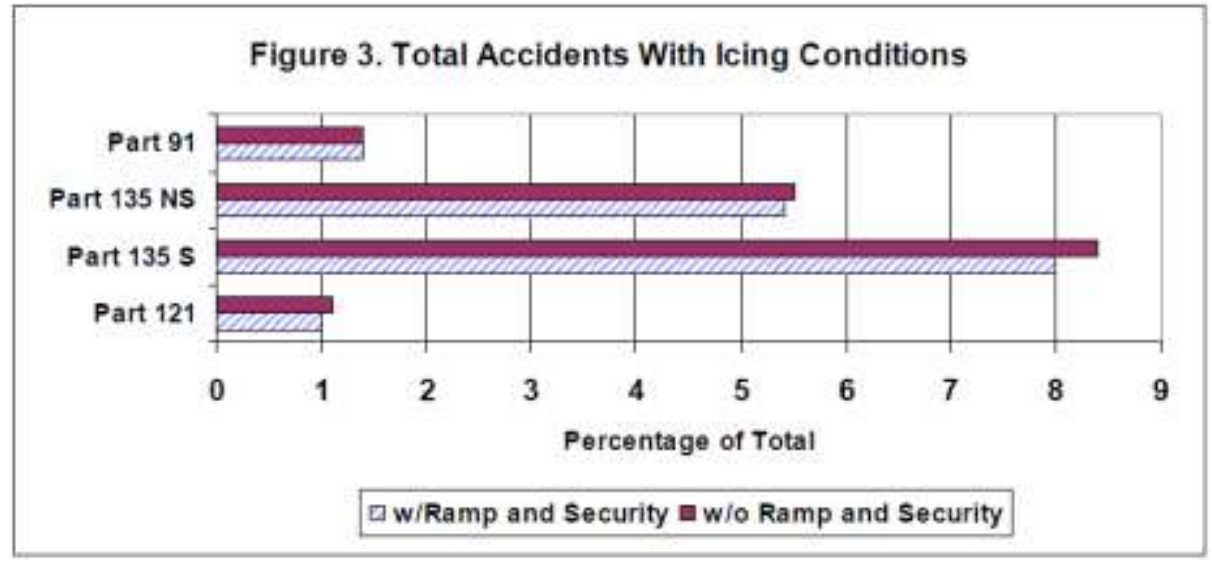

Figure 2: Plot of total accidents with icing conditions. Courtesy of NASA [40]. 


\section{Chapter 3- Model Development Methodology}

This section outlines the decision making into which aircraft was selected, why it was selected as well as model adjustments that were needed to make it ready for the icing simulation. This section will also cover the general strategy in developing the icing model itself along with the steps taken to create the equations used for the model parameters.

\subsection{Aircraft Selection}

For the selection of the aircraft to be modeled, both data for the aircraft and icing data for a similar aircraft or airfoil shape would be necessary. Based on the statistics found on ice accretions in aviation, it was decided that a civilian aircraft would be the best choice. The type of civilian aircraft finally chosen to be modeled was a twin engine business jet. This aircraft was selected because of its likelihood to being exposed to icing conditions. This type of aircraft generally serves for regional transportation and would be exposed to a variety of weather conditions. The WVU Aircraft Health Management simulation package has a civilian business jet model that had been previously developed to meet FAA regulations for flight simulator performance, and was also implemented within WVU's 6 degree of freedom motion simulator [33].

In order to use this aircraft model for this application, icing data would have to be found that could be applied to the aircraft. The next step taken was to determine the aircraft's airfoil shape and it was found to be a NACA 23014 at the wing's root and a NACA 23012 shape at the wing's tip [28]. Ultimately icing data for a NACA 23012 was found and determined to be useable because ice accretions tend to build up at the wing tips first. The ice buildup on the wingtips can lead to wing stall. The icing data used is discussed in the Icing Model section.

\subsection{Model Adjustments}

The aircraft model used relies on lookup tables in order to calculate aerodynamic forces and moments experienced during flight. This is performed within the Aircraft Dynamics subsystem. A general over view of the business jet Simulink model can be found in Figure 3.

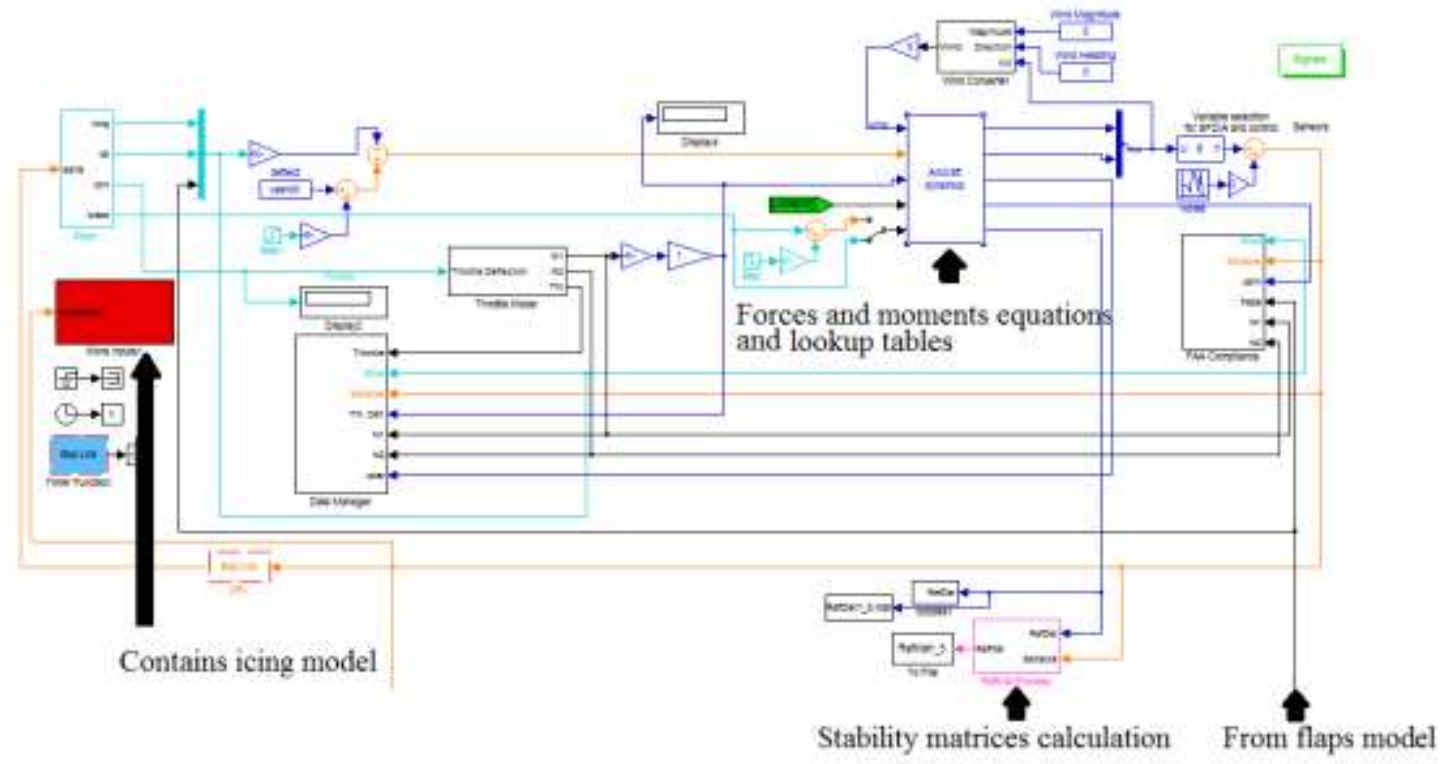

Figure 3: General overview of business jet model. 
The Aircraft Dynamics subsystem (Figure 4) contains the implementation of all the equations of motion and the calculation of the aircraft aerodynamic forces. The icing model alteration coefficients will affect these coefficients and thus the aircraft's handling and modal properties.

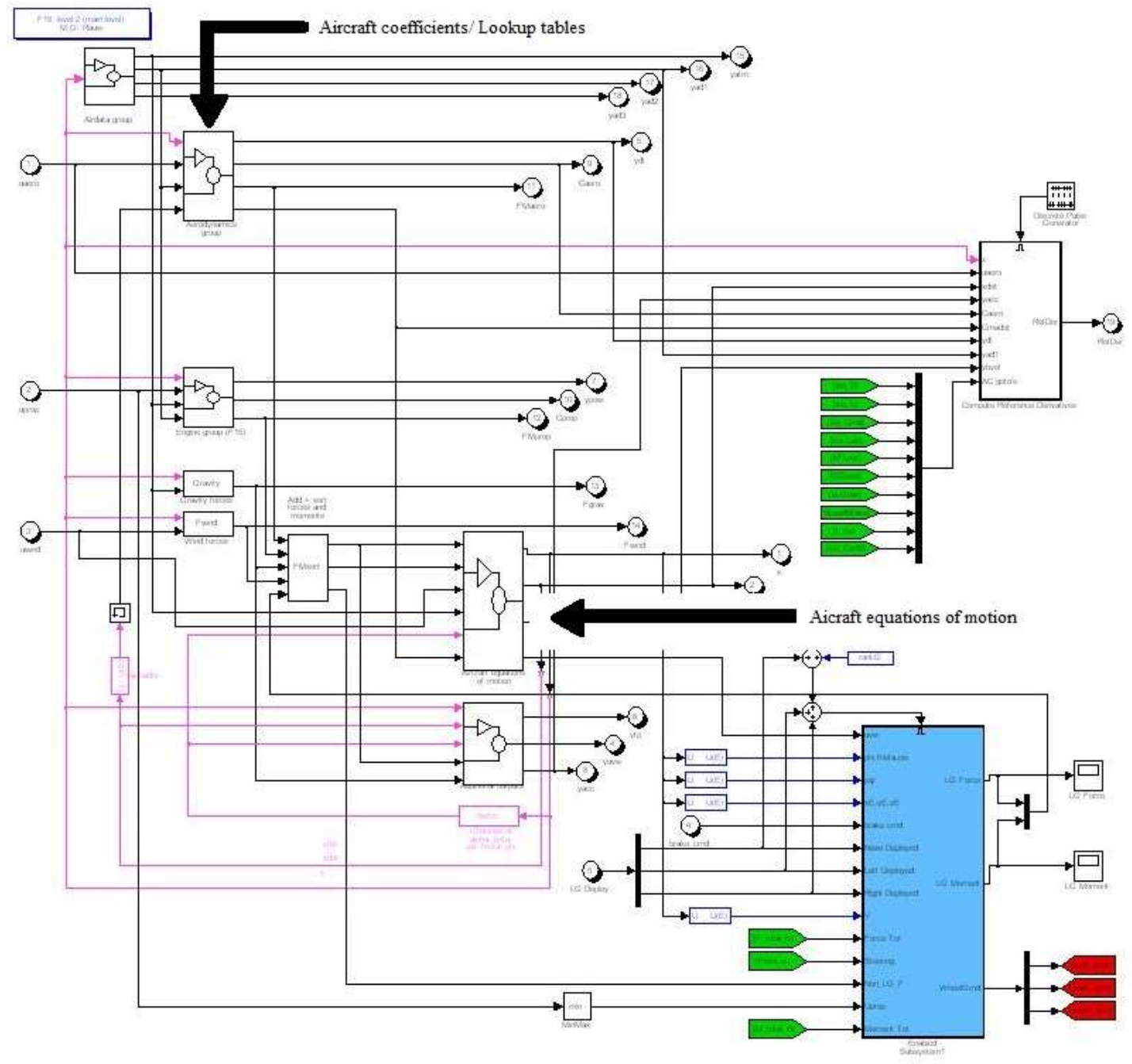

Figure 4: Aircraft dynamics subsystem.

The lookup tables are found inside the Aerodynamics Groups subsystem seen in the above figure. They contain the aircraft stability and control derivatives as a current dynamic pressure. Three aerodynamic force and three aerodynamic moment coefficients in body aces are computed based on first degree polynomials using the stability and control derivatives. Figure 5 shows the Simulink model of the aircraft aerodynamic coefficients. 


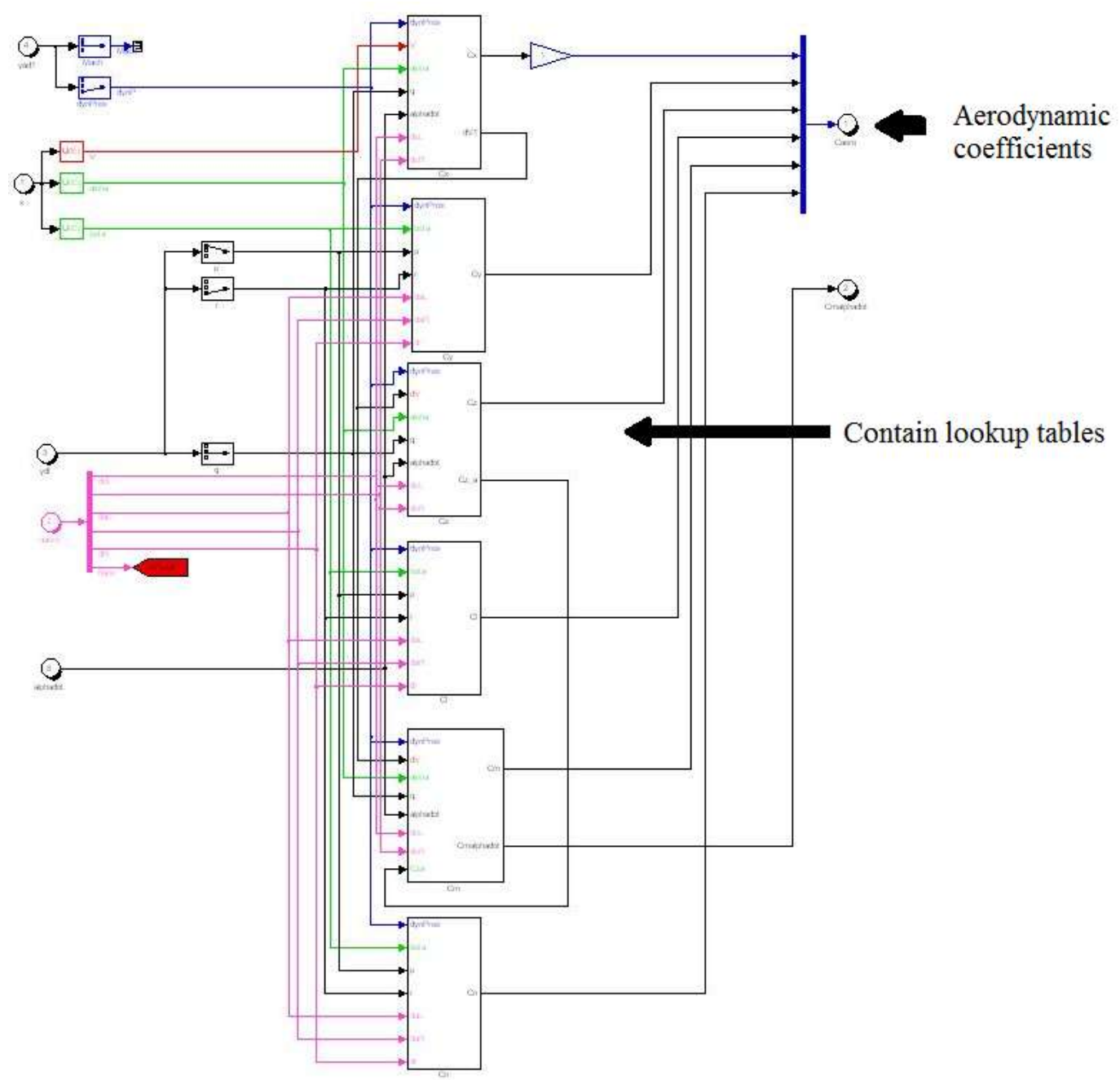

Figure 5: Aircraft coefficients subsystem.

The original business jet model needed some adjustments to facilitate the implementation of the icing model. The flaps, landing gear, and speed brake models were all set to initial default conditions and maintained constant throughout the simulation. The flaps stage selector was set to $0^{\circ}$ and the landing gear was set to be retracted by default when the model was opened. Some further customization was required for the speed brakes as well as the aircraft's flaps such that the aircraft was at the desired trim conditions at the beginning of the simulation. Figure 6 shows the default position of the flaps selector and the gain added to the speed brakes.

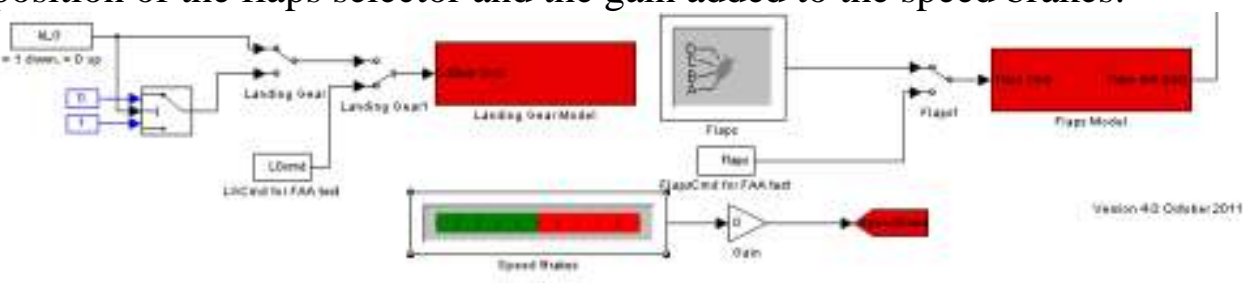

Figure 6: Landing gear, flaps, and speed brake defaults

Some modifications were necessary to improve the stall model. Because the stall angle of the aircraft changes based on the time spent in icing conditions, the stall lookup tables had to be modified into two-dimensional lookup tables. Each column of the lookup table represented a 
value for angle of attack, while each row is for different points of time. Values in between steps were found by linear interpolation. The values of the stall table themselves work as alteration coefficients sent to modify $\mathrm{C}_{\mathrm{za}}$ and $\mathrm{C}_{\mathrm{m} \alpha}$. The Simulink model of the stall table can be found in Figure 10, and Table 1 shows an excerpt from the lookup data for $\mathrm{C}_{\mathrm{m} \alpha}$ 's stall.

Table 1: Excerpt of $\mathrm{C}_{\mathrm{m} \alpha}$ stall lookup table

\begin{tabular}{lccccccccc}
\hline AOA deg & $\mathbf{0}$ & $\mathbf{6}$ & $\mathbf{7}$ & $\mathbf{8}$ & $\mathbf{9}$ & $\mathbf{1 0}$ & $\mathbf{1 2}$ & $\mathbf{1 6}$ & $\mathbf{3 0}$ \\
\hline clean & 1.000 & 1.000 & 1.000 & 1.000 & 1.000 & 1.000 & 0.950 & 0.850 & 0.75 \\
$\mathbf{t}=\mathbf{1}$ min & 1.000 & 1.000 & 1.000 & 1.000 & 0.95 & 0.95 & 0.75 & 0.75 & 0.75 \\
$\mathbf{t}=\mathbf{2 . 5}$ min & 1.000 & 1.000 & 0.95 & 0.95 & 0.85 & 0.75 & 0.75 & 0.75 & 0.75 \\
$\mathbf{t}=\mathbf{5}$ min & 1.000 & 0.95 & 0.95 & 0.85 & 0.75 & 0.75 & 0.75 & 0.75 & 0.75 \\
\hline
\end{tabular}

The constants from the table are multiplied to $\mathrm{C}_{\mathrm{m} \alpha}$ to effectively change its slope. This will allow for the changes in slope of $\mathrm{C}_{\mathrm{m}}$ without having to create specific equations for it.

\subsection{Icing Modeling Approach}

With the aircraft now flying at a steady state condition as desired, the icing model could be implemented. The original model was modified to incorporate the addition of the icing model. This would be done by calculating the necessary alteration coefficients using the data found, the current time spent in icing conditions, and angle of attack. These coefficients would then be multiplied to their corresponding stability derivatives.

The data from NASA showed the trends of how ice affects the coefficients of lift and drag. Figures 7 and 8 shows the NASA data put into Matlab and used for the creation of the icing model.

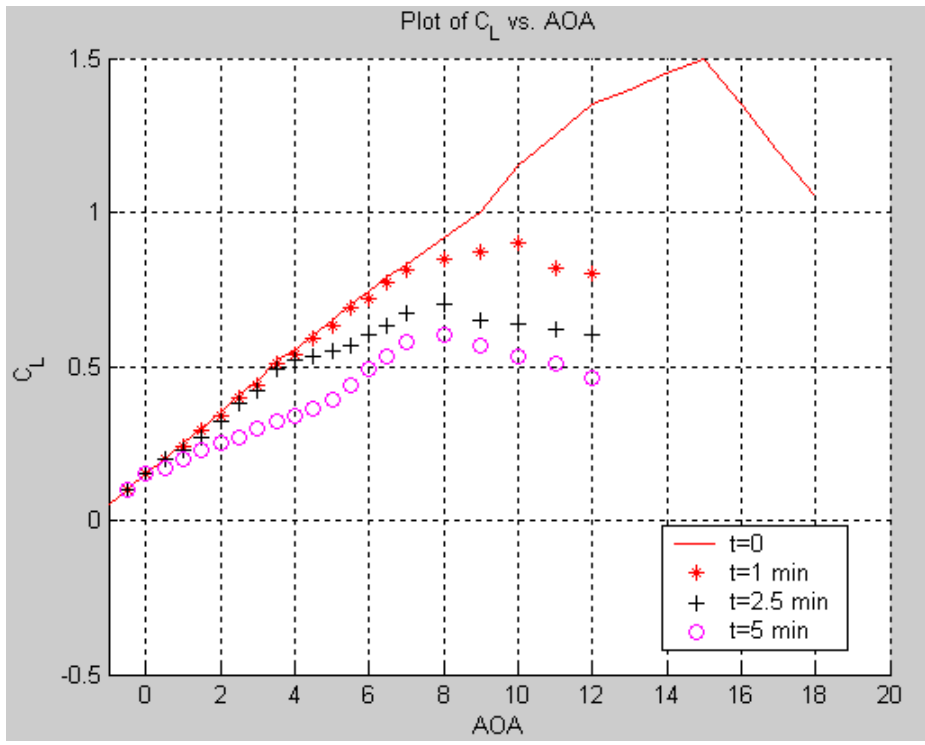

Figure 7: Lift coefficient degradation over time spent in icing

As the amount of exposure to icing conditions, the accumulating ice alters the basic profile of the airfoil causing a decrease in the amount of lift that the airfoil can create. Also stall will occur at lower angles of attack as exposure is prolonged. 


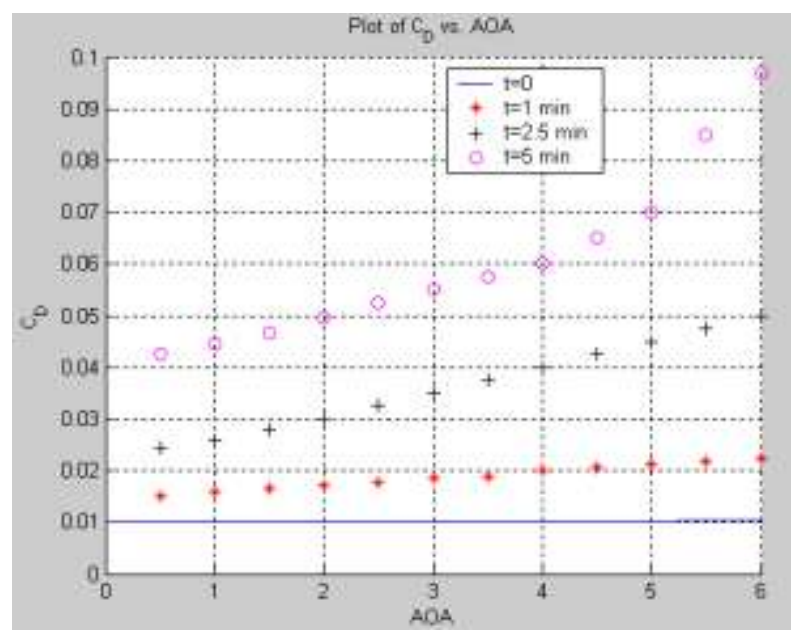

Figure 8: Drag coefficient degradation over time spent in icing

The variations for $\mathrm{C}_{\mathrm{m} \alpha}$ and the other stability and control derivatives were assumed to be linear with time and that after the five minutes in icing conditions of the NASA data the icing conditions were considered to be severe. This allowed for the lateral directional alteration coefficients calculations to be a simple gradient calculation. For lift and drag a more complex set of steps had to be taken.

To begin, the NASA data was input into Matlab by hand, see Figures 7 and 8 . The data were then normalized by dividing the values at icing conditions by the values at normal/clean conditions. This is equivalent to obtaining correction factors for lift and drag that are equal to the ratio between values at icing conditions and nominal/clean conditions. Therefore, alteration coefficients for lift would have to be less than one and for drag, greater than one. It can be said that the clean profile for both lift and drag would always have an alteration coefficient of one. An example of the normalized data of the drag coefficient or the correction factor for drag can be found in Figure 9.Using these normalized data, each time step of the data was then curve fit to create a polynomial equation for that lift or drag curve at that time step. The relationship between time steps was then studied. Through an iterative process of trial and error the final time averaged equations for the lift and drag coefficients were established. The final icing equations for all the affected derivatives, as well as for lift and drag coefficients, can be found in the Icing Model Equations section of chapter 5.

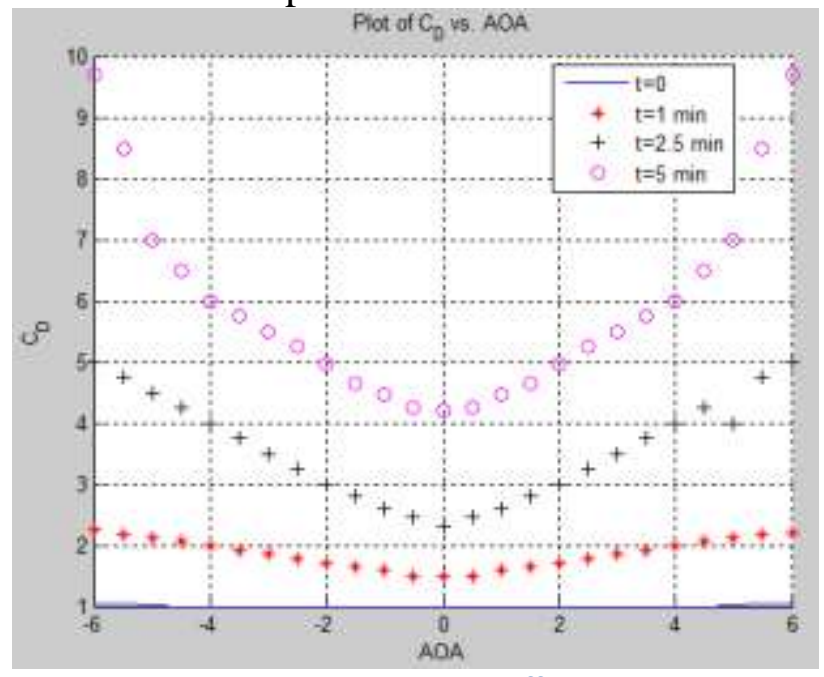

Figure 9: Normalized drag coefficient data. 
Once the icing model calculates the alteration coefficients using the angle of attack and the time spent in icing conditions, their effects on the respective aerodynamic coefficients or stability and control derivatives must be implemented. Simulink GoTo and multiplier blocks were used, as illustrated in Figure10.

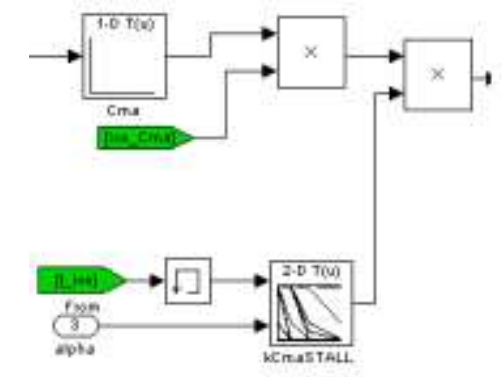

Figure 10: Moment coefficient multiplied to $C_{m \alpha}$ and the stall lookup table.

In several places within the icing model, delay blocks had to be used to avoid algebraic loops as shown in Figures 10 and 26of section 5.2. The effect of this solution was to alter the time in icing by $0.03 \%$ and was considered to be insignificant.

\subsection{Stability Derivative Model.}

The most important handling qualities requirements [46] are formulated in terms of modal parameters that are obtained from linear models. Therefore, the analysis of icing effect on handling qualities necessitated on-line linearization of the aircraft model during icing exposure. The first step required in linearizing the aircraft model and finding the system matrices is to calculate the aircraft stability derivatives. The business jet model at normal conditions consisted of lookup tables of the stability derivatives that were used to calculate the aerodynamic forces and moments based on the current dynamic pressure. This provided a reference by giving the stability derivatives for steady state flight.

The stability and control derivatives are calculated via a numerical derivative or gradient within the aerodynamic block set of the model every ten seconds of simulation time. Because these derivatives are calculated inside an enabled subsystem block, Simulink treats it as a separate model. This creates a virtual boundary which GoTo/From blocks cannot cross, even if their visibility is set to global. Therefore, any From blocks within the Compute Reference Derivatives subsystem needed to be moved outside the subsystem. The From blocks pulled from within the Compute Reference Derivatives subsystem and the subsystem itself can be seen in Figure11.

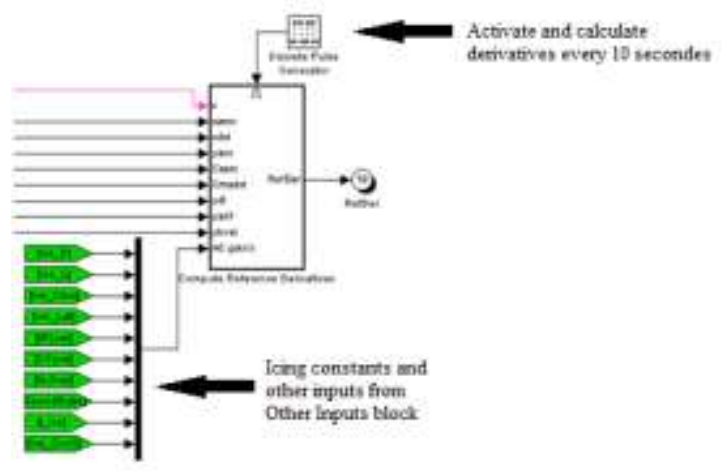

Figure 11: Icing from blocks and the compute reference derivatives subsystem. 


\section{Chapter 4- Simulation Environment}

\subsection{General Description of the Simulation Environment}

The business jet simulation model can be accessed through the Aircraft Health Management portal, a simple GUI interface that allows access to a variety of aircraft simulation models. Figure 12 shows the aircraft selection screen, and the user manual in the Appendix shows the manner in which the simulations can be started and setup.

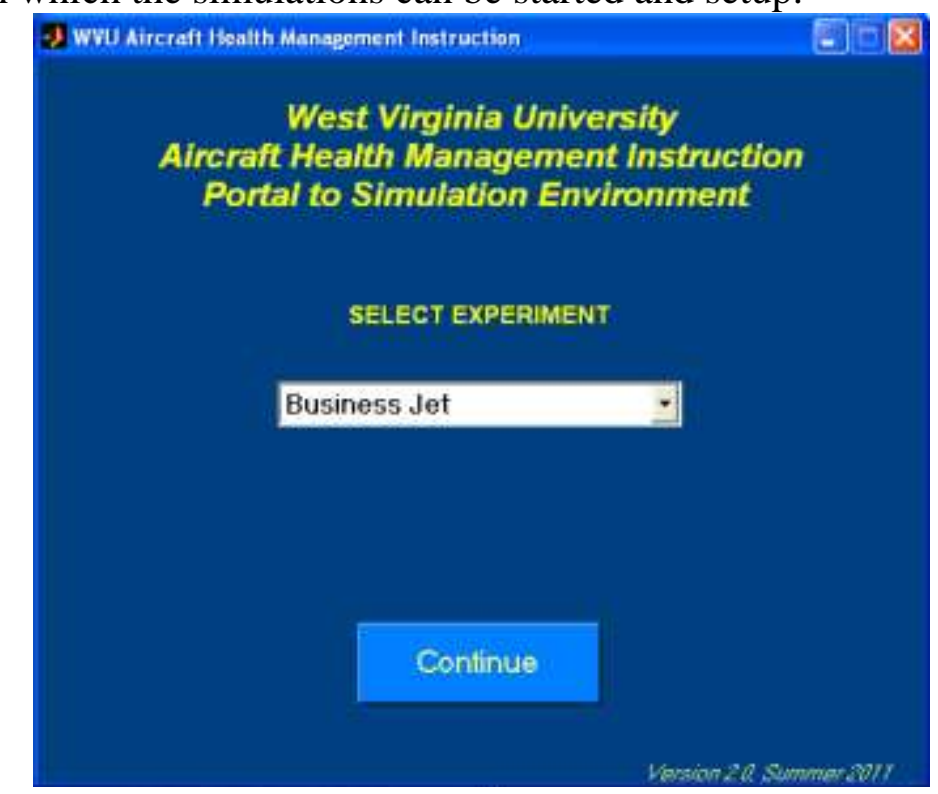

Figure 12: Aircraft health management portal, aircraft selection screen.

By selecting the business jet model from the drop down list and pressing continue will begin the initialization process of both the business jet and icing simulation. The first two windows were already implemented within the business jet model. A further GUI had to be created and added to allow for the icing model to be selected and to select which channels were to be affected by the ice accretions. The first window that appears after selecting the business jet model is the Pilot Input Menu. This menu simply determines if a controller is to be used or if a set of predetermined control inputs are to be used. The Pilot Input Menu is seen in Figure13.

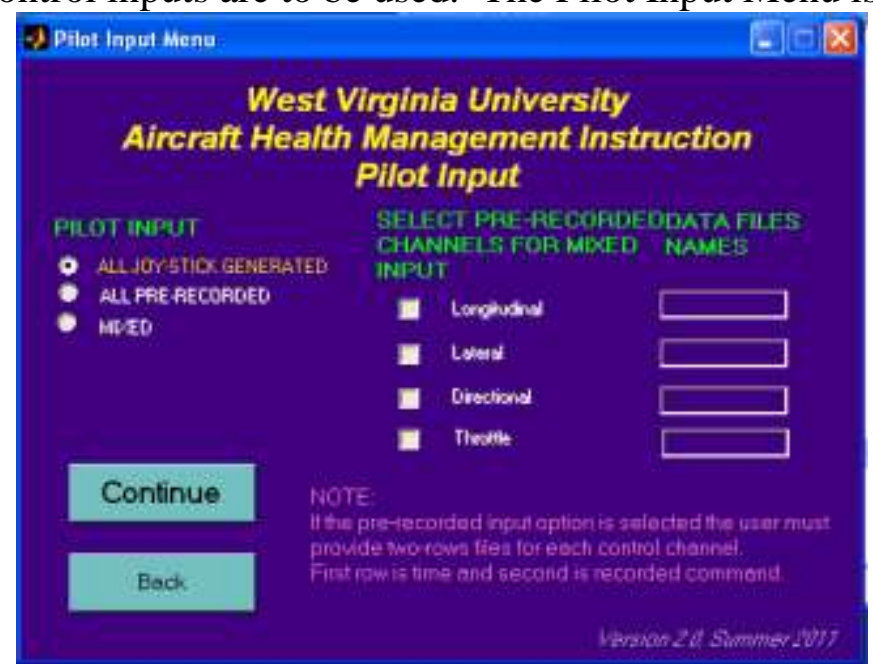

Figure 13: Pilot input menu for selecting control inputs. 
Selecting the input type and pressing continue progresses one to the initial conditions selection window. From here a drop down box presents the various initial conditions that the business jet has. However, for the icing model the only implemented initial conditions are for the IC \#01. This sets the aircraft initially to an altitude of 4450 meters and an initial velocity of 125 meters per second. The initial conditions selection box can be seen in Figure14.

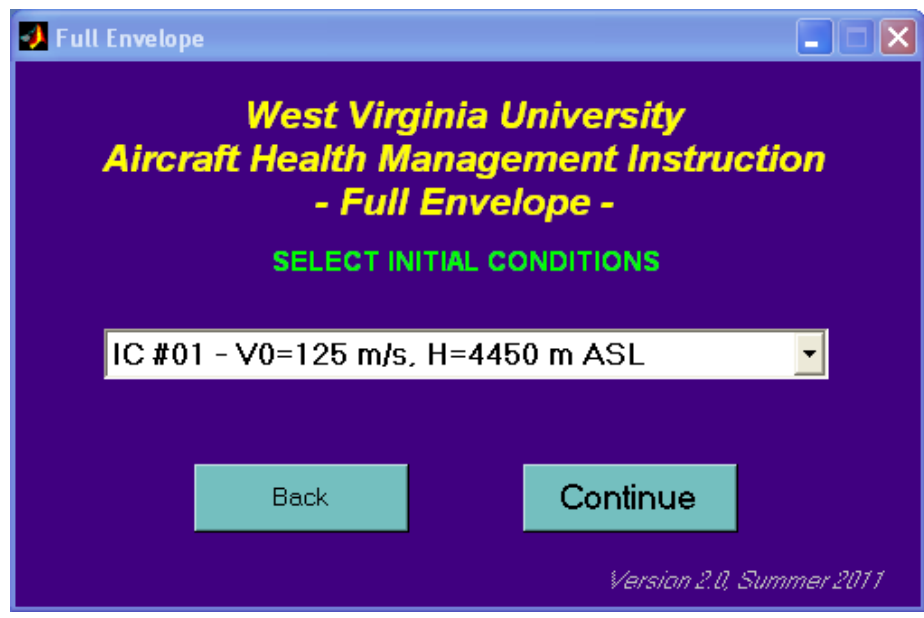

Figure 14: Initial conditions selection.

Selecting the initial conditions then takes one to the Icing Selection screen. For the purpose of studying the varying effects of ice accretion on aircraft, the effects were separated and the icing model was allowed to have individual channels selected for icing. This list included:

- Icing on all channels

- Icing affecting lift only

- Icing affecting drag only

- Icing affecting the moment coefficient only

- Icing affecting only the lateral coefficients

- Icing affecting only the lift and drag coefficients

- Icing affecting only lift, drag, and moment coefficients

A checkbox at the bottom allows for the icing of control surfaces to be turned on or off for any icing case except the nominal conditions case. The Icing Selection screen is shown in Figure 15.

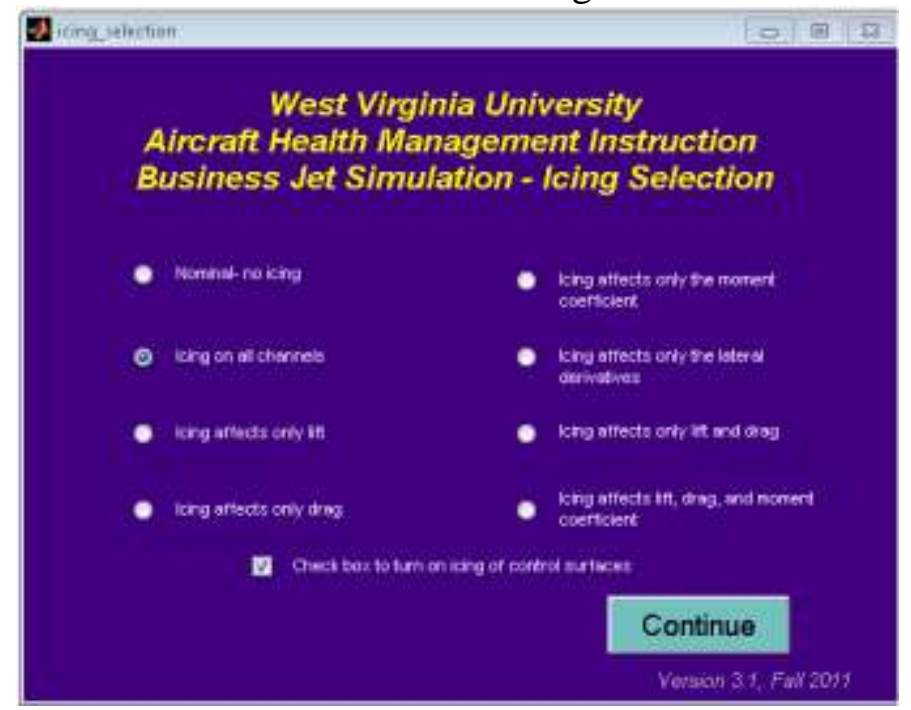

Figure 15: Icing selection screen. 
This model is part of a simulation environment for aircraft health management instruction. While the simulation of ice affecting only specific forces is unrealistic, this reductionist approach was used only to provide this option to the user solely for the academic purposes. For example, if a student, wished to see how the aircraft lift and stall properties changed throughout icing without the occurrence of throttle saturation brought on by the increasing drag, the "Icing affects only lift" selection could be used to provide the analysis. The analysis performed used the option of "Icing on all channels" and the check box for icing on control surfaces, as shown in Figure 15.

Continuing from the icing selection screen opens the Simulink model as well as an extra GUI that provides the means for starting Flight Gear and various scopes. A screenshot of the open model, Flight Gear, and some scopes can be found in Figure 16.

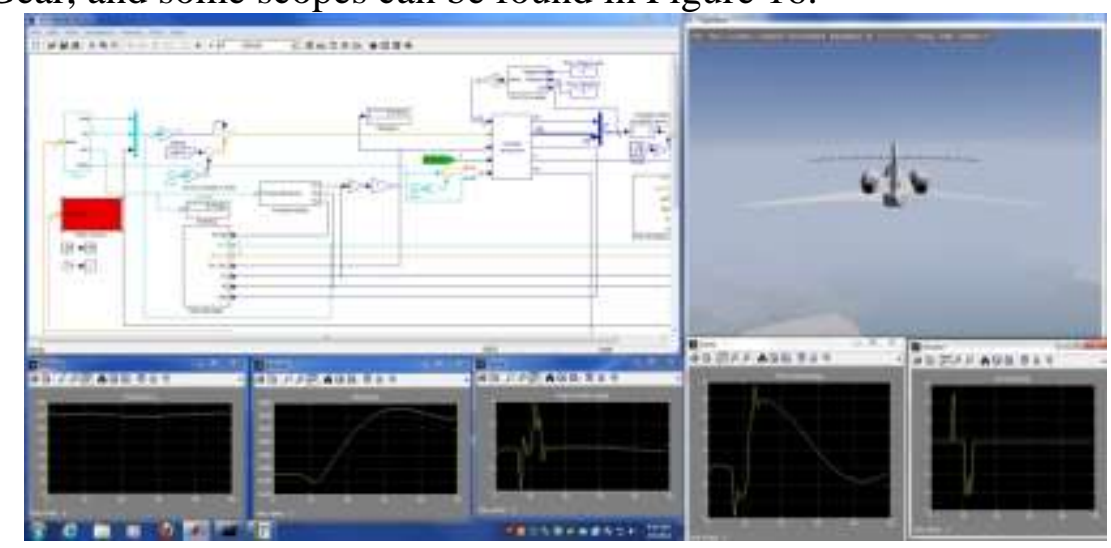

Figure 16: Screenshot of icing simulation setup.

\subsection{Linearizing the Model: Stability and Control Derivatives}

The aircraft model and look-up tables are non-linear in nature. However, in order to analyze the modal parameters in correspondence with the MIL-F-8785C [46] specifications, the non-linear system is then linearized such that the eigenvalues, and respective modal parameters, can be found and inspected. This equivalent linear system approach is recommended by MIL for handling qualities analysis. The primary advantage of this process is that this aircraft and its responses can be quantitatively compared to known military specifications of aircraft of the same classification. The variation of aerodynamic parameters over small time intervals is not large and constant icing conditions could also occur under certain circumstances.

To begin the linearization process, it is necessary to calculate the aircraft's stability and control derivatives. This is done via a gradient calculation in the Compute Reference Derivatives subsystem as mentioned above. This calculation method follows equation (1).

$$
C_{F M_{x}}=\frac{d C_{F M}}{d x} \cong \frac{\Delta C_{F M}}{\Delta x}=\frac{C_{F M}(x+\Delta \mathrm{x})-C_{F M}(x)}{\Delta x}
$$

Where $C_{F M_{x}}$ is the non-dimensional derivative of the force or moment coefficient $\mathrm{C}_{\mathrm{FM}}$, with respect to the state or control variable $\mathrm{x}$ :

$$
x=\left[V \alpha \beta p q r \delta_{e} \delta_{a} \delta_{r}\right]
$$

For example, the derivative of the longitudinal moment coefficient with respect to angle of attack can be calculated by: 


$$
C_{m_{\alpha}} \cong \frac{C_{m}(\alpha+\Delta \alpha)-C_{m}(\alpha)}{\Delta \alpha}
$$

The state or control variable is modified by a small value, $\Delta \mathrm{x}$, equation (4) shows the values used.

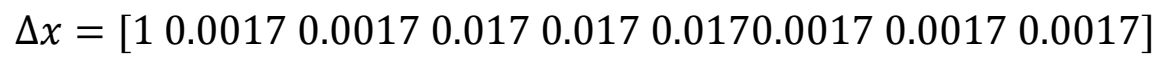

Where the first element is for velocity, second for angle of attack, third for sideslip angle, fourth through the sixth elements are for angular rates, and the remaining elements are for control deflections. The control variables are altered by $0.0017 \mathrm{rad}$ or a deflection of $0.1^{\circ}$. The calculation for all the derivatives is set up in this manner. The first section for the compute reference derivative subsystem creates the altered state or control variables, i.e. $(\alpha+\Delta \alpha)$. The first section can be found in Figure 17. The matrix from equation (4) can be found at the top of the subsystem as indicated in the figure.

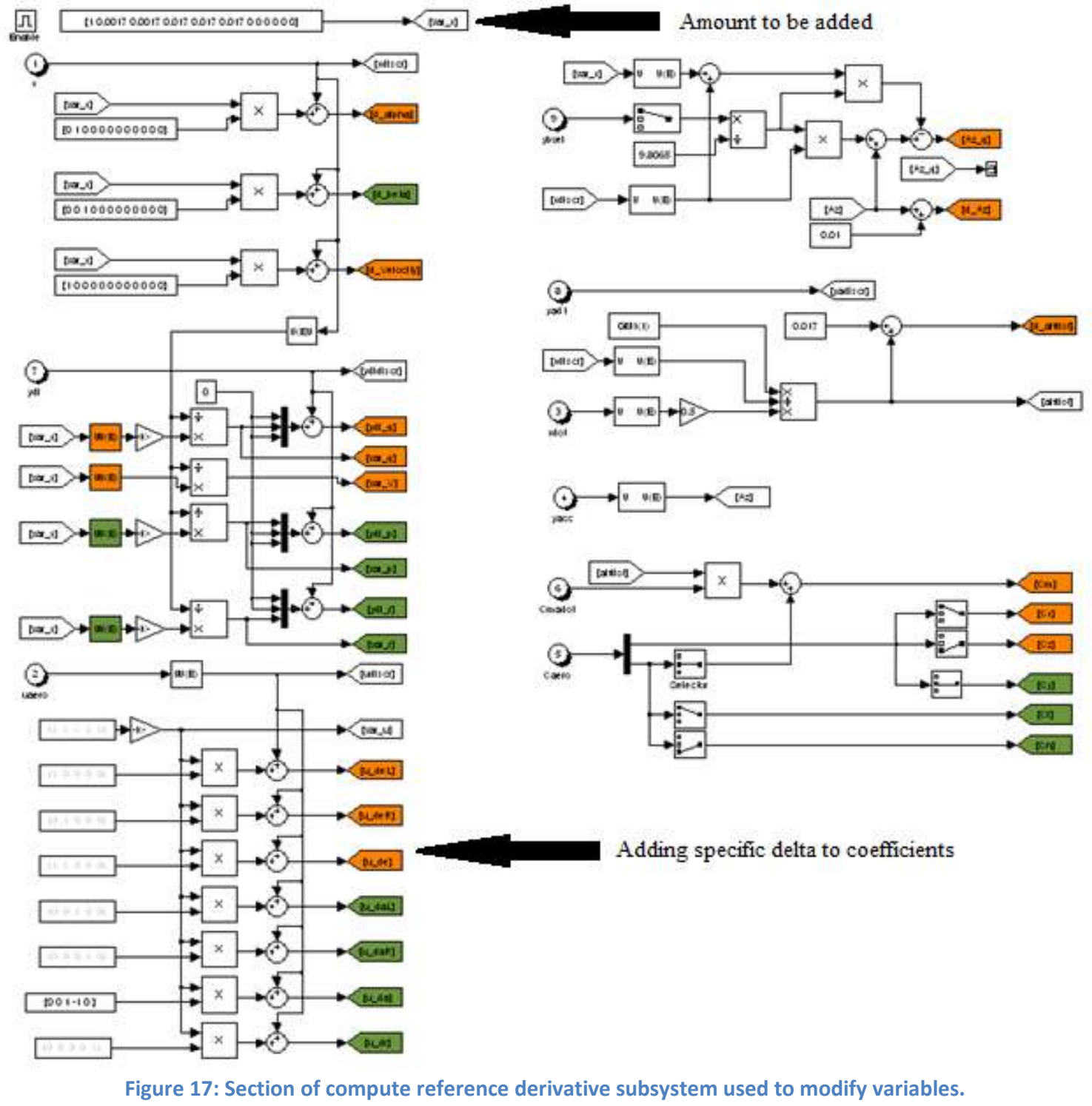

The second step part of the compute reference derivatives subsystem uses the output of the first section. The second section then uses the altered state or control variable, in place of the real value, in a copy of the aircraft dynamics model. The output of the copy of the aircraft 
dynamics will now be the altered variable, in the examples case the output would be $C_{m}(\alpha+\Delta \alpha)$. Figure 18 shows the block diagram for calculating the derivatives with respect to angle of attack.

The third process in the compute reference derivatives subsystem, arranges the stability and control derivatives, force and moment coefficients, and small values modifying the state or control variables to match equation (1).
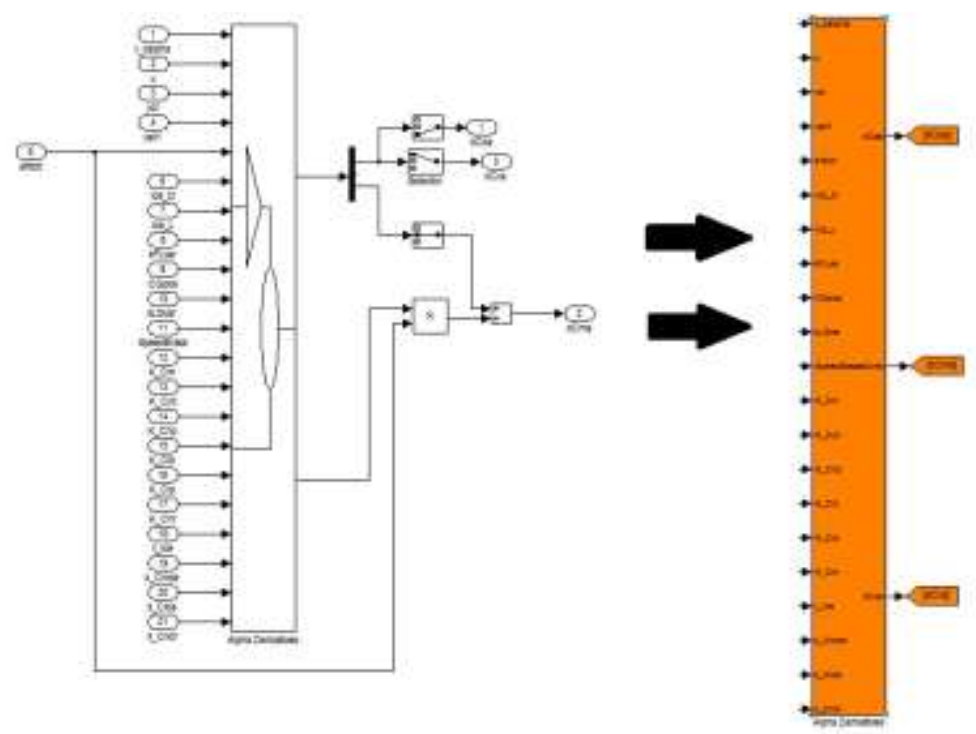

Figure 18: Alpha derivative subsystem.

\subsection{Linearizing the Model: Matrix Formulation and Eigenvalues}

The stability derivatives calculated are necessary for the process of linearizing the simulation model and obtain the stability matrix and its eigenvalues. The eigenvalues are used to compute the modal parameters for handling qualities analysis. The derivatives are used to find the coefficients of the aircraft states in the non-dimensional equations of motion. The nondimensional equations of motion are a convenient way to represent the aerodynamic parameters involved. The non-dimensional equations used are[15]:

\section{Longitudinal non-dimensional equations:}

$$
\begin{gathered}
\left(2 \mu D-2 C_{L_{0}} \tan \theta_{0}-C_{x_{u}}\right) \hat{u}-C_{x_{\alpha}} \alpha+C_{L_{0}} \theta=0 \\
\left(2 C_{L_{0}}-C_{z_{u}}\right) \hat{u}+\left(2 \mu D-C_{z_{\dot{\alpha}}} D-C_{z_{\alpha}}\right) \alpha-\left[\left(2 \mu+C_{z_{q}}\right) D-C_{L_{0}} \tan \theta_{0}\right] \theta-C_{z_{\eta}} \eta=0 \\
-C_{m_{u}} \hat{u}-\left(C_{m_{\dot{\alpha}}} D+C_{m_{\alpha}}\right) \alpha+\left(i_{B} D^{2}-C_{m_{q}} D\right) \theta-\left(C_{m_{\dot{\eta}}} D+C_{m_{\eta}}\right) \eta=0 \\
-\left(2 C_{h e}+C_{h e_{u}}\right) \hat{u}-\left(C_{h e_{\dot{\alpha}}} D+C_{h e_{\alpha}}\right) \alpha-C_{h e_{q}} D \theta+\left(i_{e} D^{2}-C_{h e_{\dot{\eta}}} D-C_{h e_{\eta}}\right) \eta=\Delta C_{f e} \\
\hat{q}-D \theta=0 \\
\text { where } \mu=\frac{m}{\rho S l}, \quad t^{*}=\frac{l}{u_{0}}, \quad \text { and } l=\frac{\bar{c}}{2}
\end{gathered}
$$




\section{Lateral non-dimensional equations:}

$$
\begin{gathered}
\left(2 \mu D-C_{y_{\beta}}\right) \beta-C_{y_{p}} \hat{p}+\left(2 \mu-C_{y_{r}}\right) \hat{r}-C_{L_{0}} \phi-C_{y_{\zeta}} \zeta=0 \\
-C_{l_{\beta}} \beta+\left(i_{A} D-C_{l_{p}}\right) \hat{p}-\left(i_{E} D+C_{l_{r}}\right) \hat{r}-\left(C_{l_{\xi}} D+C_{l_{\xi}}\right) \xi-C_{l_{\zeta}} \zeta=0 \\
-C_{n_{\beta}} \beta-\left(i_{E} D+C_{n_{p}}\right) \hat{p}+\left(i_{C} D-C_{n_{r}}\right) \hat{r}-C_{n_{\xi}} \xi-\left(C_{n_{\xi}} D+C_{n_{\zeta}}\right) \zeta=0 \\
-2 C_{h a_{p}} \hat{p}-2 C_{h a_{r}} \hat{r}+\left(i_{a} D^{2}-2 C_{h a_{\xi}}-2 C_{h a_{\xi}}\right) \xi=\Delta C_{f a} \\
-C_{h r_{\beta} \beta} \beta-C_{h r_{p}} \hat{p}-C_{h r} \hat{r}+\left(i_{r} D^{2}-C_{h r_{\zeta}} D-C_{h r_{\zeta}}\right) \zeta=\Delta C_{f r} \\
\hat{p}+\hat{r} \tan \theta_{0}-D \phi=0 \\
\hat{r} \sec \theta_{0}-D \psi=0 \\
\text { where } \mu=\frac{m}{\rho S l}, \quad t^{*}=\frac{l}{u_{0}}, \quad l=\frac{b}{2}
\end{gathered}
$$

The terms $\mu, t^{*}$, and 1 are used to non-dimensionalize the equations, where $m$ is the aircraft's mass, $\rho$ is the air density, $S$ is the wing area, $u_{0}$ is the aircraft's velocity along the $x$ direction, and $l$ is half the wing span, $b$, or chord length, $\bar{c}$.These equations were dimensionalized using these terms for use within the simulation environment. This would allow the stability derivatives that were calculated to be related to the non-dimensional equations. The rearranged dimensional equations are presented next (17-25).

Dimensional longitudinal system of linear equations:

$$
\begin{gathered}
\dot{V}=\frac{\frac{\rho}{2} S V_{0}^{2}}{m}\left[\left(\frac{2}{V_{0}} C_{L_{0}} \tan \theta_{0}+\frac{C_{x_{V}}}{V_{0}}\right) V+C_{x_{\alpha}} \alpha-C_{L_{0}} \theta\right] \\
\dot{\alpha}=\frac{1}{\left(\frac{m}{\frac{\rho}{2} S V_{0}}-\frac{C}{2 V_{0}} C_{z_{\dot{\alpha}}}\right)}\left[-\frac{1}{V_{0}}\left(2 C_{L_{0}}-C_{Z_{V}}\right) V+C_{z_{\alpha}} \alpha+\left(\frac{m}{\frac{\rho}{2} S V_{0} c}+C_{z_{q}} \frac{c}{2 V_{0}}\right) q-C_{L_{0}} \tan \theta_{0} \theta+C_{z_{\delta e}} \delta e\right] \\
\dot{q}=\frac{\frac{\rho}{2} S c V_{0}^{2}}{I_{y}}\left[\frac{1}{V_{0}} C_{m_{V}} V+\frac{c}{2 V_{0}} C_{m_{\dot{\alpha}}} \dot{\alpha}+C_{m_{\alpha}} \alpha+C_{m_{q}} \frac{c}{2 V_{0}} q+C_{m_{\delta e}} \delta e\right] \\
\dot{\theta}=q
\end{gathered}
$$

Dimensional lateral system of linear equations:

$$
\dot{\beta}=\frac{\frac{\rho}{2} S V_{0}}{m}\left[\left(\frac{1}{V_{0}} C_{y_{\beta}} \beta+\frac{b}{2 V_{0}^{2}} C_{y}\right) P+\left(\frac{m b}{2 V_{0}^{2}} C_{y_{r}}-\frac{m}{\frac{\rho}{2} S V_{0}^{2}}\right) r\right]+\frac{g}{V_{0}} \psi
$$




$$
\begin{gathered}
\dot{p}=V_{2}\left[\left(I_{z} C_{l_{\beta}}+I_{x z} C_{n_{\beta}}\right) \beta+\frac{b}{2 V_{0}}\left(I_{z} C_{l_{p}}+I_{x z} C_{n_{p}}\right) p+\frac{b}{2 V_{0}}\left(I_{z} C_{l_{r}}+I_{x} C_{n_{r}}\right) r\right] \\
\dot{r}=V_{2}\left[\left(I_{x z} C_{l_{\beta}}+I_{x} C_{n_{\beta}}\right) \beta+\frac{b}{2 V_{0}}\left(I_{x z} C_{l_{p}}+I_{x} C_{n_{p}}\right) p+\frac{b}{2 V_{0}}\left(I_{x z} C_{l_{r}}+I_{x} C_{n_{r}}\right) r\right] \\
\dot{\phi}=p+r \tan \theta_{0} \\
V_{2}=\frac{\rho S b V_{0}^{2}}{2\left(I_{x} I_{z}-I_{x z}^{2}\right)}
\end{gathered}
$$

where $\mathrm{V}_{0}$ and $\theta_{0}$ are the aircraft's initial velocity and pitch angle. Expanding and re-writing these equations into a matrix format gives the final state space representation used for the handling qualities evaluation.

\section{Longitudinal state space system:}

$$
\begin{aligned}
& \dot{X}=A_{\text {lng }} \vec{x}+B_{\text {lng }} \vec{u}
\end{aligned}
$$

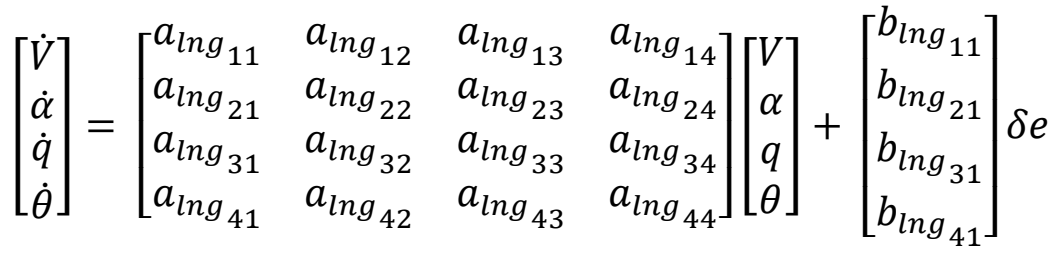

$$
\begin{aligned}
& \text { where: } a_{\operatorname{lng}_{11}}=\frac{\rho S V_{0}}{m} C_{z_{0}} \tan \theta_{0}+\frac{\rho S V_{0}}{2 m} C_{x_{V}} \\
& a_{\operatorname{lng}_{12}}=\frac{\rho S V_{0}}{2 m} C_{x_{\alpha}} \\
& a_{\operatorname{lng}_{13}}=0 \\
& a_{\operatorname{lng}_{14}}=-\frac{\rho S V_{0}^{2}}{2 m} C_{z_{0}} \\
& a_{\operatorname{lng}}=\frac{C_{z_{V}}-2 C_{z_{0}}}{V_{0} V_{1}} \\
& a_{l n g_{22}}=\frac{C_{z_{\alpha}}}{V_{1}} \\
& a_{\operatorname{lng} 23}=\frac{1}{V_{1}}\left(\frac{2 m}{\rho S V_{0} c}+C_{z_{q}} \frac{c}{2 V_{0}}\right) \\
& a_{\text {lng }}=-\frac{C_{z_{0}} \tan \theta_{0}}{V_{1}}
\end{aligned}
$$




$$
\begin{aligned}
& a_{l n g_{31}}=\frac{\rho S c V_{0}^{2}}{2 I_{y}}\left(C_{m_{\alpha}}+\frac{c}{2 V_{0}} C_{m_{\dot{\alpha}}} a_{l n g_{21}}\right) \\
& a_{l n g_{32}}=\frac{\rho S c V_{0}^{2}}{I_{y}}\left(C_{m_{\alpha}}+\frac{c}{2 V_{0}} C_{m_{\dot{\alpha}}} a_{\operatorname{lng}_{22}}\right) \\
& a_{l n g_{33}}=\frac{\rho S c V_{0}}{2 I_{y}}\left(\frac{c}{2}\right)\left(C_{m_{q}}+C_{m_{\dot{\alpha}}} a_{\operatorname{lng}_{23}}\right) \\
& a_{\operatorname{lng}_{34}}=\frac{\rho S c V_{0}}{2 I_{y}}\left(\frac{c}{2}\right)\left(C_{m_{\dot{\alpha}}} a_{\operatorname{lng}_{24}}\right) \\
& a_{\operatorname{lng}_{41}}=0 \\
& a_{\operatorname{lng}_{42}}=0 \\
& a_{\operatorname{lng}_{43}}=1 \\
& a_{\operatorname{lng}_{44}}=0 \\
& b_{\operatorname{lng}_{11}}=0 \\
& b_{\operatorname{lng}}=\frac{C_{x_{\delta e}}}{V_{1}} \\
& b_{l n g_{31}}=C_{m_{\delta e}}+\frac{c}{2 V_{0}} C_{m_{\dot{\alpha}}} b_{l n g_{21}} \\
& b_{\operatorname{lng}_{41}}=0 \\
& \text { and } V_{1}=\frac{2 m}{\rho S V_{0}}-\frac{c}{2 V_{0}} C_{z_{\dot{\alpha}}}
\end{aligned}
$$

\section{Lateral state space system:}

$$
\begin{gathered}
\dot{X}=\boldsymbol{A}_{l \boldsymbol{t}} \overrightarrow{\boldsymbol{x}}+\boldsymbol{B}_{l \boldsymbol{t}} \vec{u} \\
{\left[\begin{array}{c}
\dot{\beta} \\
\dot{p} \\
\dot{r} \\
\dot{\phi}
\end{array}\right]=\left[\begin{array}{llll}
a_{l t_{11}} & a_{l t_{12}} & a_{l t_{13}} & a_{l t_{14}} \\
a_{l t_{21}} & a_{l t_{22}} & a_{l t_{23}} & a_{l t_{24}} \\
a_{l t_{31}} & a_{l t_{32}} & a_{l t_{33}} & a_{l t_{34}} \\
a_{l t_{41}} & a_{l t_{42}} & a_{l t_{43}} & a_{l t_{44}}
\end{array}\right]\left[\begin{array}{c}
\beta \\
p \\
r \\
\phi
\end{array}\right]+\left[\begin{array}{ll}
b_{l t_{11}} & b_{l t_{12}} \\
b_{l t_{21}} & b_{l t_{22}} \\
b_{l t_{31}} & b_{l t_{32}} \\
b_{l t_{41}} & b_{l t_{42}}
\end{array}\right]\left[\begin{array}{c}
\delta a \\
\delta r
\end{array}\right]} \\
\text { where } a_{l t_{11}}=C_{y_{\beta}} \frac{\rho S V_{0}}{2 m} \\
a_{l t_{12}}=\frac{\rho S b}{4 m} C_{y_{r}}
\end{gathered}
$$




$$
\begin{aligned}
& a_{l t_{13}}=\left(\frac{\rho S b}{4 m} C_{y_{r}}\right)-1 \\
& a_{l t_{14}}=\frac{g}{V_{0}} \\
& a_{l t_{21}}=\left(I_{z} C_{l_{\beta}}+I_{x z} C_{n_{\beta}}\right) V_{2} \\
& a_{l t_{22}}=\left(I_{z} C_{l_{p}}+I_{x z} C_{n_{p}}\right) V_{3} \\
& a_{l t_{23}}=\left(I_{z} C_{l_{r}}+I_{x z} C_{n_{r}}\right) V_{3} \\
& a_{l t_{24}}=0 \\
& a_{l t_{31}}=\left(I_{x Z} C_{l_{\beta}}+I_{x} C_{n_{\beta}}\right) V_{2} \\
& a_{l t_{32}}=\left(I_{x z} C_{l_{p}}+I_{x} C_{n_{p}}\right) V_{3} \\
& a_{l t_{33}}=\left(I_{x z} C_{l_{r}}+I_{x} C_{n_{r}}\right) V_{3} \\
& a_{l t_{34}}=0 \\
& a_{l t_{41}}=0 \\
& a_{l t_{42}}=1 \\
& a_{l t_{43}}=\tan \theta_{0} \\
& a_{l t_{44}}=0 \\
& b_{l t_{11}}=C_{y_{\delta a}} \frac{\rho S V_{0}}{2 m} \\
& b_{l t_{12}}=C_{y_{\delta r}} \frac{\rho S V_{0}}{2 m} \\
& b_{l t_{21}}=\left(I_{z} C_{l_{\delta a}}+I_{x z} C_{n_{\delta a}}\right) V_{2} \\
& b_{l t_{22}}=\left(I_{z} C_{l_{\delta r}}+I_{x z} C_{n_{\delta r}}\right) V_{2} \\
& b_{l t_{31}}=\left(I_{x z} C_{l_{\delta a}}+I_{x} C_{n_{\delta a}}\right) V_{3} \\
& b_{l t_{32}}=\left(I_{x z} C_{l_{\delta r}}+I_{x} C_{n_{\delta r}}\right) V_{3} \\
& b_{l t_{41}}=0 \\
& b_{l t_{42}}=0
\end{aligned}
$$




$$
\begin{gathered}
\text { and } V_{2}=\frac{\rho S b V_{0}^{2}}{2}\left(\frac{1}{I_{x} I_{z}-I_{x Z}^{2}}\right) \\
V_{3}=\frac{\rho S b^{2} V_{0}}{4}\left(\frac{1}{I_{x} I_{z}-I_{x Z}^{2}}\right)
\end{gathered}
$$

Where, $\mathrm{c}$ is the chord length of the aircraft's wings. Because the modal parameters are only dependent on the A matrix, the $\mathbf{B}$ matrix can be neglected.

These equations are implemented within the RefMat Process subsystem. This subsystem can be seen at the bottom of Figure 3, and the RefMat subsystem itself is shown in Figure 19.

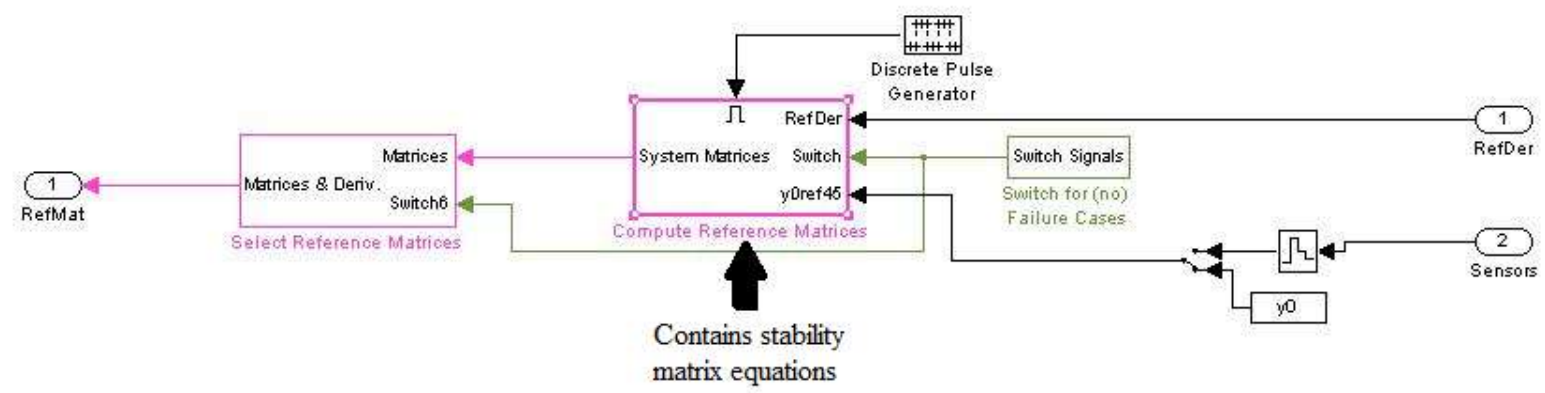

Figure 19: RefMat process subsystem.

The equations for the stability matrices are inside the Compute Reference Matrices subsystem and broken down into the lateral and longitudinal directions. The Compute Reference Matrices subsystem is shown in Figure20.

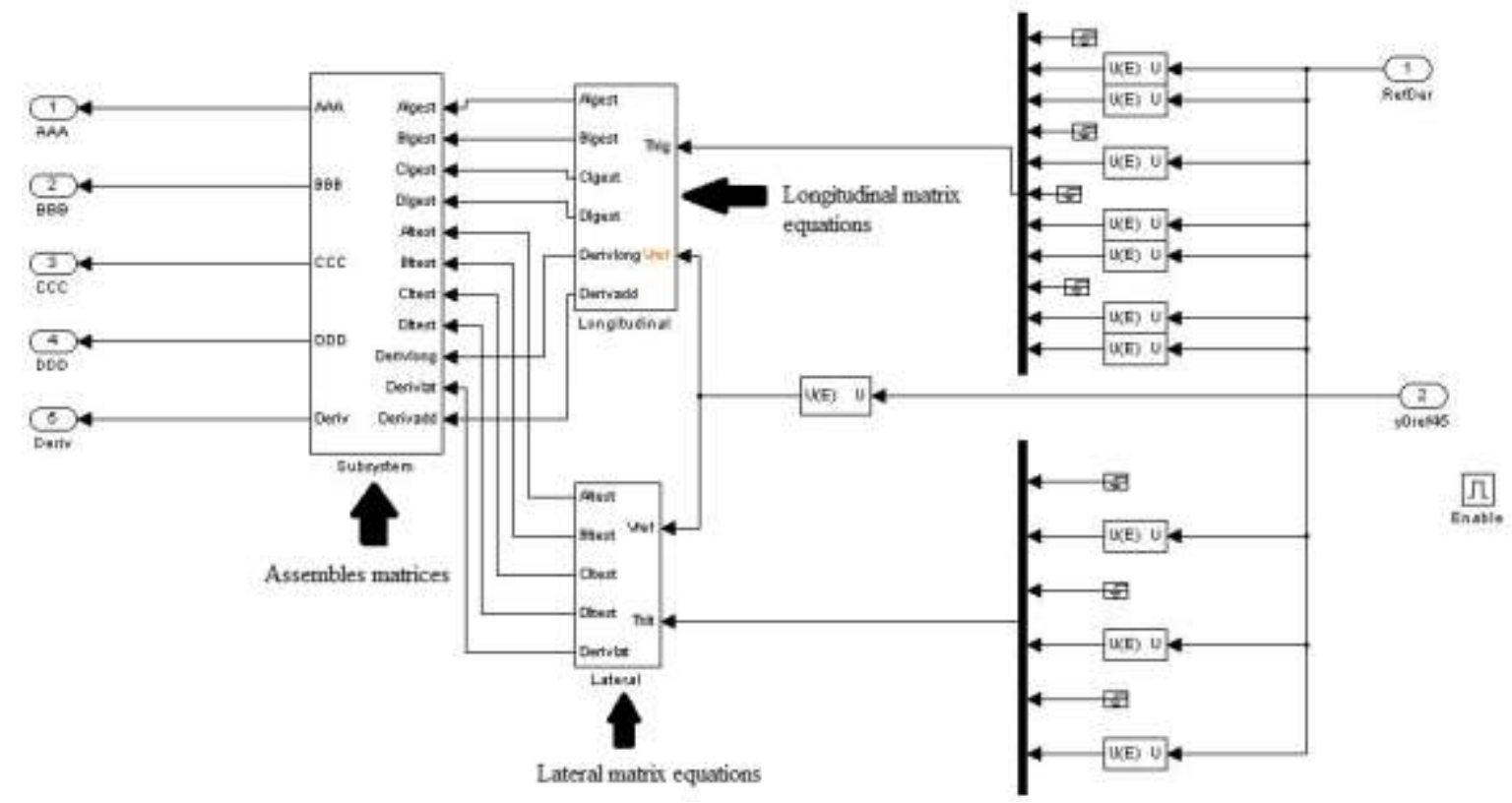

Figure 20: Compute reference matrices subsystem.

The actual equations for the stability matrices are implemented inside the Longitudinal and Lateral subsystems as noted in the above figure. The portion of the Longitudinal subsystem building the A matrix is shown in Figure21. 


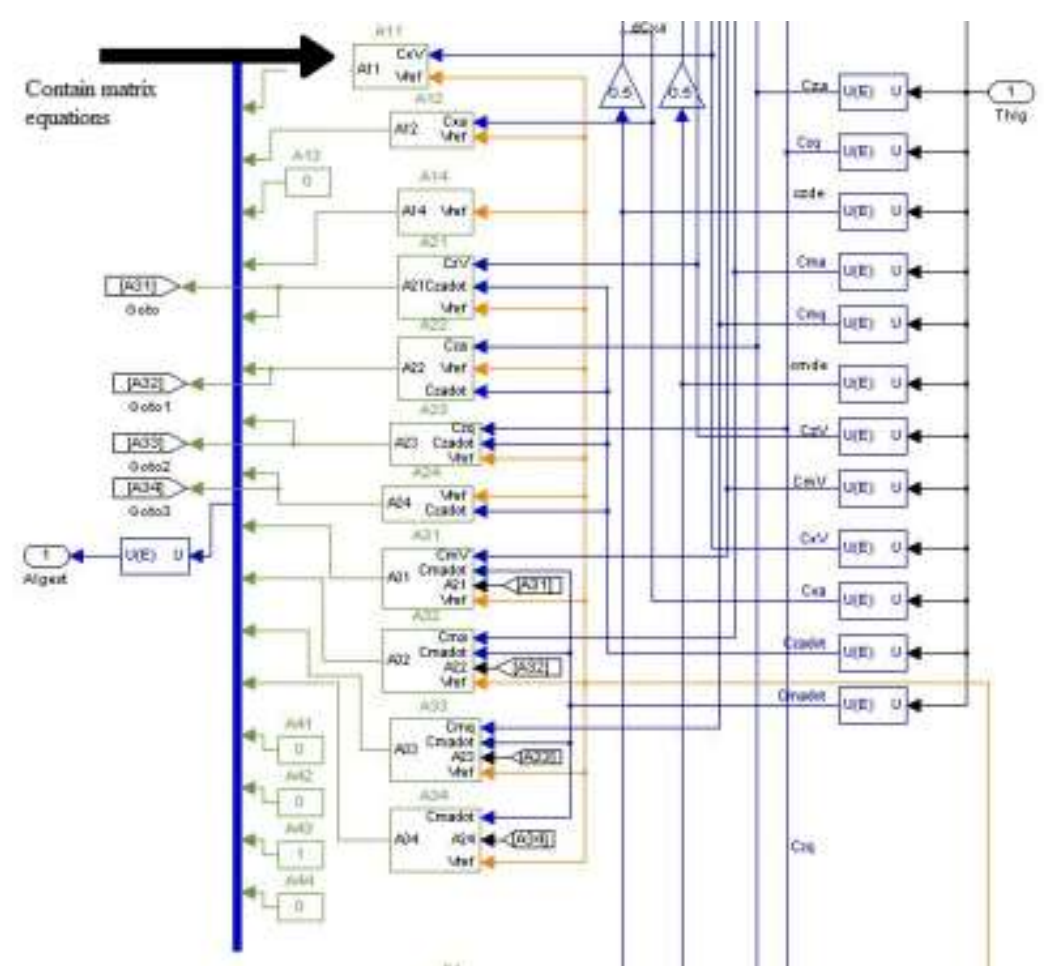

Figure 21: Building and implementation of longitudinal matrix equations.

Each position of the matrix has its own subsystem so that they may be individually calculated. As an example, $a_{\operatorname{lng} 11}$ is shown in Figure22.

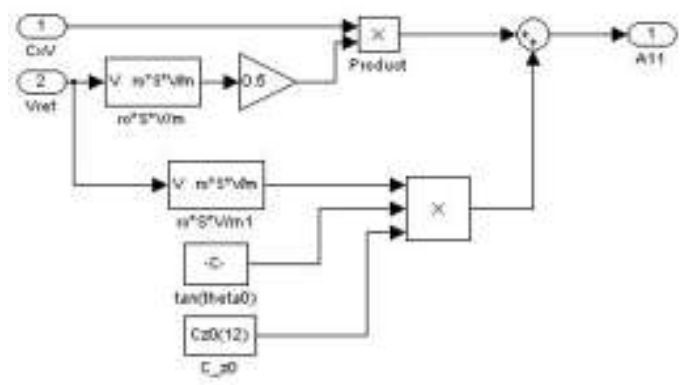

Figure 22: $a_{\text {Ing11 }}$ subsystem.

Each value of the matrix is then sent to be organized and sent to a file. The matrices are organized such that coupling terms are neglected, as:

$$
\left[\begin{array}{cc}
A_{\text {lng }} & 0 \\
0 & A_{l t}
\end{array}\right]
$$

The subsystem constructing the matrix follows the calculation of the longitudinal and lateral matrix equations. The subsystem builds the matrix as a vector and saves it as a data file for further examination later using Matlab scripts. The construct matrices subsystem can be seen in Figure23. 


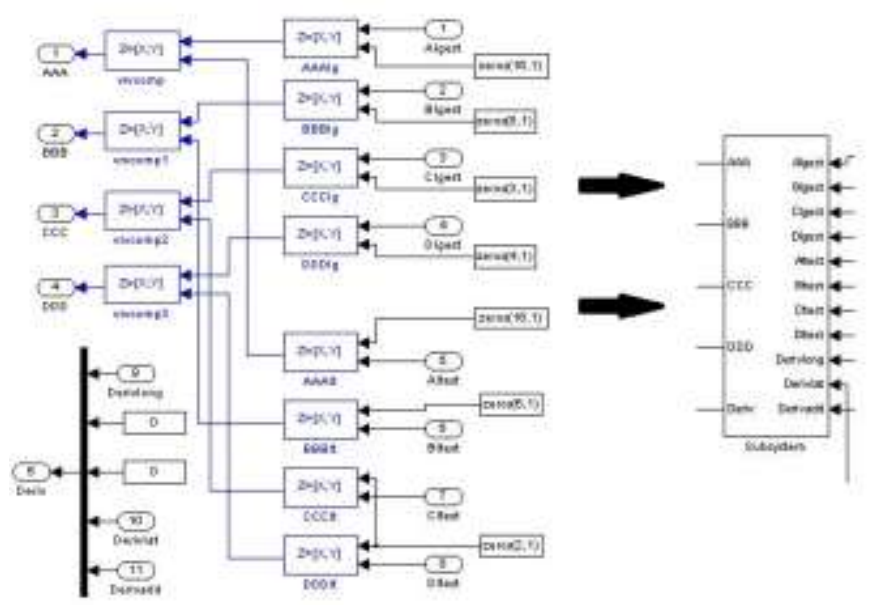

Figure 23: Construct matrices into vector to go to file.

The Matlab scripts implement the use of eigenvalues for the study of the aircraft's modal parameters; therefore, the stability matrix, $\mathbf{A}$, is the primary interest. The eigenvalues are the solutions to the characteristic equation, which matches the form of equation (80) or (86) depending on the type of solution. Complex conjugate solutions follow equation (80) and real solutions follow equation (86). The eigenvalues of the stability matrix are found by solving the following equation [45]:

$$
\operatorname{det}(\boldsymbol{A}-\lambda \boldsymbol{I})=\mathbf{0}
$$

Where $\lambda$ is an eigenvalues of $\mathbf{A}, \mathbf{I}$ is the identity matrix, and det is the operator of taking the determinant of $\mathbf{A}-\lambda \mathbf{I}$. Expanding the expression for the longitudinal case gives:

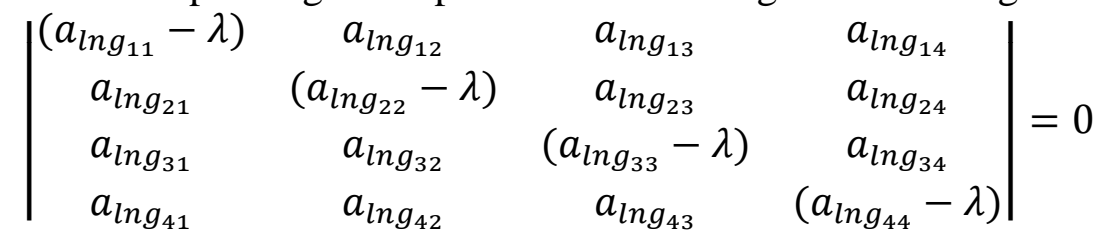

Solving equation (79), the eigenvalues of the longitudinal stability matrices are obtained. A similar approach is used to obtain the lateral-directional stability matrix. Each stability matrix contains four eigenvalues. Typically, the longitudinal dynamics modal configuration consists of two pairs of complex conjugates and the lateral matrix contains one pair of complex conjugates and two real eigenvalues. These eigenvalues then have to be associated to the modes of motion that they represent. This can be done through examining the eigenvectors. Each eigenvalue has a corresponding eigenvector. These eigenvectors first need to be normalized before they can be further examined. With the normalized eigenvectors, the structure will then be able to help determine if an eigenvalue corresponds to the short period or phugoid mode. For example, the alpha response of the aircraft is more affected by the short period than the phugoid mode. Through examination of the normalized eigenvectors, if the value in the eigenvector structure corresponding to alpha is large, then the associated eigenvalue is part of the short period. More details are discussed in Chapter 5 with the validation data.

The next step is to convert these eigenvalues into the modal parameters. For the complex conjugate eigenvalues, it is known that they fit the form of a general second order system characteristic equation:

$$
s^{2}+2 \zeta \omega_{n} s+\omega_{n}^{2}=\left(s-\lambda_{1}\right)\left(s-\lambda_{2}\right)
$$


where $\mathrm{s}$ is the Laplace variable, $\zeta$ is the damping coefficient, $\omega_{\mathrm{n}}$ is the natural frequency, and $\lambda$ are eigenvalues. The eigenvalues of the system are complex conjugates and can be expanded into polynomials so that:

$$
(s-a+b i)(s-a-b i)=s^{2}-2 a s+\left(a^{2}+b^{2}\right)
$$

From which it can be seen that:

$$
\begin{gathered}
-2 a=2 \zeta \omega_{n} \\
a^{2}+b^{2}=\omega_{n}^{2}
\end{gathered}
$$

Simply rearranging these equations for $\zeta$ and $\omega_{\mathrm{n}}$ gives:

$$
\begin{gathered}
\zeta=-\frac{a}{\omega_{n}} \\
\omega_{n}=\sqrt{a^{2}+b^{2}}
\end{gathered}
$$

Of the four eigenvalues from the lateral-directional stability matrix, the two real values are for the roll and spiral time constants. The time constant is the time it takes a generic first order system to reach $63 \%$ of its steady state value in response to a step input. The general first order system equation can be seen in equation (86).

$$
\frac{1}{s-a}
$$

The time constant is then defined as:

$$
t_{\text {Roll,Spiral }}=-\frac{1}{a}
$$




\section{Chapter 5- Icing Model}

The following sections will cover: the derived icing equations, the implementation of the equations and the icing model within the simulation environment, data validation tests, as well as some simulation tests and examples.

\subsection{Icing Model Equations}

The lift and drag coefficients of the aircraft can be modified using the NASA data mentioned. From that data, it was determined that the aerodynamic coefficients would be a function of time spent in the icing conditions and the aircraft's current angle of attack. In addition to the lift and drag characteristics, it was noted that other parameters would also need to be modified for ice accretions. These parameters included the aircraft's moment coefficient as well as several stability derivatives along the lateral channel and also some control derivatives for icing of ailerons, elevators, and the rudder. However, NASA's data did not contain any information for them. Therefore, it was necessary to use two methods of modifying aircraft aerodynamic parameters. Additional information from the literature on predicted icing effects on light aircraft [28] revealed that the stability derivatives of the aircraft were modified by a percentage based on exposure to icing conditions. Other research with the Dehavilland Twin Otter has used similar processes of modifying an aircraft stability or control derivative by a percentage based on icing conditions [4]. The data found from literature showed that under severe icing conditions the following occurs:

- $\mathrm{C}_{\mathrm{m} \alpha}$ decreases by $9.9 \%$

- $\mathrm{C}_{\mathrm{Y} \beta}$ decreases by $20 \%$

- $\mathrm{C}_{1 \beta}$ decreases by $10 \%$

- $\mathrm{C}_{\mathrm{lP}}$ decreases by $10 \%$

- $\mathrm{C}_{\mathrm{n} \beta}$ reduces by $20 \%$

- $\mathrm{C}_{\mathrm{nr}}$ reduces by $6.1 \%$

These changes were assumed to be linear with time. The percentages mentioned are assumed to occur after five minutes in icing conditions. This assumption means that the maximum effects on the lateral channel and longitudinal channel will occur at the same time.

Modifying $\mathrm{C}_{\mathrm{m} \alpha}$ allows for the change in the slope of the moment coefficient. The remaining control derivatives mentioned are along the aircraft's lateral channel and will affect the aircraft's Dutch roll as well as roll and spiral time constants.

The equation used for calculating the icing alteration coefficients for the lateral derivatives was relatively simple, a gradient calculation of the percent degradation over the time period desired. For example, $\mathrm{C}_{Y \beta}$ is reduced by $20 \%$ in severe conditions. In order to match this data to the NASA data, "severe" icing conditions are assumed to occur after five minutes of exposure. Therefore an equation for the icing alteration factor for the control derivatives can be formulated as:

$$
k_{C_{Y \mathrm{~B}}}(t)=1-\left(\frac{0.2}{5}\right) * t=1-(0.04 * t)
$$

Where $\mathrm{k}_{\mathrm{CY} \beta}$ is an icing alteration coefficient or correction factor affecting $\mathrm{C}_{\mathrm{Y} \beta}$ and $\mathrm{t}$ is the current time spent in icing conditions. Note that the unit for time for all the icing equations is in minutes. The equation for $\mathrm{C}_{1 \beta}$ will be the only one that has a slight variation as compared to the other 
equations. $\mathrm{C}_{1 \beta}$ is normally negative and becomes more negative as time in icing increases, therefore its constant will be greater than one. The remaining equations would then be as follows:

$$
\begin{gathered}
k_{C_{l \mathrm{~B}}}(t)=1+(0.02 * t) \\
k_{C_{l P}}(t)=1-(0.02 * t) \\
k_{C_{n r}}(t)=1-(0.0122 * t) \\
k_{C_{n \beta}}(t)=1-(0.04 * t) \\
k_{C_{m \alpha}}(t)=1-(0.0198 * t)
\end{gathered}
$$

Ice can also affect the aircrafts control surfaces, especially the horizontal tail section. Therefore, for simulations the moment control derivatives were modified in the same manner. The control surfaces were set to be similarly affected to the lateral coefficients so that there was a $10 \%$ loss over the five minute period. The equations used for the control derivatives are as follows:

$$
\begin{aligned}
& k_{C_{m_{\delta e}}}(t)=1-(0.02 * t) \\
& k_{C_{l_{\delta a}}}(t)=1-(0.02 * t) \\
& k_{C_{n_{\delta r}}}(t)=1-(0.02 * t)
\end{aligned}
$$

The remaining two equations are for lift and drag coefficients, $\mathrm{k}_{\mathrm{L}}$ and $\mathrm{k}_{\mathrm{D}}$ respectively. These equations were more challenging to create. By going through the process discussed in 3.3, and through a process of trial and error, the equations for the icing alteration coefficients of lift and drag were developed. These equations produce a factor that modifies the aircraft's $\mathrm{C}_{\mathrm{x}}$ and $\mathrm{C}_{\mathrm{z}}$ stability derivatives based on the aircraft's current angle of attack and the amount of time it has spent in icing. The equations developed are:

$$
\begin{gathered}
k_{D}(t, A O A)=0.05 * t *|A O A|^{1.7}+0.275 * t+1 \\
k_{L}(t, A O A)=-0.0015 * t *|A O A|^{1.75}+1
\end{gathered}
$$

Where $k_{D}$ and $k_{L}$ are the alteration factors to be multiplied to $C_{x 0}$ and $C_{z 0}$ respectively. The multiplication process of the constants to the derivatives is the same as the lateral and control derivatives. Plots of $\mathrm{C}_{\mathrm{D} 0}$ and $\mathrm{C}_{\mathrm{L} 0}$, Figures 24 and 25 respectively, use these equations over a range of angles of attack to check their accuracy. 


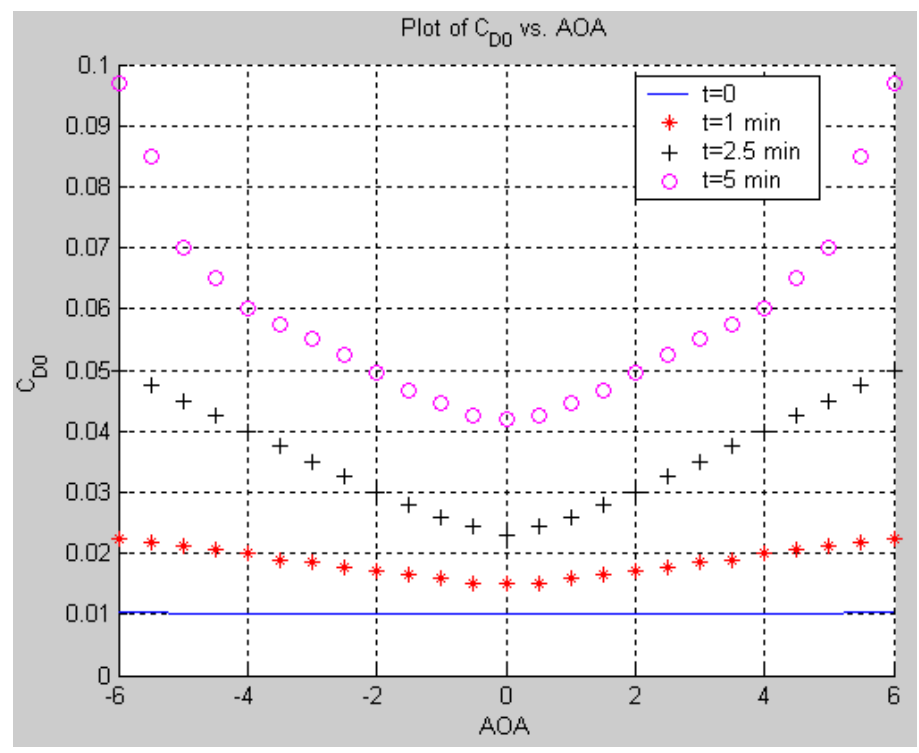

Figure 24: Plot of $C_{D 0}$ using the equation $k_{D}$.

The lift coefficient curve shows only the linear range because the effects of stall are created via a lookup table, similar to the one for $\mathrm{C}_{\mathrm{m} \alpha}$ mentioned in section 3.2. This lookup table modifies the aircraft's $\mathrm{C}_{\mathrm{L} \alpha}$ coefficient. Modifying this coefficient effectively modifies the slope of the $\mathrm{C}_{\mathrm{L} 0}$ line, allowing for the creation of the maximum $\mathrm{C}_{\mathrm{L} 0}$ point followed by the drop off of the coefficient after stall has been reached.

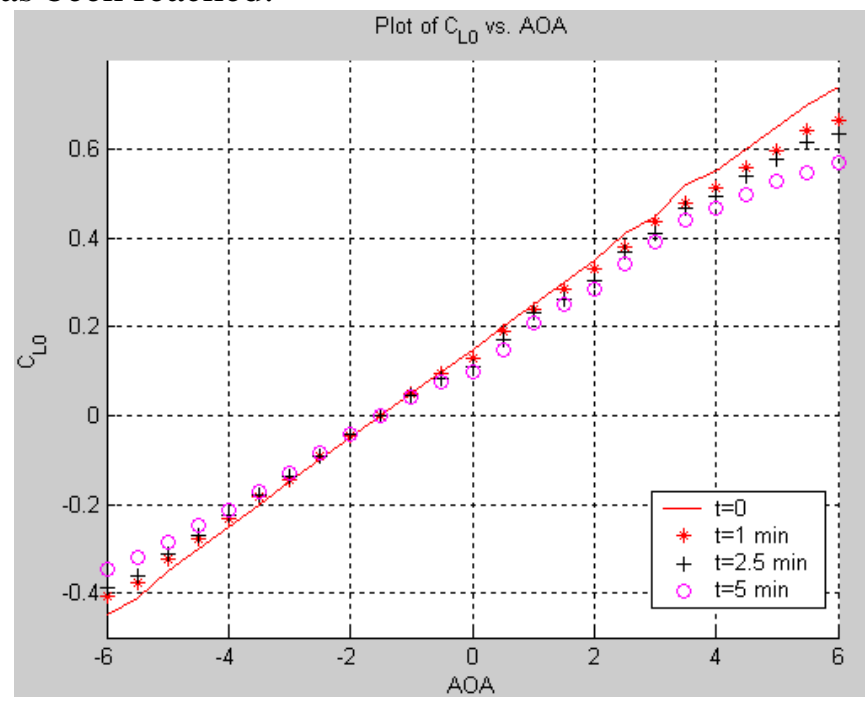

Figure 25: Plot of $\mathrm{C}_{\mathrm{L}}$ using the equation $\mathrm{k}_{\mathrm{L}}$.

\subsection{Implementation of Equations and the Icing Model}

The icing model of the simulation can be found within the More Inputs1 subsystem. The icing section takes the aircrafts current angle of attack and altitude from the sensors array. The time in icing is then found via a created s-function called ice_counter_lvl1sfcn. While within this range the current iteration is added to a counter to increase the time spent in the icing conditions. If the aircraft is outside the range the iteration is subtracted so that ice may "melt," restoring the aircrafts dynamics. The icing altitude range can be easily altered from within the ice_counterlvl1sfen.m file. The range is defined within the S-function as minimum of 200 meters to a maximum of 5000 meters. This range was selected because icing probabilities are 
less than $1 \%$ when the aircraft is lower than 200 meters or higher than 5000 meters [12]. However, this s-function does not output the time spent within icing conditions, it outputs the number of simulation iterations spent within icing conditions. Therefore, it is necessary to multiply this counter by the simulation time step and divide by 60 to convert to minutes. This is done simply by a gain of $0.02 / 60$, which can be seen in Figure26.

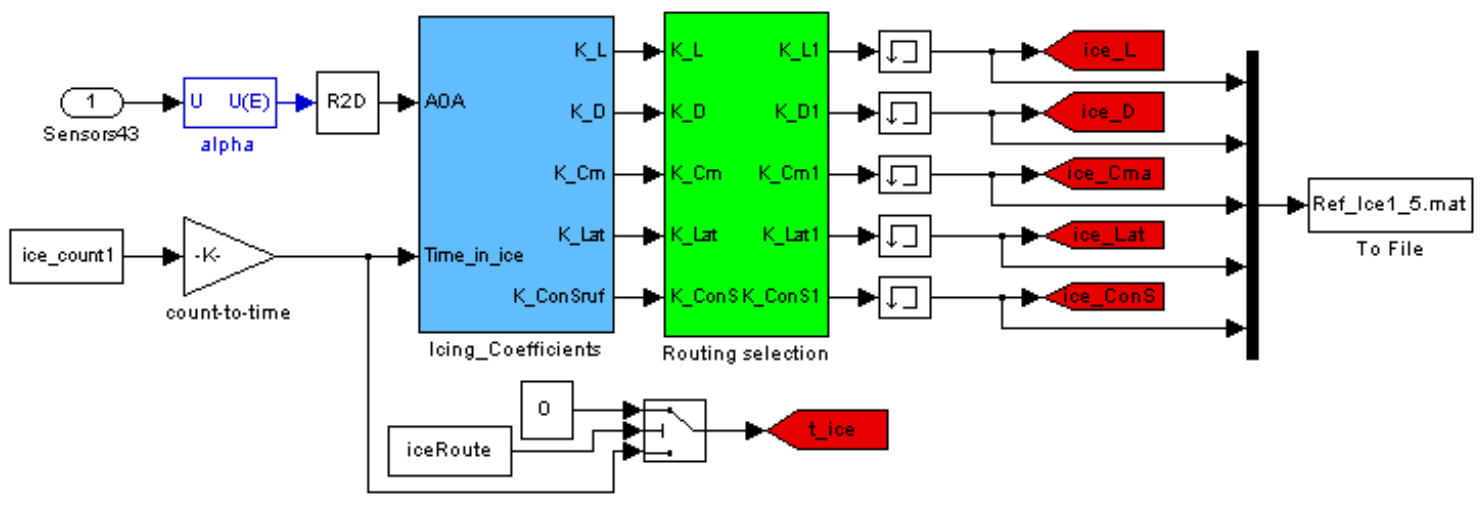

Figure 26: Icing model.

Inside the Icing_Coefficients subsystem all the equations of the icing constants can be found within their respective subsystems. The Icing_Coefficients subsystem can be seen in Figure27.

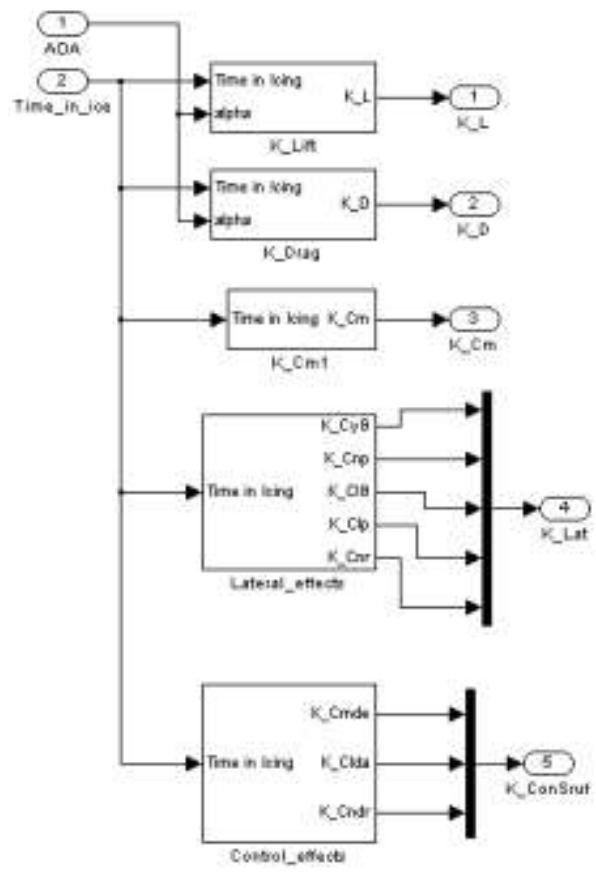

Figure 27: Icing_Coefficients subsystem.

The equations for the lift and drag constants were implemented using a user defined function block. An example for the $\mathrm{k}_{\mathrm{L}}$ equation can be seen in Figure 28. 


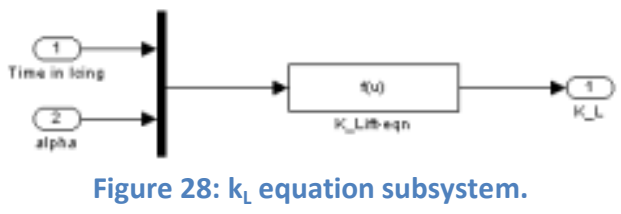

The mux bar combines the signals for the single input user function to use both signals. Figure 29 shows the equations implemented within the user defined function blocks.

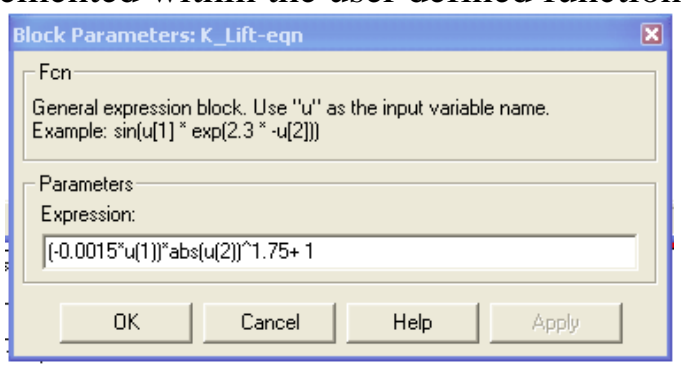

Figure 29: $\mathrm{k}_{\mathrm{L}}$ equation block settings.

The remaining equations for $\mathrm{C}_{\mathrm{m} \alpha}$ and the other lateral derivatives were set up using Simulink blocks. The subsystem K_Cm1 in Figure27 contains the equation modifying $\mathrm{C}_{\mathrm{m} \alpha}$, the equation block diagram can be seen below in Figure 30 .

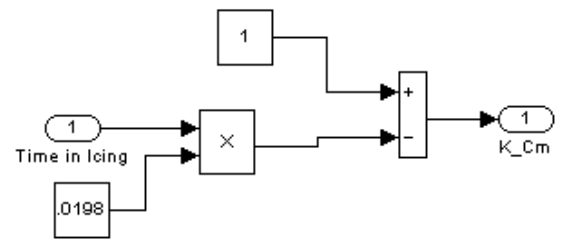

Figure 30: Block diagram of $\mathrm{C}_{\mathrm{m \alpha}}$ equation.

The lateral_effects subsystem is shown in Figure31, and the equations implemented can be found in Figure32.

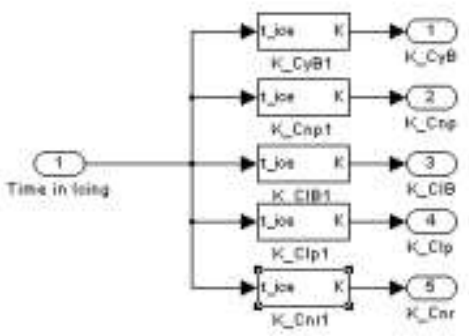

Figure 31: Lateral_effects subsystem. 


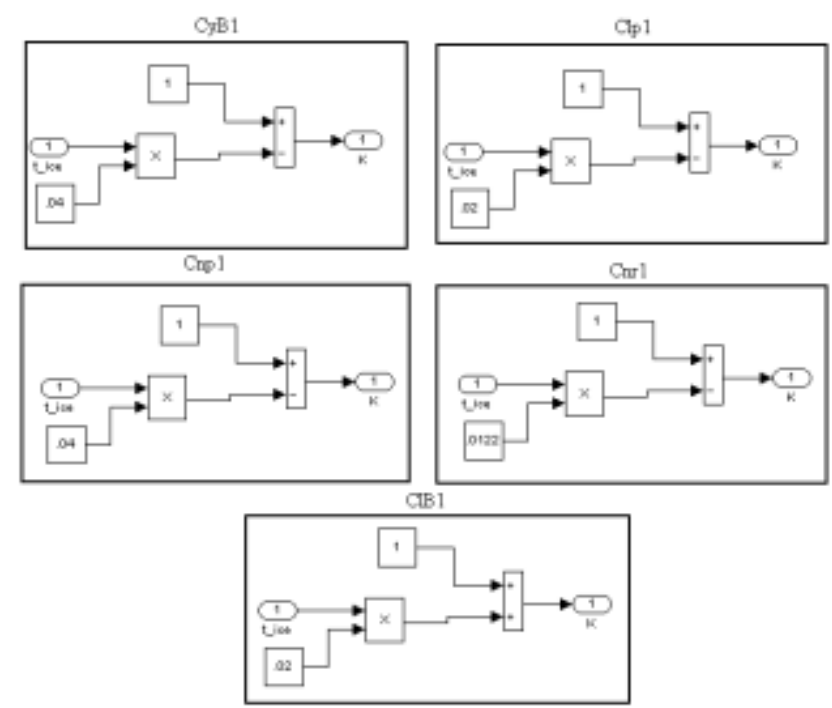

Figure 32: Lateral stability derivative icing block diagrams.

The control derivatives were also implemented through Simulink blocks to create their respective equations.

\subsection{Model Verification}

The model was validated through several different methods. First, the procedure of computing the stability and control derivatives is verified by comparing the calculated values at steady state to the aircraft lookup tables. Then, simulations are performed to qualitatively assess the dynamic response of the model. Also the poles and modal parameters of the aircraft under nominal conditions are compared to a general business jet aircraft to see if they match.

\subsubsection{Verification of Derivative Computation}

Under nominal steady level conditions the calculated stability derivatives are expected to match those of the aircraft lookup tables. Therefore, this comparison will help ensure that the gradient-based approximation of the derivatives and its implementation are sound. The derivatives values under nominal conditions were first extracted from the lookup tables. These values were then compared to the values that have been calculated. The following table shows the data from the lookup tables and compares it to the values calculated in the stability derivatives subsystem.

Table 2: List of stability derivatives from lookup table compared to calculated.

\begin{tabular}{ccc}
\hline Derivative & Lookup Table Value & Calculated Value \\
\hline$C_{\mathrm{z \alpha}}$ & -6.3027 & -6.3024 \\
$\mathrm{C}_{\mathrm{m} \alpha}$ & -1.4546 & -1.4553 \\
$\mathrm{C}_{\mathrm{zq}}$ & -71.48 & -71.49 \\
$\mathrm{C}_{\mathrm{mq}}$ & -21.02 & -21.03 \\
$\mathrm{C}_{\mathrm{z} \delta \mathrm{eL}}$ & -0.2477 & -0.248 \\
$\mathrm{C}_{\mathrm{m} \delta \mathrm{e}}$ & -0.4973 & -0.4978 \\
$\mathrm{C}_{\mathrm{z} \delta \mathrm{eR}}$ & -0.2477 & -0.247 \\
$\mathrm{C}_{\mathrm{m} \delta \mathrm{e}}$ & -0.4973 & -0.4978
\end{tabular}




\begin{tabular}{|c|c|c|}
\hline $\mathrm{C}_{\mathrm{z} \delta \mathrm{e}}$ & -0.4955 & -0.495 \\
\hline $\mathrm{C}_{\mathrm{m} \delta \mathrm{e}}$ & -0.9947 & -0.9956 \\
\hline$C_{z \dot{\alpha}}$ & 141.3 & 141.3 \\
\hline $\mathrm{C}_{\mathrm{m} \dot{\alpha}}$ & 4.9575 & 4.9574 \\
\hline$C_{y \beta}$ & -1.5 & -1.5 \\
\hline $\mathrm{C}_{1 \beta}$ & -0.0525 & -0.0525 \\
\hline$C_{n \beta}$ & 0.0992 & 0.0992 \\
\hline $\mathrm{C}_{\mathrm{yp}}$ & 0 & 0 \\
\hline $\mathrm{C}_{\mathrm{lp}}$ & -0.2138 & -0.2138 \\
\hline $\mathrm{C}_{\mathrm{np}}$ & -0.1176 & -0.1176 \\
\hline $\mathrm{C}_{\mathrm{yr}}$ & 0.4175 & 0.4175 \\
\hline $\mathrm{C}_{\mathrm{lr}}$ & 0.1537 & 0.1537 \\
\hline $\mathrm{C}_{\mathrm{nr}}$ & -0.363 & -0.363 \\
\hline$C_{\text {y } \delta a L}$ & 0 & 0 \\
\hline $\mathrm{C}_{\mathrm{l} \delta \mathrm{aL}}$ & 0.0323 & 0.0343 \\
\hline $\mathrm{C}_{\mathrm{n} \delta \mathrm{aL}}$ & -0.002 & -0.002 \\
\hline$C_{\text {yōaR }}$ & 0 & 0 \\
\hline $\mathrm{C}_{\mathrm{loaR}}$ & -0.0323 & -0.0343 \\
\hline $\mathrm{C}_{\mathrm{n} \delta ̊ a R}$ & 0.002 & 0.002 \\
\hline$C_{\text {y } \delta a}$ & 0 & 0 \\
\hline $\mathrm{C}_{1 \delta \bar{a}}$ & 0.0646 & 0.0646 \\
\hline$C_{n \delta a}$ & -0.004 & -0.004 \\
\hline $\mathrm{C}_{\mathrm{y} \delta \mathrm{r}}$ & 0.81 & 0.81 \\
\hline $\mathrm{C}_{18 \mathrm{r}}$ & 0.006 & 0.006 \\
\hline $\mathrm{C}_{\mathrm{n} \delta \mathrm{r}}$ & -0.043 & -0.043 \\
\hline $\mathrm{C}_{\mathrm{zV}}$ & -0.4051 & -0.3957 \\
\hline $\mathrm{C}_{\mathrm{mV}}$ & -0.088 & -0.086 \\
\hline $\mathrm{C}_{\mathrm{xV}}$ & -0.0675 & -0.0658 \\
\hline$C_{x \alpha}$ & 0.2808 & 0.2808 \\
\hline
\end{tabular}

The calculated values used in the table are averaged throughout a simulation under nominal conditions. Throughout the numerical calculation process, the values of the calculated derivatives will change slightly. These small changes are due to the linear interpolation between look-up table values and the small variances in dynamic pressure. However the changes are negligible as the average values of all the derivatives closely match those of the look-up tables. Figure 33 shows a couple of the calculated derivatives and how they will change throughout a simulation. These derivatives were calculated under nominal steady level flight conditions with no pilot inputs. 


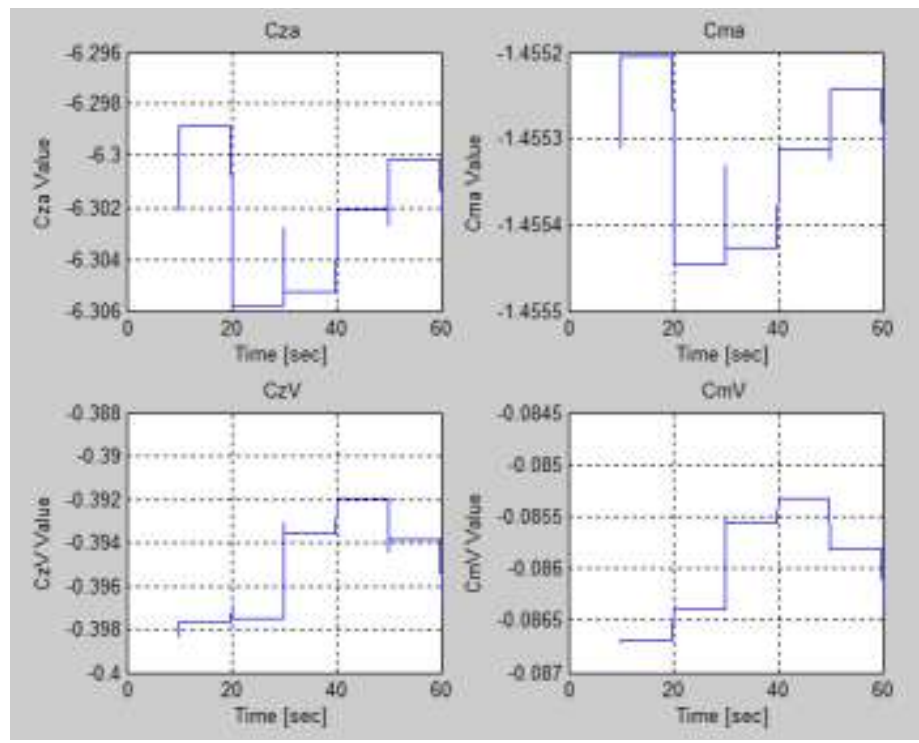

Figure 33: $\mathrm{C}_{\mathrm{za}}, \mathrm{C}_{\mathrm{ma}}, \mathrm{C}_{\mathrm{z}}$, and $\mathrm{C}_{\mathrm{mv}}$ values calculated within the calculate derivatives subsystem.

The business jet model used follows the typical break-down of having two pairs of complex conjugate roots. For a business jet, the general characteristic equation roots fall around $-1+/-\mathrm{j}(2.65)$ for the short period mode, $-0.0043+/-\mathrm{j}(0.092)$ for the phugoid mode, and -0.0653 $+/-\mathrm{j}$ (1.69) for the Dutch roll mode [40]. In addition, the roots corresponding to the roll and spiral time constants are -0.0010 for spiral and -0.5003 for roll time constant. These values should be similar to the eigenvalues taken from the lateral-directional $\mathbf{A}$ matrix. By performing a simple simulation under both nominal and steady level flight conditions, data for determining the aircraft's nominal pole position can be acquired. After performing a couple of simulations under nominal conditions, the nominal pole placement for the aircraft was found to be $-1.5585+/$ $\mathrm{j}(2.1942)$ for the short period mode, $-0.01098+/-\mathrm{j}(0.1083)$ for the phugoid mode, and -0.4686 $+/-\mathrm{j}(2.2502)$ for the Dutch roll mode. The time constant values for the aircraft at nominal conditions are -0.0088 for the spiral time constant and -2.6305 for the roll time constant. This shows that under nominal conditions the aircraft will react to control inputs similarly to other aircraft in the same class.

\subsubsection{Verification of Icing Model Implementation}

The experimental data used to build the icing equations came from two different sources. The icing data for lift and drag coefficients came from plots containing the effects of icing on those coefficients [38]. These plots covered a range of angles of attack, the values for lift and drag coefficients at those angles of attack, as well as values for lift and drag coefficients at varying times in icing conditions. The lift coefficient data showed the accepted trends of a reduction in lift and a reduced stall angle. The data also covered topics such as the average water droplet size and the shape of the ice on the leading edge of the airfoil. The data for the lift coefficient can be found in Figure 34. 

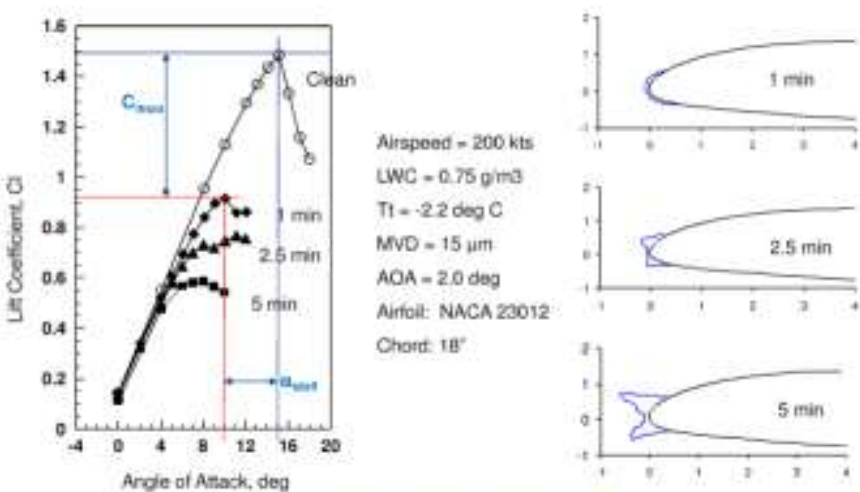

NASA king Fesearch Tunnel Fesulte

Figure 34: Data presented by NASA [38].

Similar data was given for the drag coefficient from the same source. The drag data was also consistent with general trends of drag coefficient data associated with icing. The data showed drag increased with time as the time in icing increased, the ice shapes, and the average water droplet size, which were both consistent with the lift data as well. Figure 35 shows the drag coefficient data.

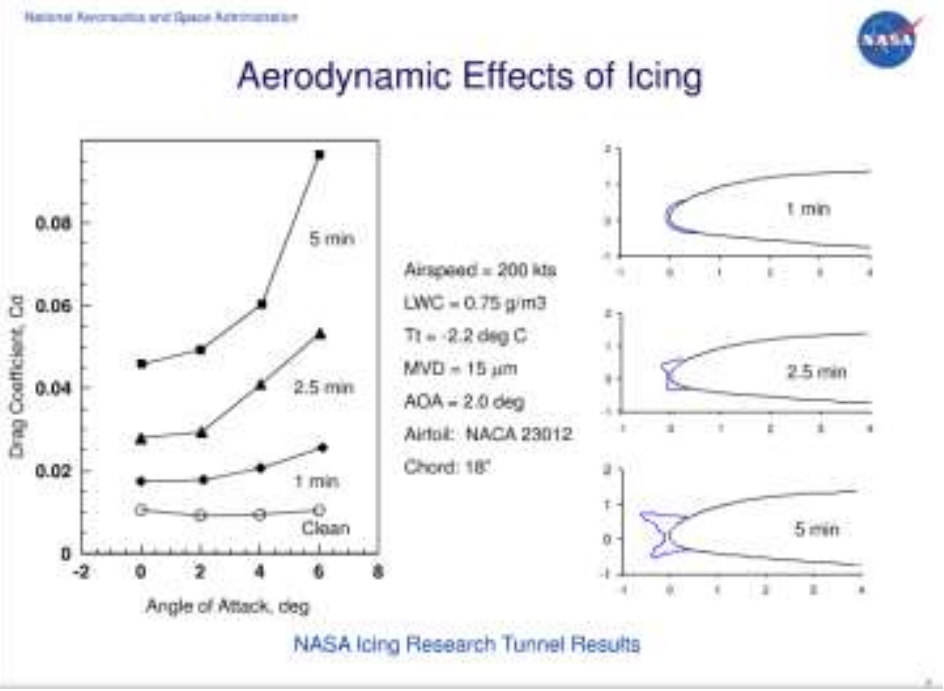

Figure 35: NASA data presented for drag coefficient [36]

This data was then normalized and equations developed to create icing alteration coefficients to be used within the simulation, see equations (97) and (98). Using a combination of the icing alteration coefficient equations and the stall lookup tables, the following plot was made of the lift coefficient with respect to the aircraft's angle of attack. 


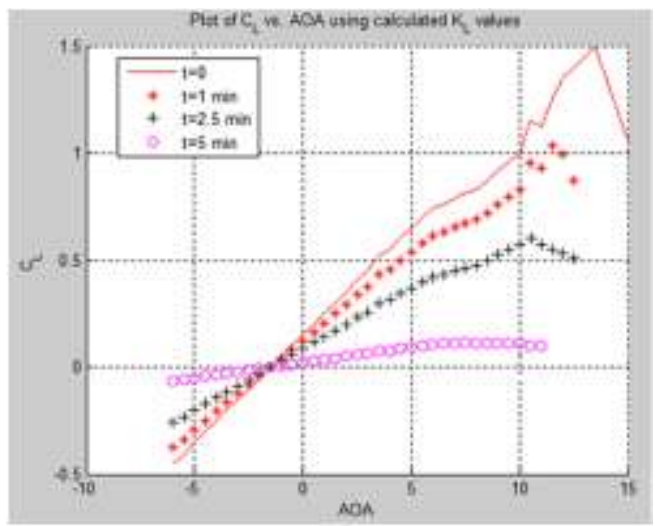

Figure 36: Plot of $C_{L}$ against angle of attack using icing constant equations and stall lookup tables.

Figure 37 shows the plot of $\mathrm{C}_{\mathrm{D}}$ against angle of attack. The plot was created using equation 97 and a range of angles of attack.

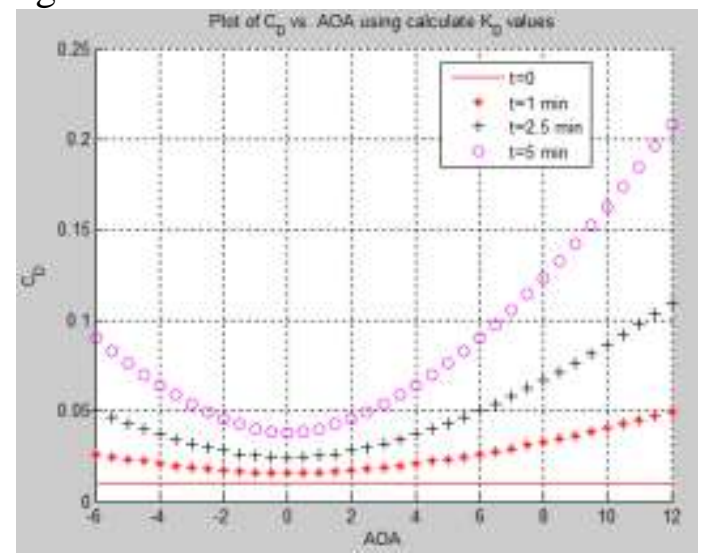

Figure 37: $C D$ against angle of attack using the icing constant equation.

The lateral-directional icing alteration coefficients equations were developed based on data from a separate source [28]. The data from the source gives a maximum percentage of degradation to lateral stability derivatives and control derivatives. These maximum values were assumed to be under a severe situation. Icing effects were assumed to follow the same pattern as the data for lift and drag, a linear variation of the alteration coefficients with time in icing. This assumption allowed for the development of the linear equations for the correction factors of the lateral-directional stability and control derivatives.

\subsection{Simulations}

To further qualitatively verify the model, numerical simulations were performed. These simulations were designed to demonstrate the aircraft degrading performance and handling qualities by comparing doublet input responses under both nominal conditions and icing conditions. The setup method can be found in the User Manual in the Appendix. Doublet inputs were chosen because they excite adequately the dynamic response of the system and produce symmetric effects with respect to the aircraft's steady level flight conditions. Also a simulation time of seven minutes was used in order to achieve full icing effects on the aircraft, along with some extrapolated effects. In order to compare the data from the clean simulation and the icing simulation, the same control deflections for doublets is required. The control inputs used for both simulation tests are shown in Figures 38and 39. 


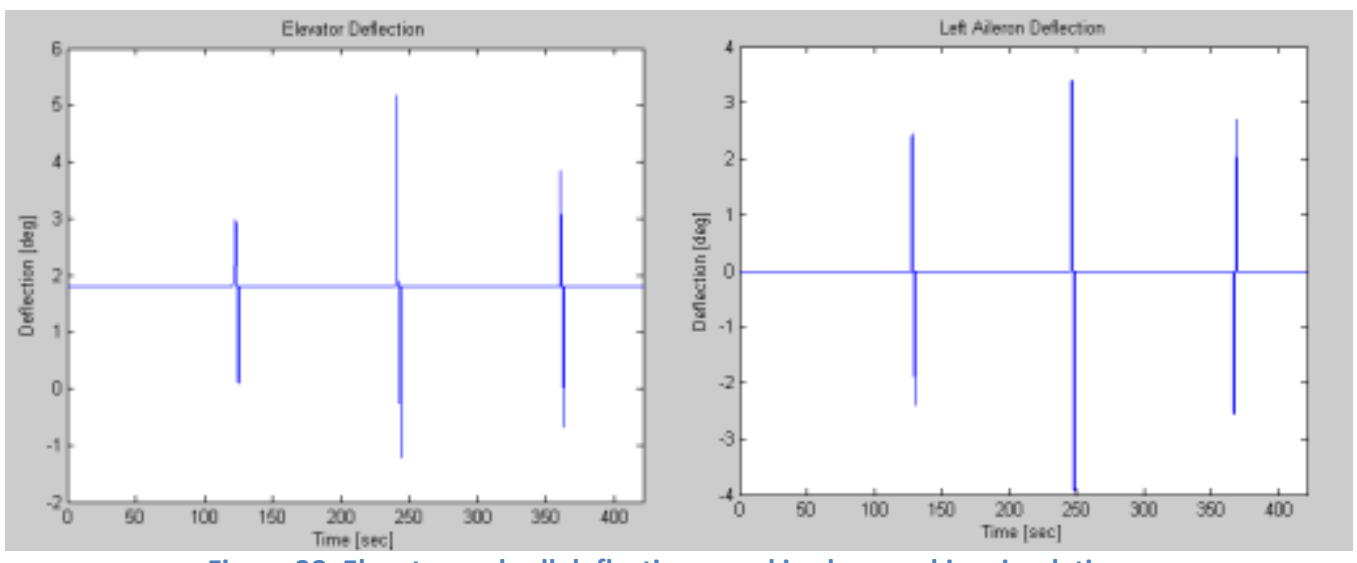

Figure 38: Elevator and roll deflections used in clean and ice simulations.

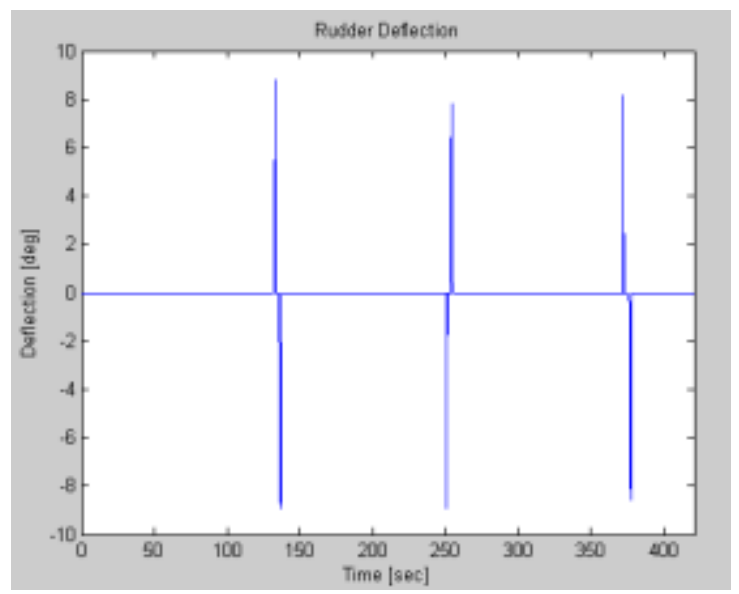

Figure 39: Rudder deflections used for clean and ice simulations.

These inputs are added to the pilot's current input, therefore it will be possible for the pilot to apply inputs to keep the aircraft at steady state conditions in icing and still utilize the same control doublets as the clean simulation. Also note that the elevator has an offset of 1.7 degrees at trim in steady state flight.

\subsubsection{Clean/ Nominal Flight}

The clean flight is performed under normal conditions with no ice accretions on any surfaces of the aircraft. By analyzing the aircraft's pitch, roll, and yaw rate responses to standard decoupled inputs, one can assess the nominal dynamic response of the aircraft.

The pitch rate response shows the aircrafts response to the elevators control deflections. The aircraft's nominal case responses can be seen in Figure40. Each of the three pitch inputs can be clearly seen, and the short period and phugoid modes are distinguishable. 


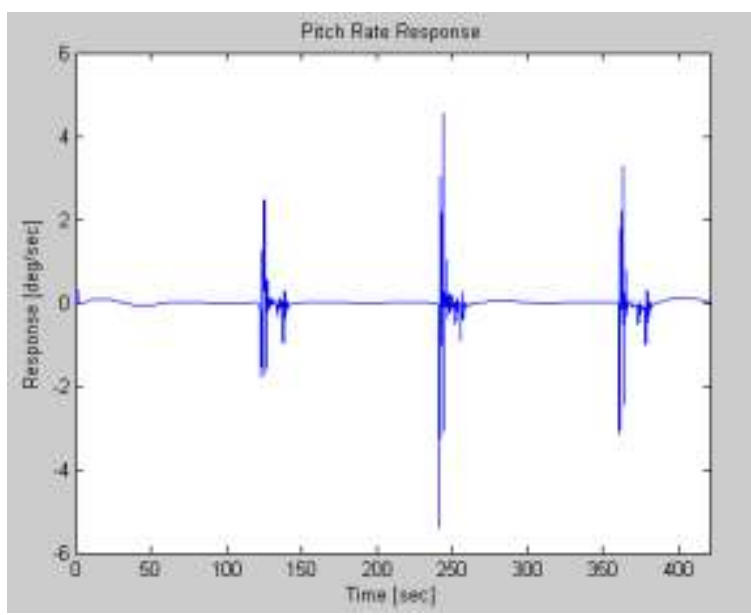

Figure 40: Pitch rate response under nominal conditions.

By zooming in on the first control input and comparing its respective response the aircraft's dynamic response can be more clearly seen. The input is shown in Figure 41 and shown next to the aircraft's pitch rate response. The pitch rate response clearly shows the short period and phugoid responses and they have been marked on the plot. These simulation results show a longitudinal dynamic response well correlated to the modal configuration determined in section 4.2.

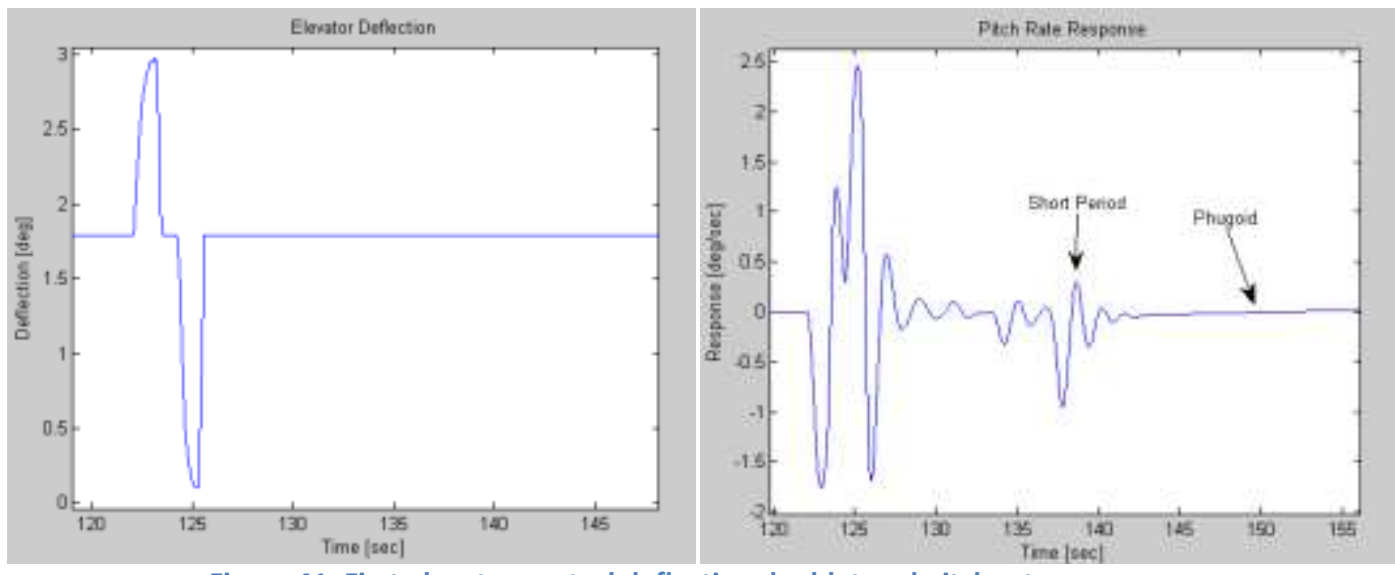

Figure 41: First elevator control deflection doublet and pitch rate response.

The elevator deflection is then followed shortly by an aileron input on the roll channel. The roll rate response to the aileron doublets throughout the simulation can be found in Figure 42 .

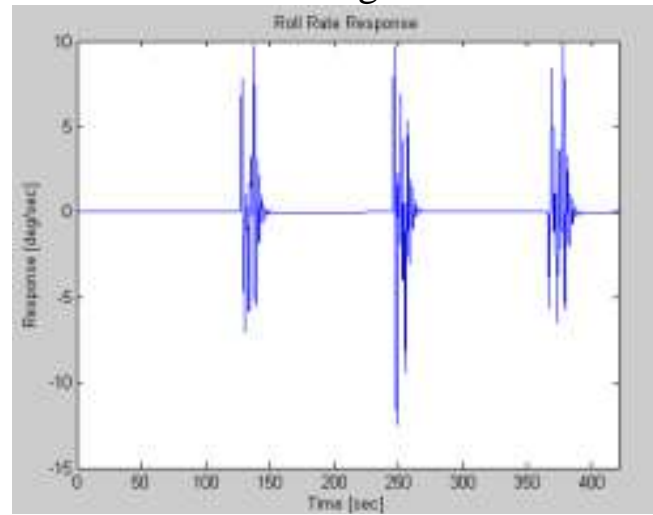

Figure 42: Roll rate response of aileron doublets. 
Upon closer examination the inputs and modes of dynamic response can be seen. The second aileron input shows a clear response of the aircraft. The control doublet from the left aileron can be found in Figure 43 and the corresponding aircraft response is plotted next to it.

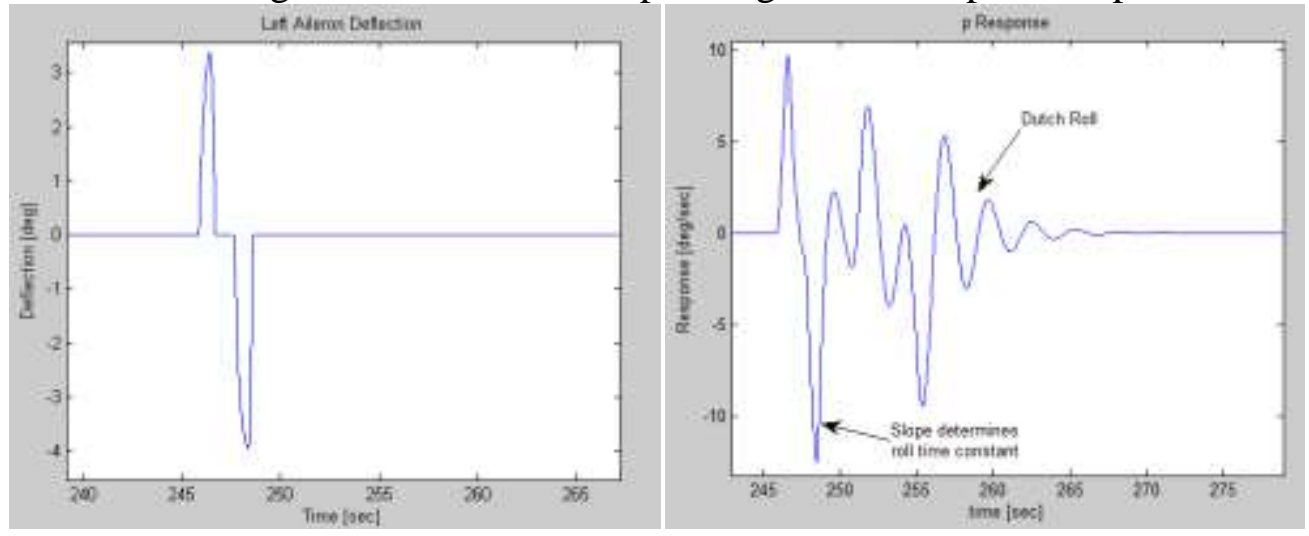

Figure 43: Second doublet from the left aileron and the roll rate response it created.

Again, the response modes can be seen in the plot of the roll rate response. The aircraft's roll time constant can also be found in the roll response. It determines how quickly the aircraft will respond to a lateral control input.

The final doublet of the series is a rudder doublet. This excites the aircraft's yaw rate response and more clearly shows the Dutch roll response and spiral mode of the aircraft. The yaw rate response of the aircraft from all three doublet inputs can be seen in Figure 44.

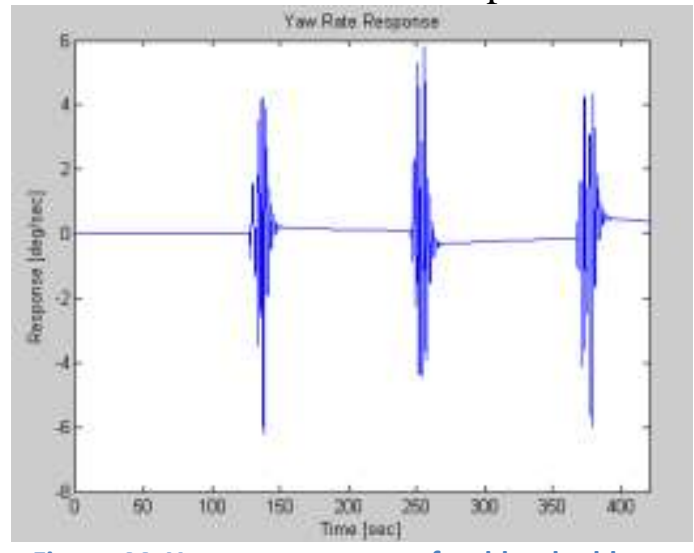

Figure 44: Yaw rate response of rudder doublets.

Closer examination of the simulation reveals not only the dynamic response of the aircraft to rudder inputs primary control channel (yaw) but also the coupling of the roll and yaw channels. Figure 45 shows the input command of the rudder and the yaw rate response of the aircraft. 


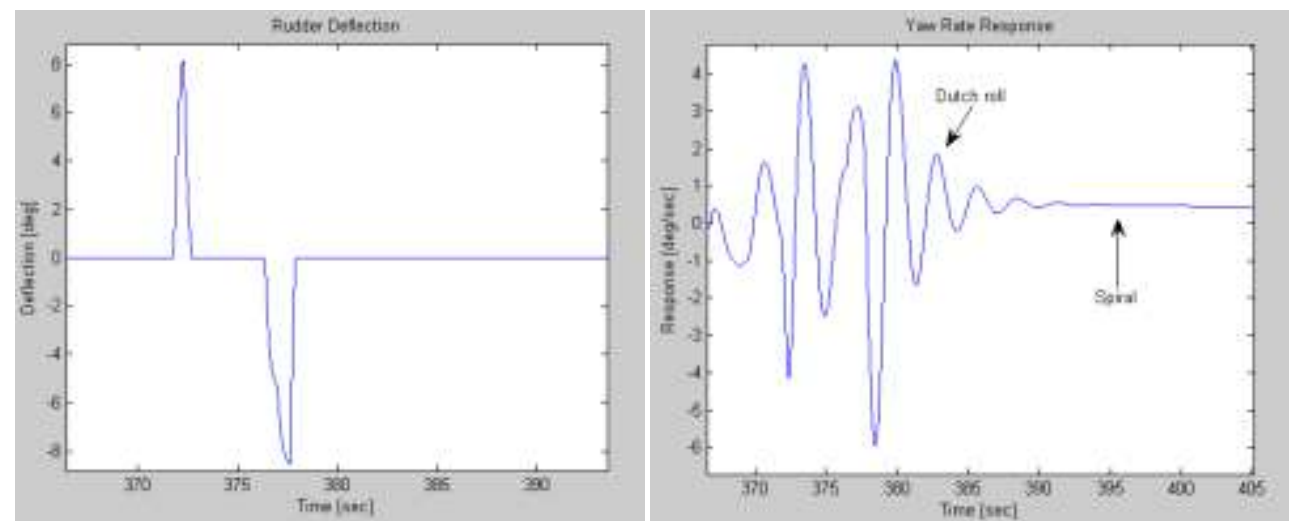

Figure 45: (Left) Third rudder doublet input. (Right) Yaw rate response to third rudder doublet.

These simulation results show that the lateral-directional dynamic response of the model is as expected based on the modal configuration determined in section 4.2.

\subsubsection{Icing Condition Simulations}

Two different icing simulations were performed to verify various effects of icing on the aircraft. The first icing simulation also utilizes the same control inputs from the clean simulation in order to perform the same doublets at various points of time spent in icing. This allows one to compare the nominal condition response to the response of the aircraft under icing conditions and how the response degrades. The second simulation begins with the aircraft in nominal conditions for one minute, and then the aircraft enters the icing conditions. The goal of the second simulation is to see how long the aircraft can maintain the steady level flight conditions with use of pilot inputs. For both simulations, as the ice accumulates on the aircraft, losses in lift and drag can be adjusted with throttle inputs only. Once the maximum amount of thrust is achieved, it then becomes necessary to use aerodynamic control inputs. Eventually the aircraft can no longer maintain the steady level flight condition and begins to descend. The inclusion of further pilot inputs brings risk of stall conditions to the aircraft.

\subsubsection{Aircraft Response to Doublets}

For the first simulation each of the three doublets now occurs after two, four, and six minutes of exposure to the icing conditions. For the first half of the simulation, steady level flight can be maintained with changes in throttle position only. As more time passes, the aircraft requires more control deflections in order to maintain the steady level flight conditions showing the aircraft's gradual decay of performance. This is consistent with the general observation of increased drag and reduced lift with time in icing. Figure 46 shows the elevator doublets and the pitch commands used to keep the aircraft at steady level flight for the icing simulation shown alongside to the pitch rate response. 


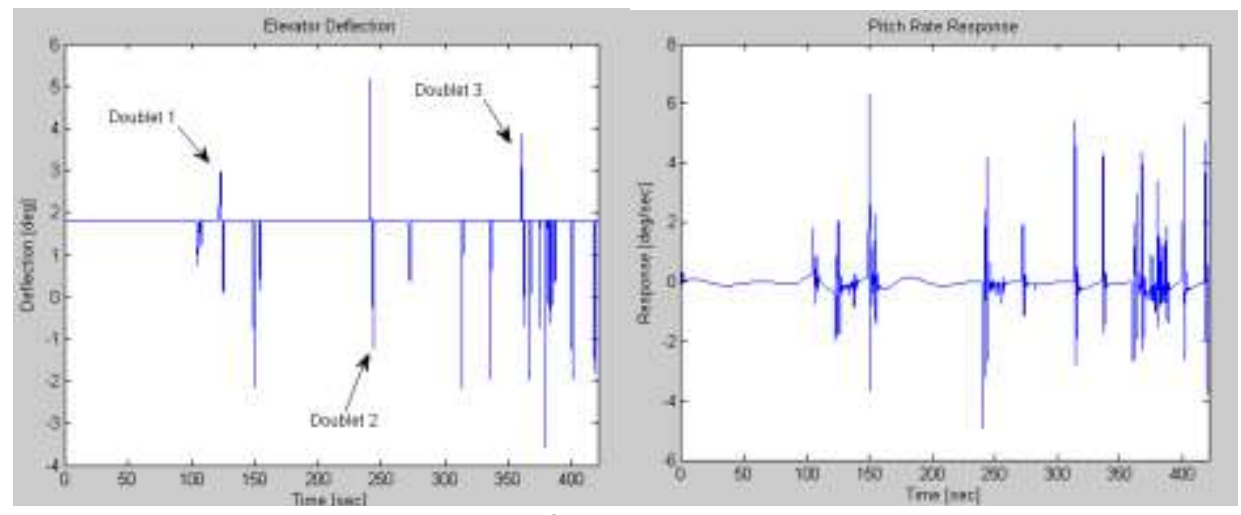

Figure 46: Elevator inputs for icing simulation and the pitch rate responses.

For the first three minutes the aircraft responds almost as though it were at nominal conditions, there is little degradation of the modal parameters and the losses in velocity due to drag coefficient increases can be corrected with increasing throttle inputs. The aircraft's phugoid mode is also distinguishable within this time period. By closer examination of the first doublet input, the aircraft's short period response can also be observed. Through comparison of this response to that of the nominal scenario it can be seen that there is little degradation to the short period and phugoid modes after the two minutes within icing conditions. A plot of the nominal condition and icing condition responses have been plotted together in Figure 47 to allow for an easier qualitative comparison.

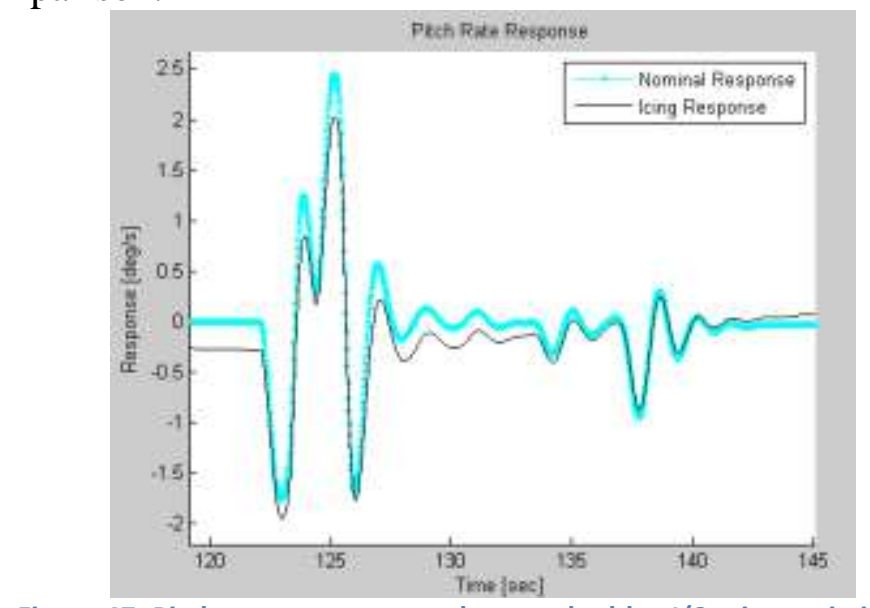

Figure 47: Pitch rate response to elevator doublet 1 (2 minutes in icing).

After four minutes within the icing conditions, the response has become more noticeably affected. The magnitude of the aircraft response is lower compared to the nominal conditions even though the input is still the same. The change in the short period frequency is also small but noticeably lower on the plot in Figure 48. 


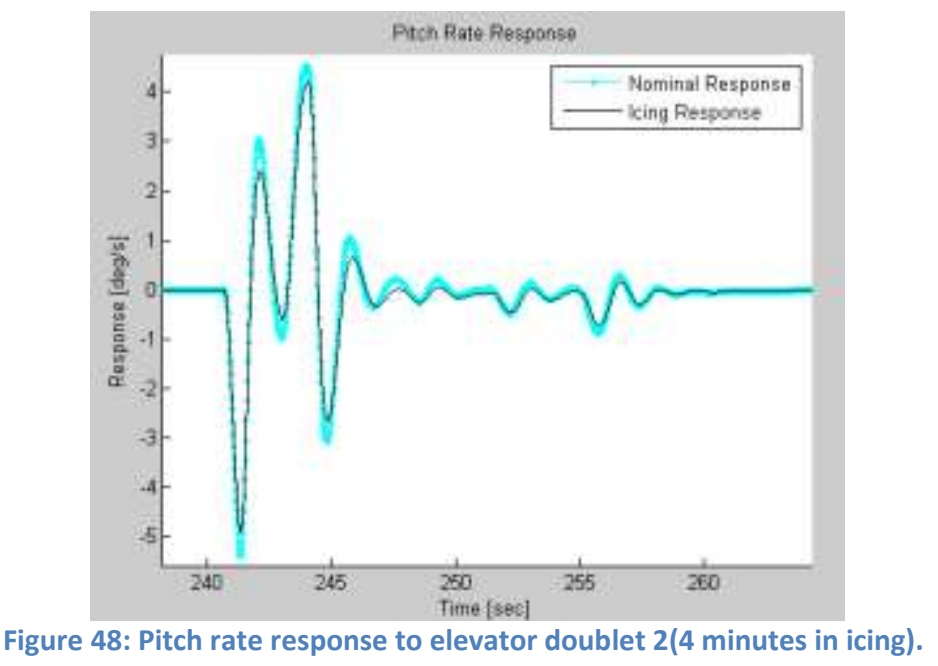

As the ice continued to build in the simulation, the aircraft began to require more pilot inputs in order to maintain the steady level flight conditions. In Figure 49, the plot shows the elevator inputs for maintaining the steady level flight conditions that were near the doublet input.

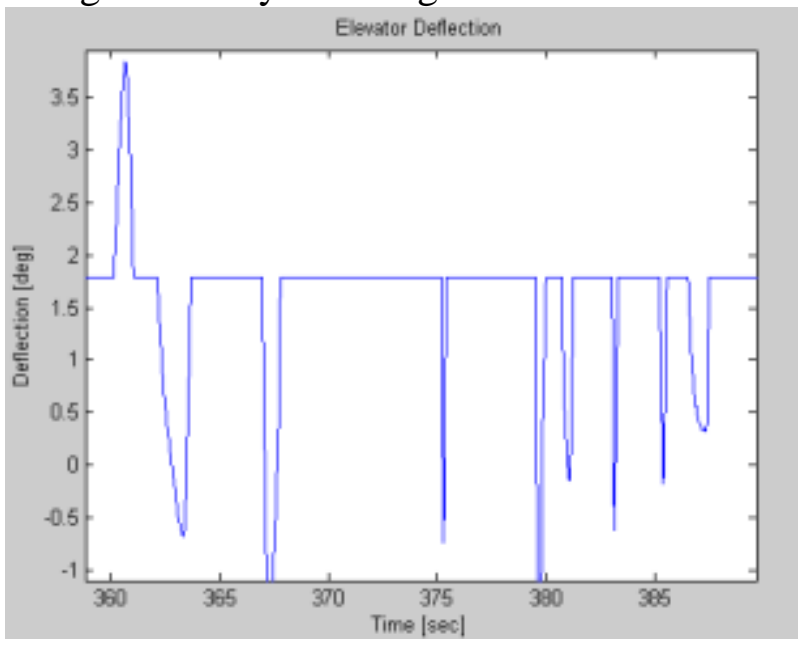

Figure 49: Elevator doublet 3(6 minutes in icing) and additional commands to maintain steady level flight.

The elevator input at about 367 seconds shows up on the response in addition to the doublet, the doublet response is still observable; however the phugoid response is rather hidden. For the response to the elevator doublet (Figure 50), the detrimental effect of icing to the short period response is even more prevalent. The magnitude of the response of the aircraft to the doublets is noticeably less than the nominal response; this is consistent with a reduction of the control effectiveness and with an increase in damping as compared to the four minute response. The peaks of the response also no longer occur at the same time, which is consistent with a reduction of the frequency even further than it had at the four minute response. 


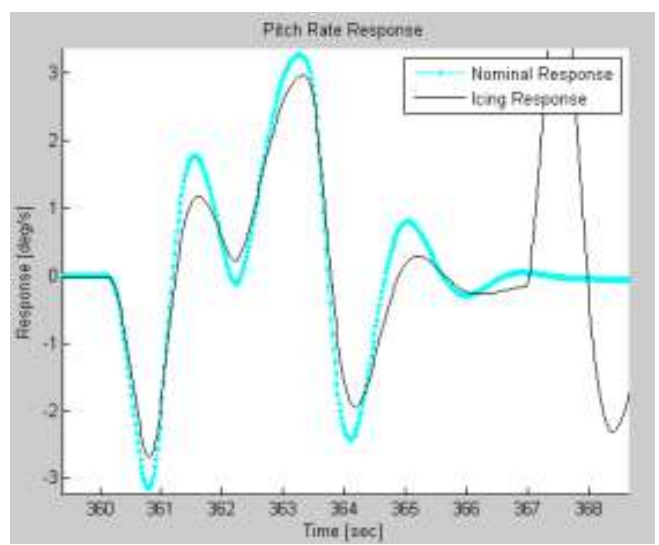

Figure 50: Pitch rate response of elevator doublet 3(6 minutes in icing) and additional steady state flight commands.

The roll doublets excite primarily the aircraft roll mode response but also exhibit the Dutch roll. As with the elevator inputs, as time spent in icing increased, so did the need for more control inputs to keep the aircraft at steady level flight. Figure 51 shows the roll doublets used and the needed control inputs to keep the aircraft at steady level flight, and also shows the aircraft's roll rate response to these inputs.

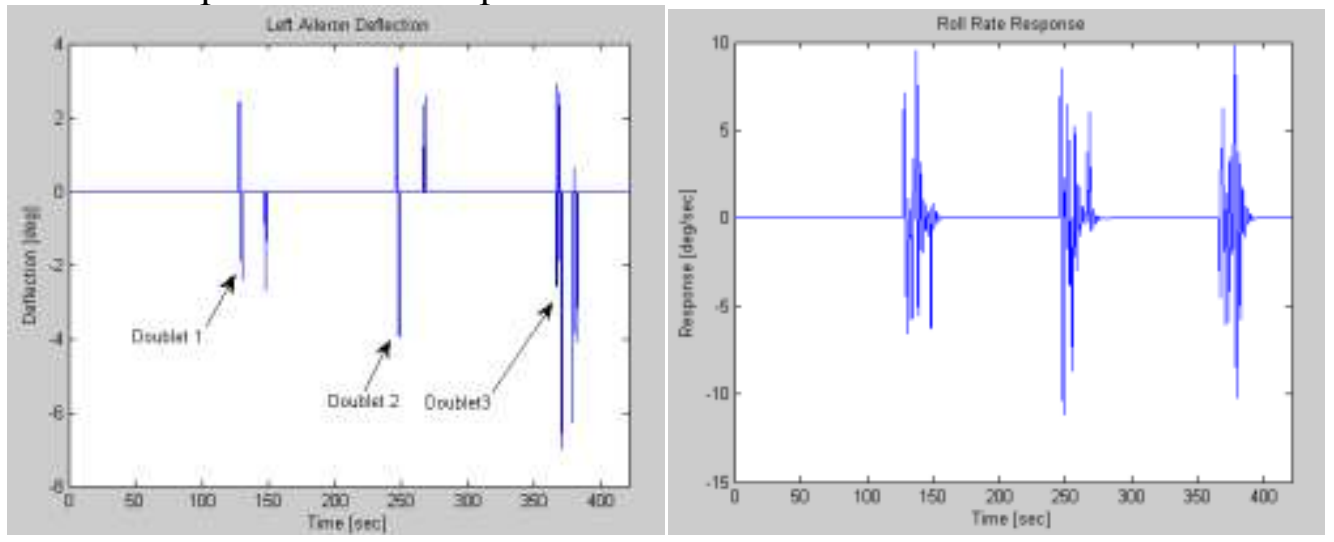

Figure 51: Left aileron doublets for icing simulation and the roll rate responses.

The first doublet occurs just after two minutes in the icing conditions. Figure 52 shows the roll rate response to the first doublet. In the plot it can be seen that the damping has been affected minutely and the frequency is almost unchanged.

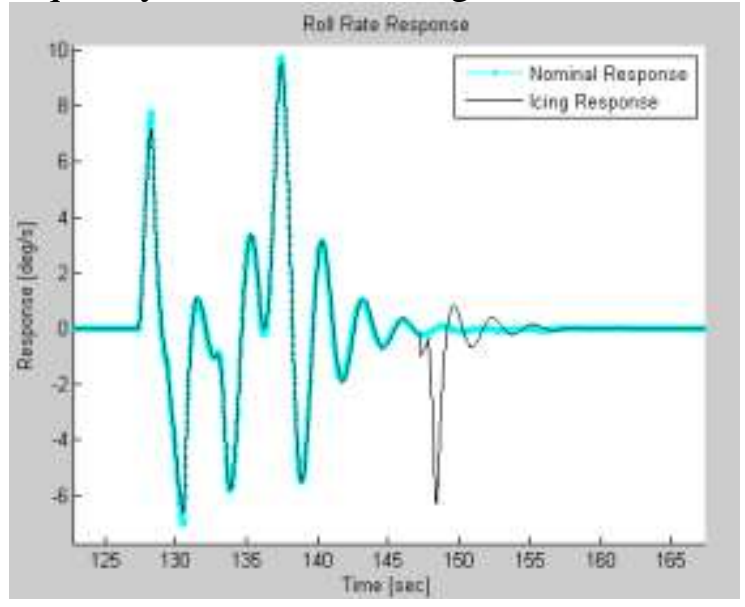

Figure 52: Roll rate response to roll doublet 1 (2 minutes in icing). 
The second doublet response (Figure 53) shows a slight decrease in the aircraft's Dutch roll damping, and also a decrease in the Dutch roll frequency. The roll is difficult to determine from the plots and the effects on it will be discussed in greater detail in the next chapter.
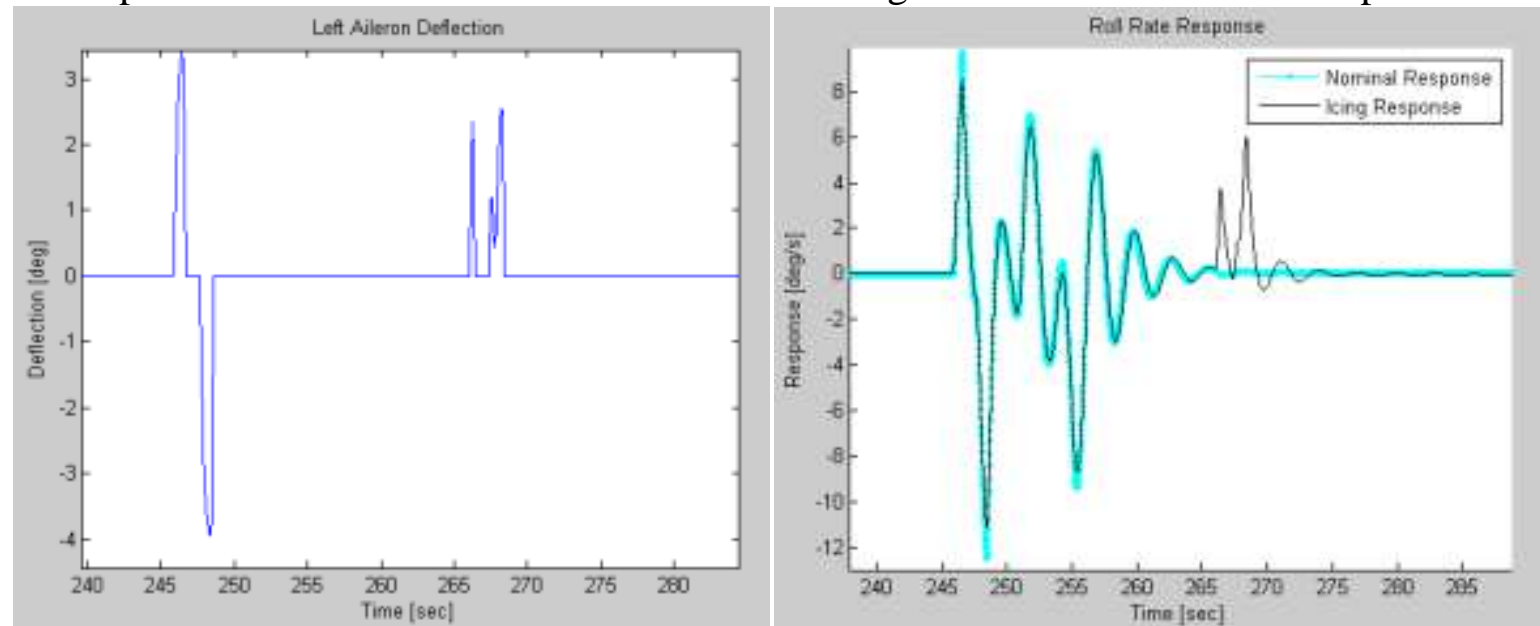

Figure 53: Roll doublet 2(4 minutes in icing) and steady state command input shown next to the roll rate response.

The decrease in the Dutch roll frequency and damping is more noticeable after six minutes in the icing conditions (Figure 54). The peaks of the response for the icing conditions reach a higher magnitude that those of the nominal condition response. The icing response also takes longer to damp out, showing the reduction in the Dutch roll damping as well.
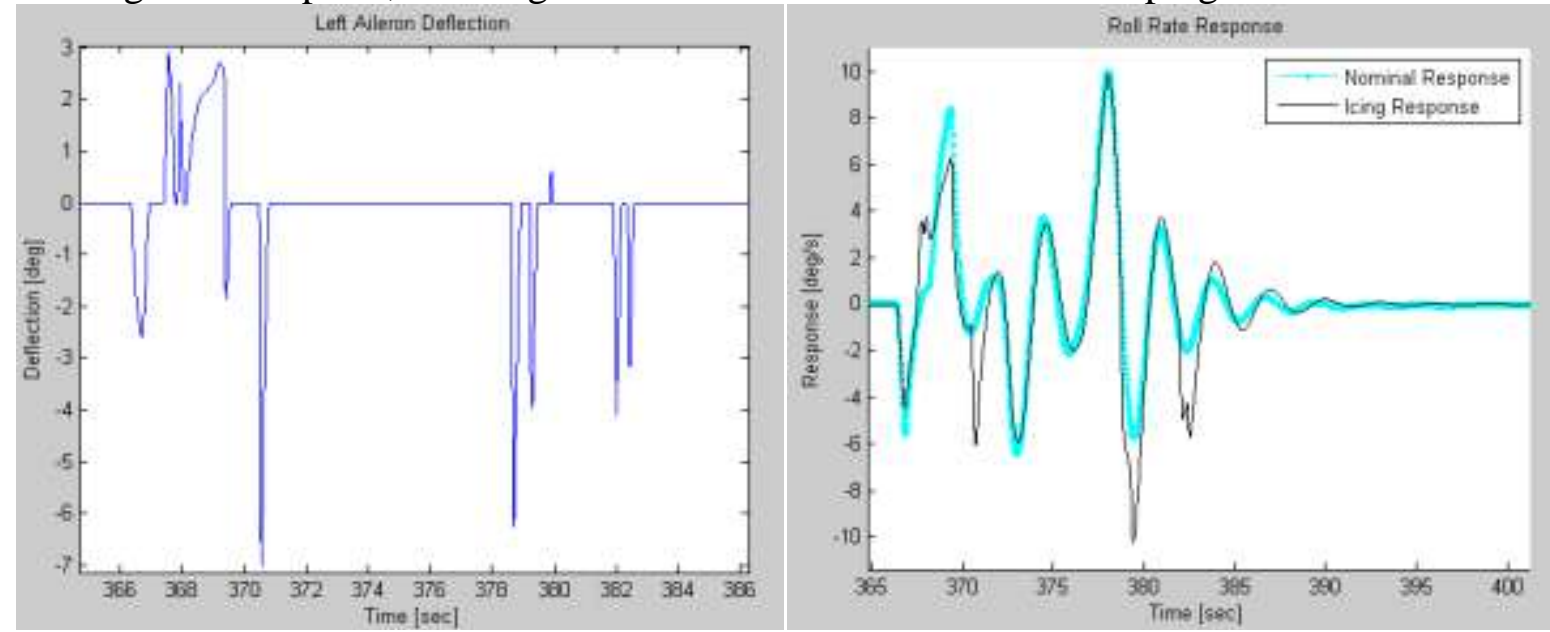

Figure 54: Roll doublet 3(6 minutes in icing) and additional steady state roll commands shown next to the roll rate response.

Following each of the roll doublets, a yaw doublet was input. These doublets are of similar magnitude and will excite the aircraft yaw rate response. The yaw inputs also excite the lateral dynamics of the aircraft more so than the roll inputs did. The Dutch roll mode of the aircraft can be more clearly seen from the yaw inputs. Figure 55 show s the rudder doublets used and the yaw rate response to these doublets. 


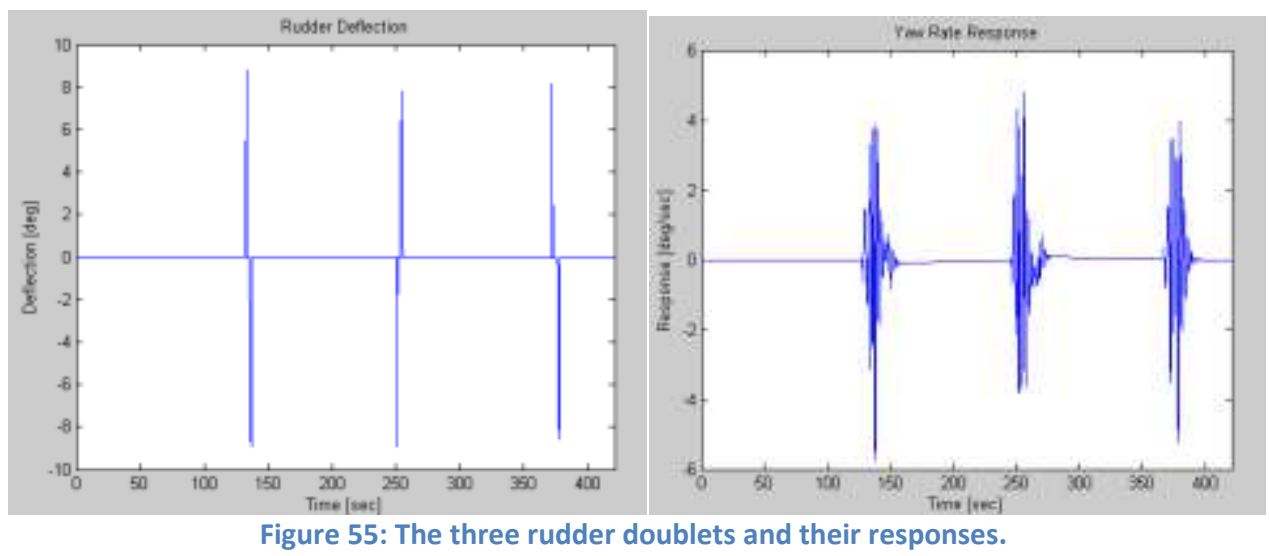

The aircraft directional response after two minutes in the icing conditions does not reveal much about the degradation of the modal parameters. Figure 56 shows the yaw rate response to the first rudder doublet after about two minutes within the icing conditions. Because of the shorter time between the last roll input and this rudder input, this plot also shows some of the coupling between the yaw and roll channels.

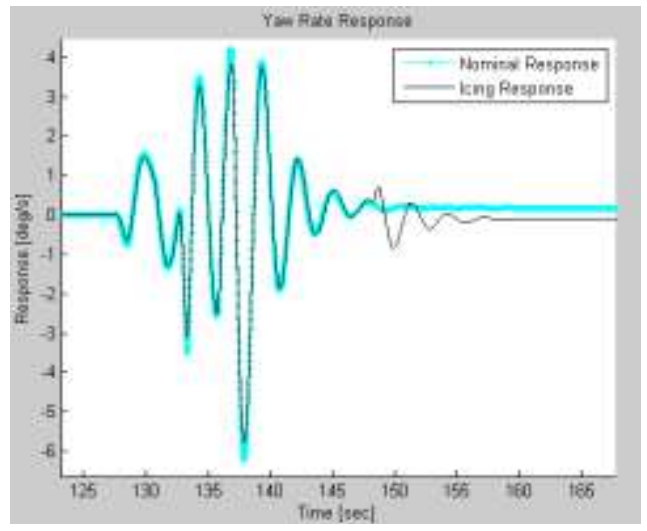

Figure 56: Yaw rate response to rudder doublet 1 (2 minutes in icing).

After four minutes in the icing conditions, the second rudder doublet reveals that the Dutch roll frequency has decreased, matching the results from the roll responses. The damping has also begun to decrease though it is hardly visible in Figure 57, which shows the aircraft's yaw rate response to the second yaw doublet.

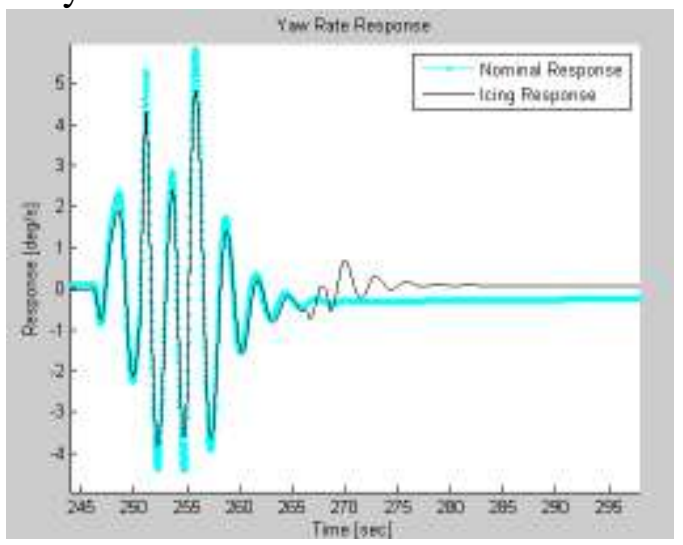

Figure 57: Yaw rate response to rudder doublet 2(4 minutes in icing). 
The third rudder doublet shows more of the detrimental effects of icing. The Dutch roll frequency has been further decreased, and the damping has also reduced. The plot in Figure 58 shows the yaw rate response on the aircraft after six minutes in the icing conditions.

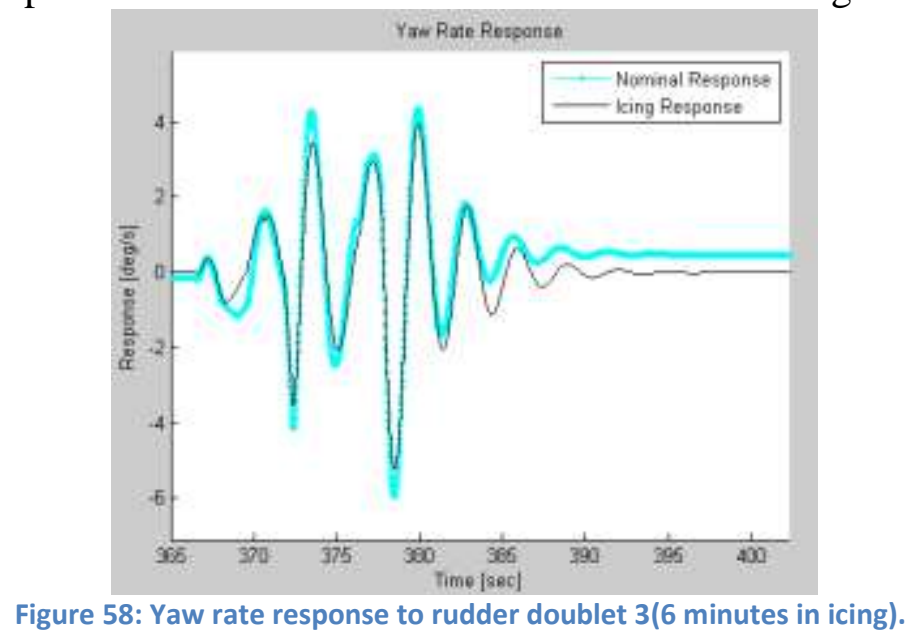

\subsubsection{Maintaining Steady Level Flight}

The second simulation's goal was to further examine the effects of icing on the performance of the aircraft. This simulation had to be set up so that the aircraft could find a steady state flight condition and then enter the icing conditions. This was done by subtracting one minute from the icing time. To prevent ice time from being negative a saturation block was also added. With this layout, the aircraft simulation could be initialized and a steady state flight condition found. After the one minute period with no-icing, the aircraft would begin accumulating icing as normal. The layout of the icing model with the added blocks can be seen in Figure 59.

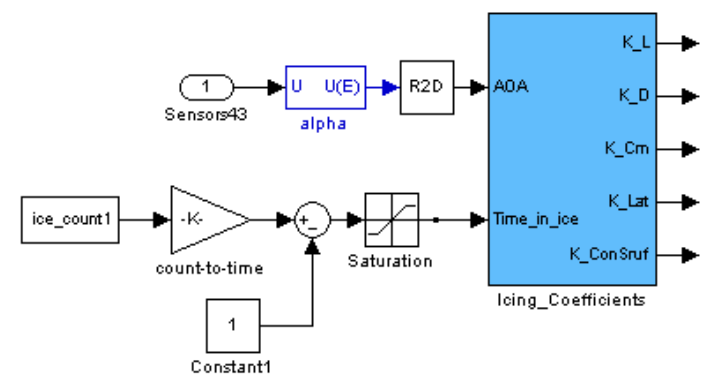

Figure 59: Time in icing modifications.

Through out the flight inputs on the control stick and throttle were made in order to maintain the steady level flight conditions. Most of the required stick inputs were on the elevator control surface deflections. This kept the aircraft at an angle of attack and pitch angle to maintain a desired altitude. As drag increased and velocity decreased it became necessary to have larger elevator inputs to maintain altitude. The elevator and throttle inputs used during the simulation can be found in Figure 60; while the aileron and rudder deflections are in Figure 61. 

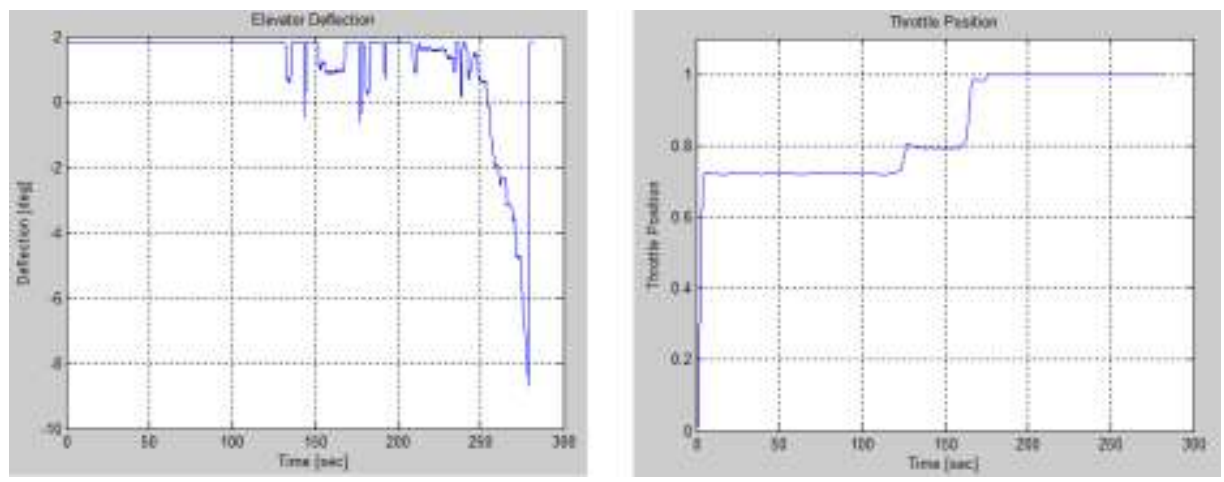

Figure 60: Elevator and throttle deflections for steady level flight.
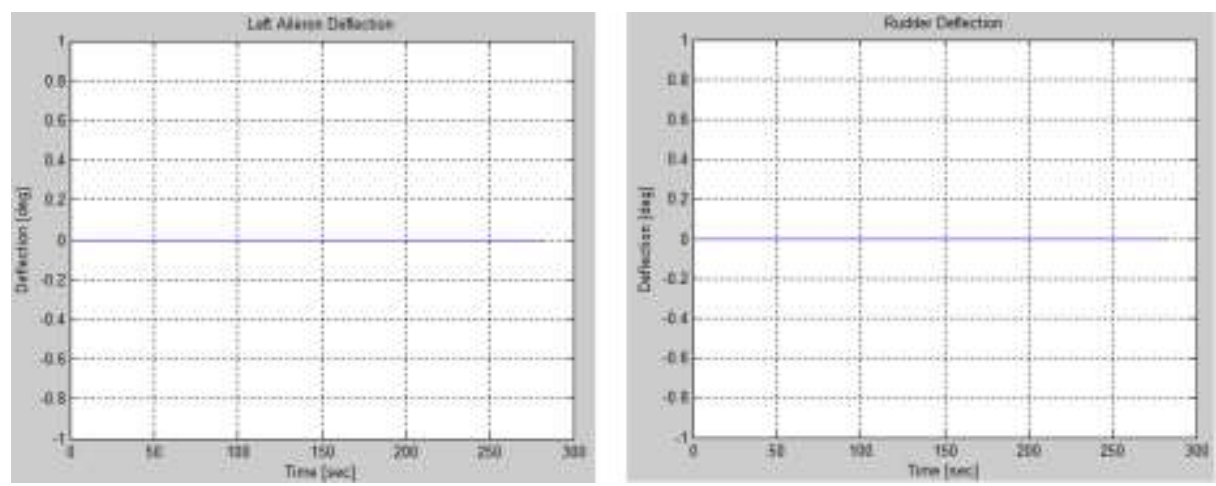

Figure 61: Aileron and rudder deflections for maintaining steady level flight.

As seen from the pilot inputs, the aircraft can be maintained at steady level flight conditions with primarily throttle inputs. The increase in thrust counters the building drag due to ice. However, after about two minutes in the icing conditions the aircraft reaches its maximum amount of thrust. As the ice continues to build on the aircraft surfaces, elevator inputs became necessary to maintain altitude. A plot of the aircraft's altitude can be seen in Figure 62 .

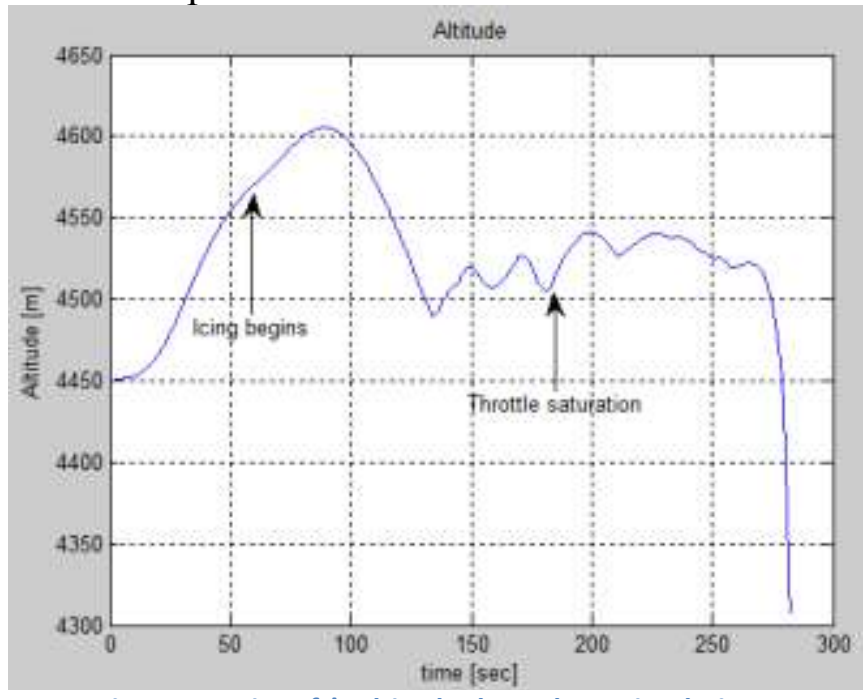

Figure 62: Aircraft's altitude throughout simulation.

Even though the aircraft is at maximum thrust, the ice continues to build, further increasing drag. In addition to ice, the increasing aircraft's angle of attack adds to the increase in 
overall drag. These two effects combined cause the aircraft to begin losing velocity. A plot of the aircraft's velocity can be found in Figure 63.

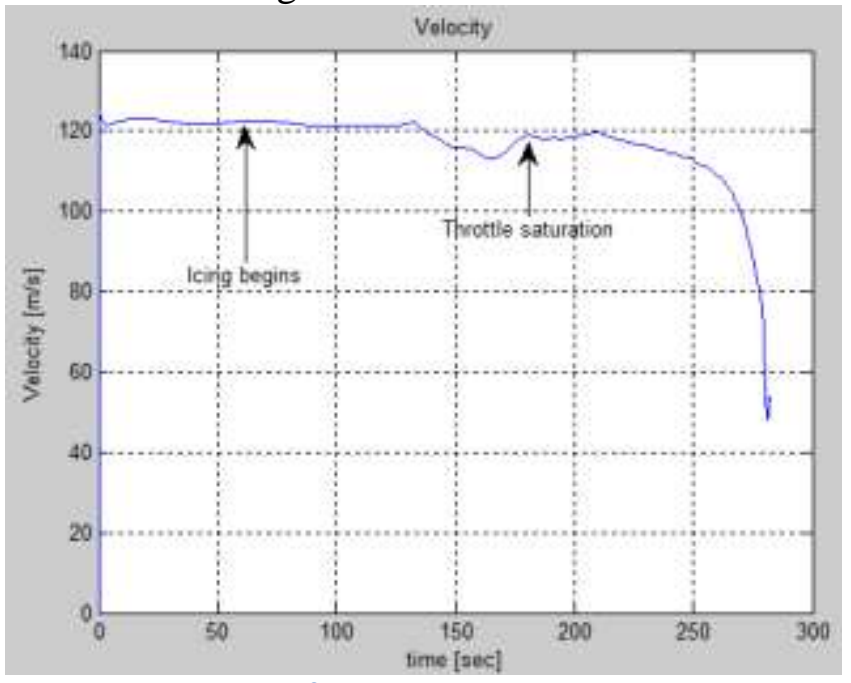

Figure 63: Aircraft velocity throughout simulation.

From the plot it can be seen that the velocity begins to decline shortly after three minutes in the icing conditions. With the loss in velocity the aircraft will begin losing altitude regardless of the pilot's further inputs. After four minutes in the icing conditions the velocity becomes much harder to maintain and stall conditions are rapidly approached.

By using gravity for assistance, some velocity can be gained to assist the pilot. However, if flight conditions deem that the altitude needs to be maintained, the only option left to the pilot is to continue applying elevator commands to maintain the aircraft's pitch angle and altitude. With the rapidly decreasing velocity and the increasing elevator deflections used to maintain pitch angle, the aircraft's angle of attack quickly begins to increase, presenting dangers of stall. Figure 64 shows the aircraft's angle of attack and pitch attitude throughout the simulation.
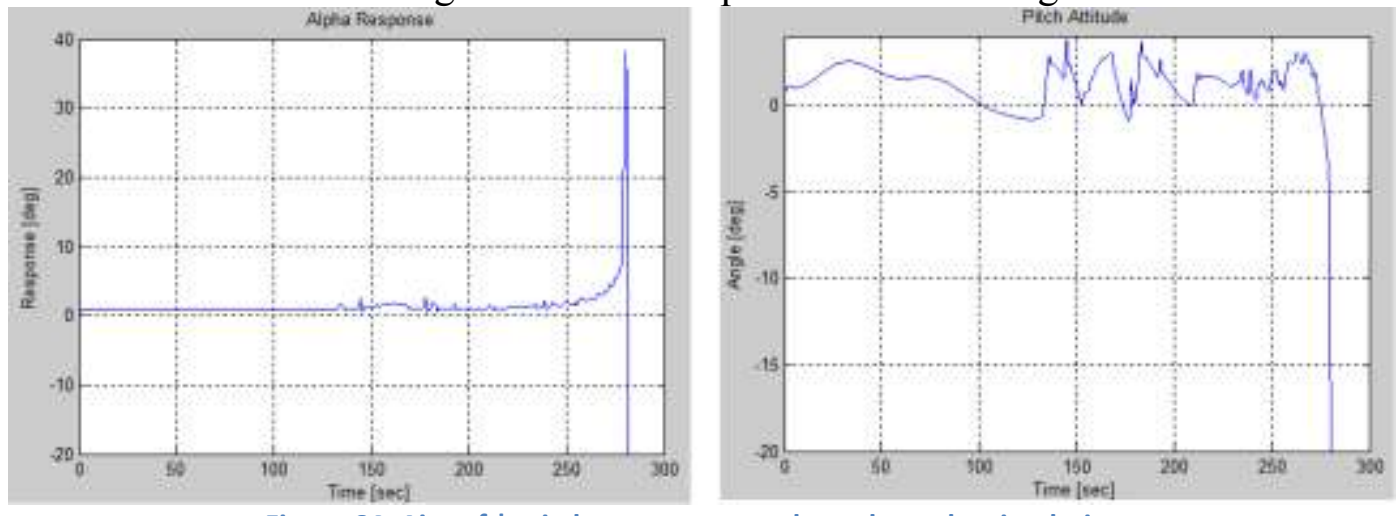

Figure 64: Aircraft's pitch rate response throughout the simulation.

Looking at the aircraft's angle of attack response, stall can be seen when the angle of attack begins to rapidly increase. When the angle of attack reaches the maximum value and begins its sharp descent corresponds to when the aircraft pitches down due to the stall. 


\subsubsection{Coordinated Turn Simulation}

In order to further examine the effects of icing on the aircraft's handling qualities, a simulation was performed where the aircraft has to maintain a coordinated turn with a bank angle of $-20^{\circ}$. This simulation would be performed under similar conditions as the previous simulations. The aircraft begins in normal conditions for one minute, during which time the aircraft also begins the coordinated turn. After the one minute in nominal conditions the aircraft is subjugated to the icing conditions for seven minutes. This will also allow for some extrapolation of the icing data during the simulation.

Due to the aircraft's spiral time constant, it naturally tries to return to the steady level flight conditions. Therefore, it became necessary to implement a roll hold controller that would maintain the constant bank angle. Figure 65 shows the roll controller as implemented for this simulation.

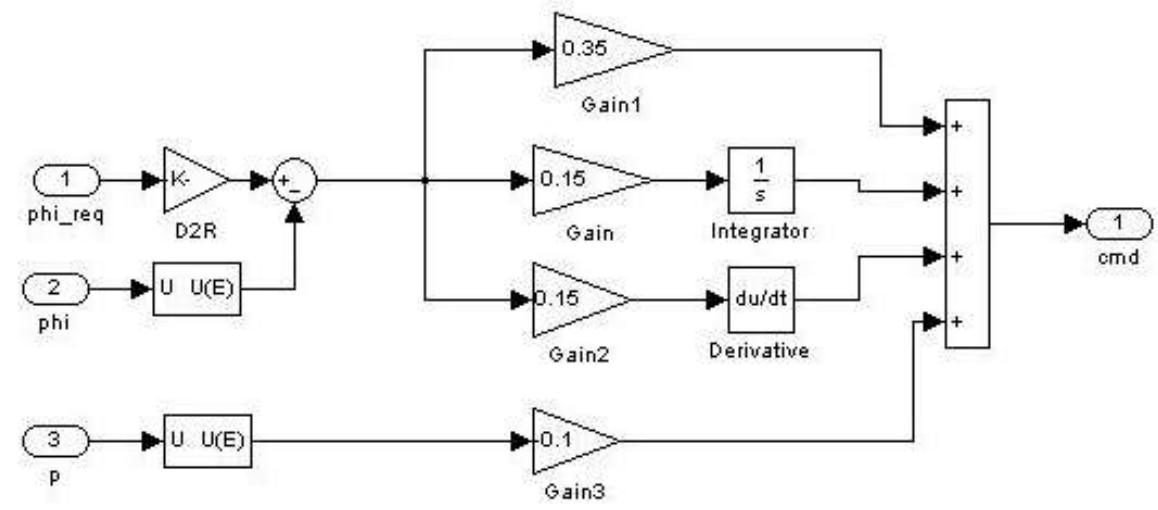

Figure 65: PID roll attitude hold controller.

For the test a desired bank angle of $-20^{\circ}$ was given to the controller, causing the aircraft to bank left for the turn. The simulation is first given five seconds to settle into a steady state condition then the step input is given to the controller. Figure 66 shows the aircraft's bank angle and response to the step input under nominal conditions.

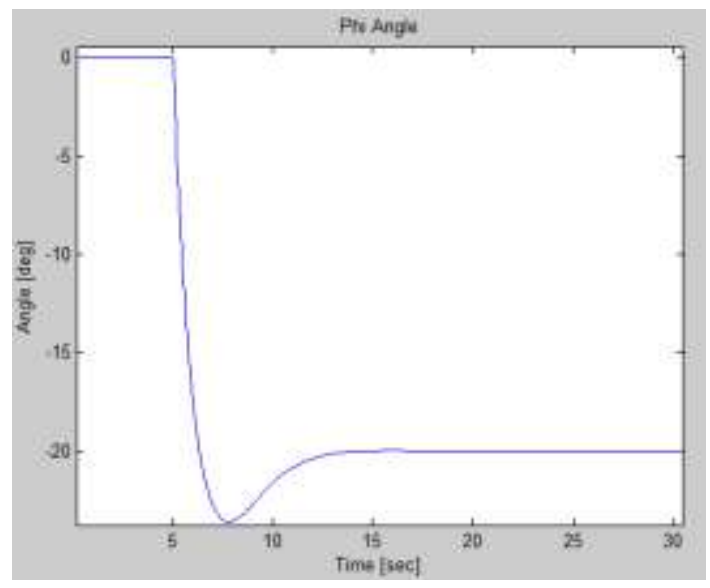

Figure 66: Aircraft roll angle for clean simulation.

Throughout the simulation, only throttle and aileron inputs were used. The aileron commands were used to roll to and maintain the desired bank angle and were provided by the PID controller. Figure 67 shows the inputs for the ailerons and the throttle. 

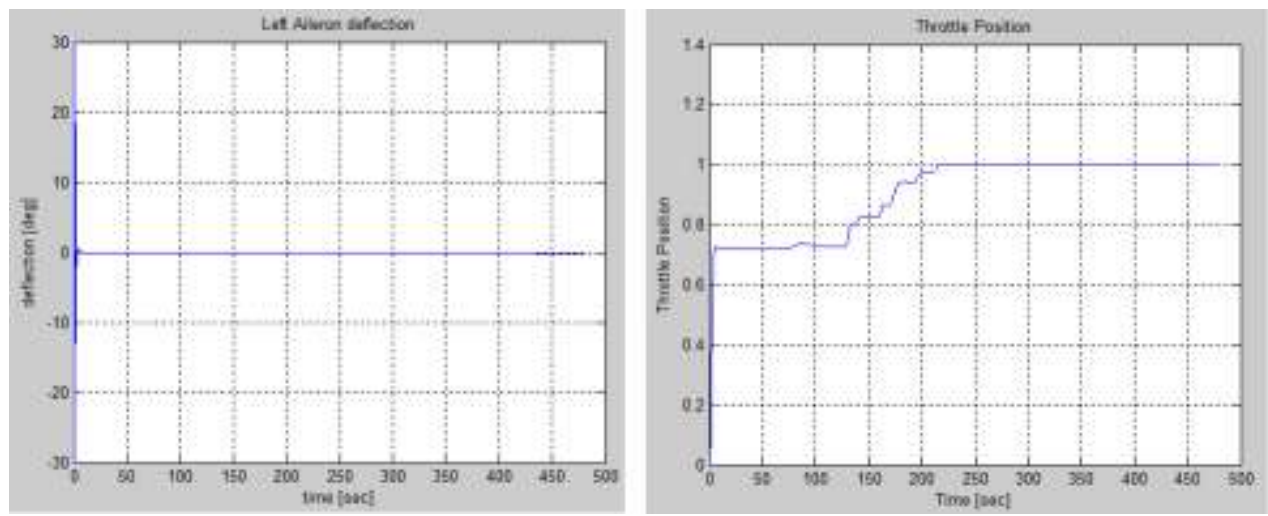

Figure 67: Aileron control inputs (left) and throttle command (right).

Because the aircraft begins at normal conditions, the aileron inputs provided by the PID controller result in the same response shown in Figure 68. Once the aircraft begins the turn, it begins to slowly lose altitude. Ice accretions further accelerate the loss of both velocity and altitude. The throttle inputs work to counteract some of the losses in velocity until the throttle is saturated.

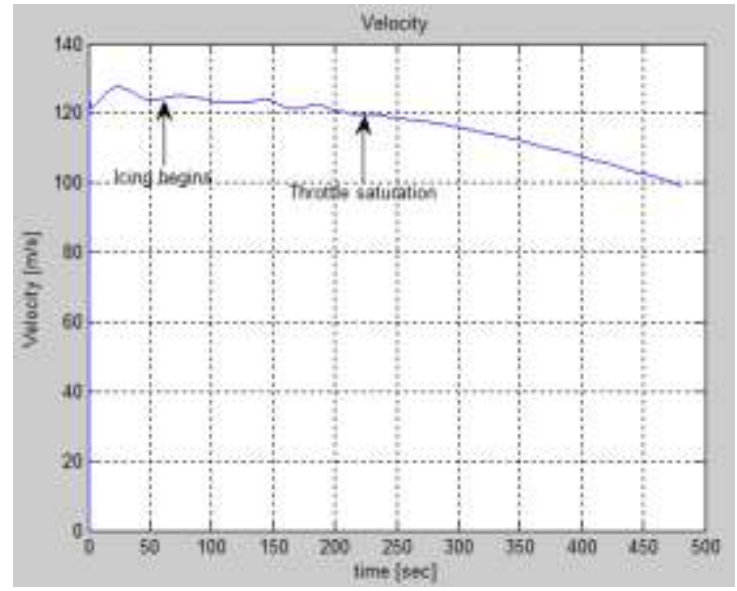

Figure 68: Aircraft velocity throughout turn simulation.

Once the throttle has been saturated, the aircraft begins to quickly lose more velocity due to the continuing ice accretions. The continued loss in velocity leads to a larger rate of descent in the aircraft's altitude as can be determined from Figure 69.

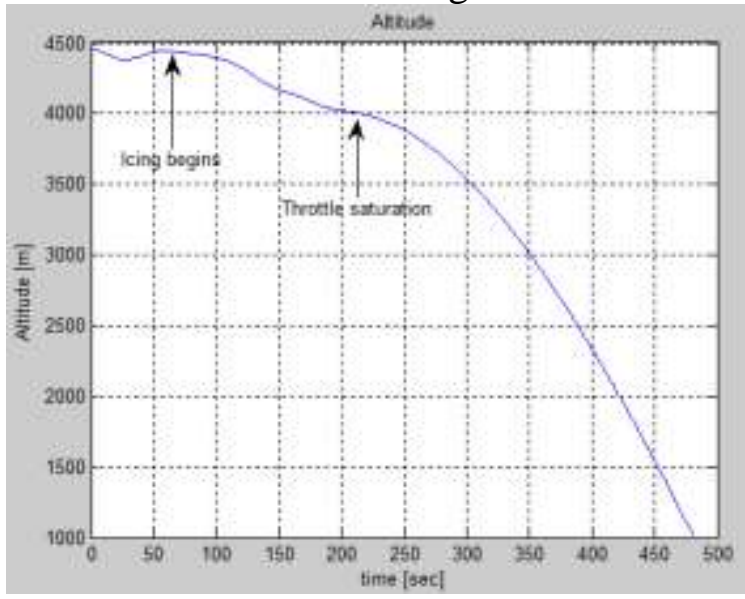

Figure 69: Aircraft altitude throughout turn simulation. 
As the velocity changes so do the requirements for the aircraft to maintain the $-20^{\circ}$ bank angle. As the velocity changes and the ice accretions affect the control derivatives, the amount of aileron deflection needed to maintain the bank angle is also altered. Figure 70 shows the aileron deflections throughout the simulation to better display the alteration of required deflection.

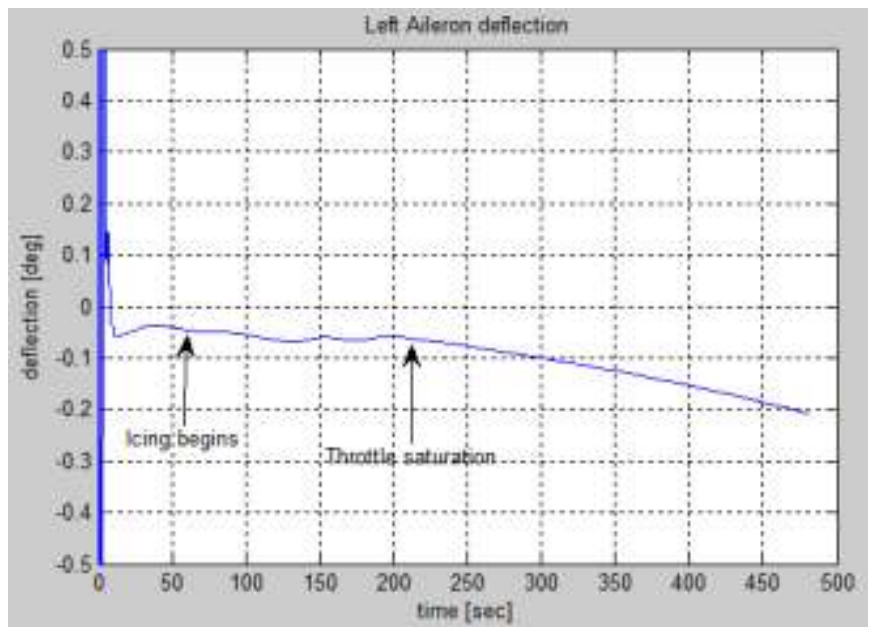

Figure 70: Aileron deflections throughout turn simulation. 


\section{Chapter 6- Analysis of Icing Impact on Aircraft Dynamics}

This chapter will analyze the most significant effects of icing on the handling qualities and performance of the aircraft as the time spent in icing conditions increases. The data was taken over range of times, starting from a clean airfoil up to a time of eight minutes in icing conditions. This will demonstrate the effects from the experimental data as well as the data from literature that was used. The simulations were performed multiple times to check for consistency by essentially freezing the icing exposure time at one minute intervals from zero to eight minutes. This allowed the full range of data to be tested and also allow for a bit of extrapolation of the icing equations.

For each time interval in icing the aircraft's stability derivatives were calculated along with the stability matrices and their eigenvalues. The eigenvalues were associated to typical dynamic modes and the modal parameters (damping, natural frequency and time constants) were computed using equations 80 through 87 . The results of which are discussed for the longitudinal character first followed by the lateral-directional channel.

In addition to looking at the trends of how the various modal parameters change, the handling characteristics of the aircraft were also studied based on current handling qualities regulations. Going by military specifications for aircraft of similar size and speed capabilities, the business jet aircraft could be compared to aircraft of medium weight and low-to-medium maneuverability also referred to as Class II [46]. Of the various types of flight in which military aircraft participate in, in this study category B was considered, which includes climb, cruise, loiter, and descent. The aircraft's levels of flying characteristics are broken down into three levels. Level one corresponds to a ranking between 1 and 3 on the Cooper-Harper scale [10][23] and means that the aircraft's handling qualities are clearly adequate for all mission flight phases. Level two corresponds to a ranking between 4 and 6 and means that the aircraft can adequately perform the mission but with an increase in pilot workload, degradation in mission effectiveness, or both. The third level is declared following a pilot ranking between 7 and 9 if the aircraft can be controlled safely but pilot workload is excessive, the mission effectiveness is inadequate, or a combination of both [46].

\subsection{Icing Effects on Handling Qualities 6.1.1 Longitudinal Handling Qualities}

The data for the longitudinal dynamics include both the short period and phugoid modes of motion. Figure 71 shows how the short period natural frequency changes as the amount of time spent in icing conditions increases. The total change in the short period frequency is $15.43 \%$. The reduction is slightly visible in the plots of the longitudinal response of the aircraft, especially at the higher icing exposure times. Looking back on the elevator doublet after six minutes in icing has occurred, now shown here in Figure 72, it can be seen that the maximum peaks of the aircraft's response do not match to when the peaks occur for the nominal case. This change in the time of the occurrence of the peaks is due to the lower short period frequency. In contrast, the damping of the short period increased with the time spent in icing conditions. The total change in the short period damping is $6.97 \%$. Looking again at the figure shows that the aircraft's magnitude of response to the elevator doublets is lower than that of the nominal conditions. 


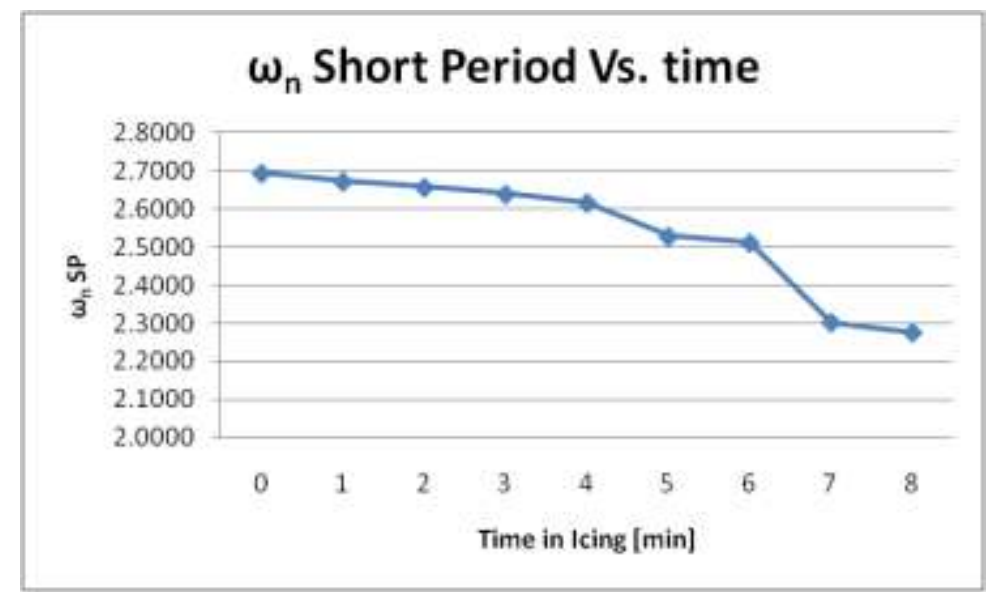

Figure 71: Changes in short period frequency over time.

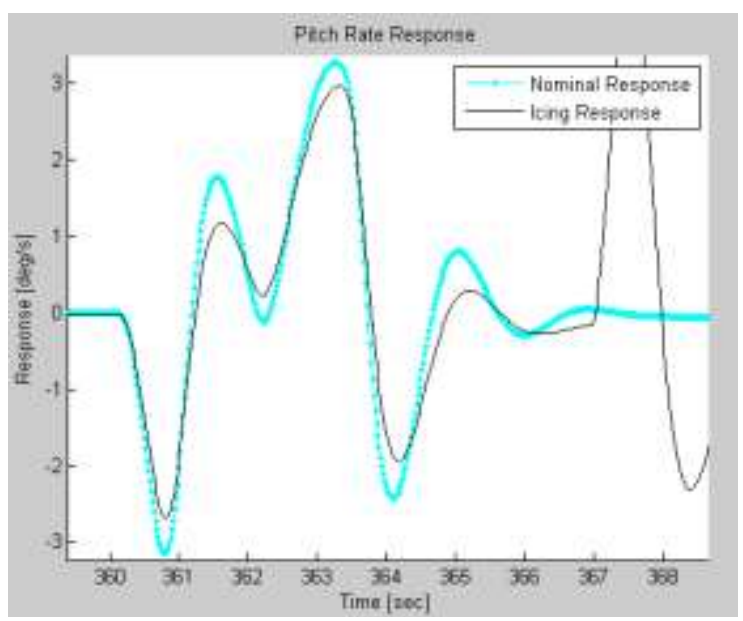

Figure 72: Pitch rate response of aircraft after 6 minutes in icing.

This lower response magnitude is due to the increase in the damping of the short period response. Figure 73 shows the changes in the short period damping as the time spent in icing increases. The increase in the damping is due to the fact that while the $\mathrm{C}_{\mathrm{mq}}, \mathrm{C}_{\mathrm{z \alpha}}$, and $C_{m_{\dot{\alpha}}}$ derivatives decrease, which should decrease the damping, the natural frequency decreases as well. The natural frequency has a slightly dominant effect resulting in an increase of the short period damping. It should be noted that no gravimetric effects (mass, inertias, center of gravity location) have been included in this analysis. 


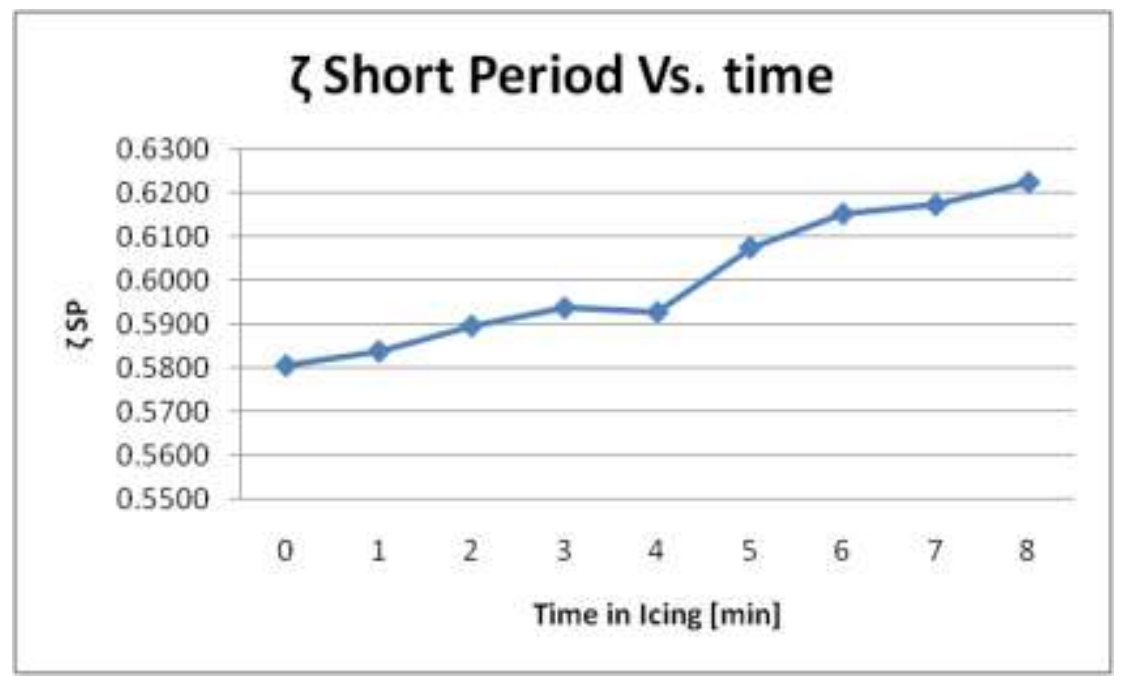

Figure 73: Changes in short period damping over time.

Following the short period mode of flight is the slower phugoid mode. The relative alterations to the phugoid during icing are the most severe of the modal parameters. As time in icing increases so does the frequency of the phugoid response. Figure 74 shows how the phugoid frequency increases with respect to the time spent in icing conditions.

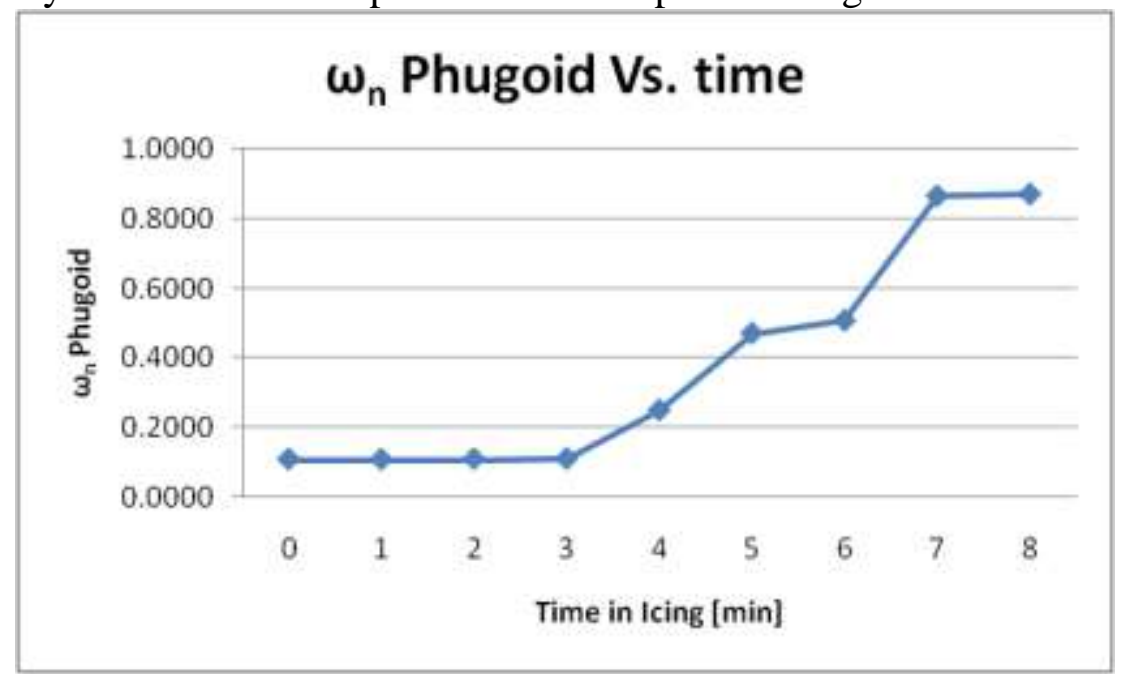

Figure 74: Changes in phugoid frequency over time.

After eight minutes in the icing conditions the frequency of the phugoid mode has increased by $87.5 \%$.

Figure 75shows the phugoid response of the iced aircraft compared to the nominal case after three minutes within the icing conditions. The increased frequency can be seen compared to that of the nominal condition response. 


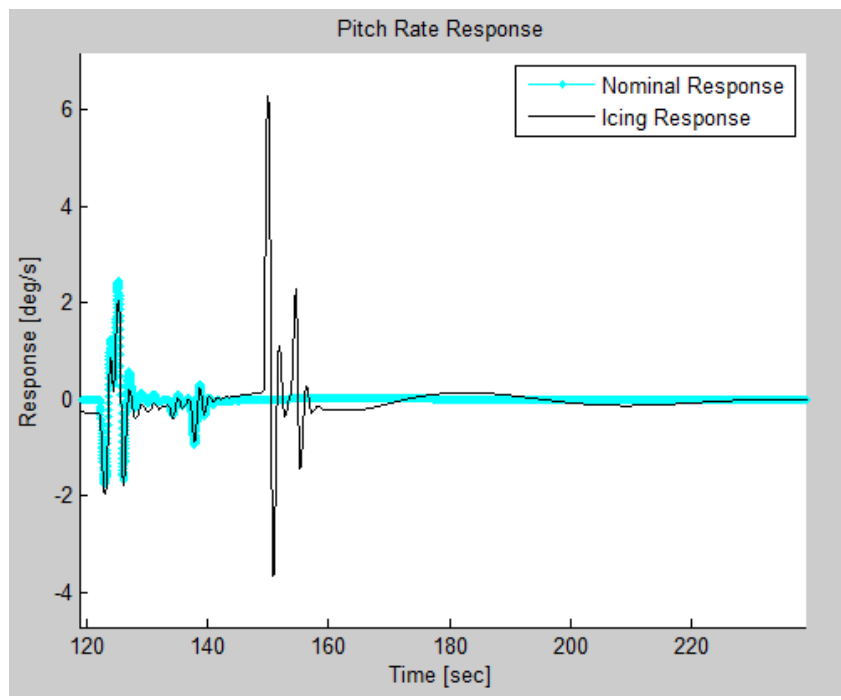

Figure 75: Plot showing phugoid response after 3 minutes of icing.

Figure 75 also shows that the phugoid damping increases as the time in icing conditions increases. The phugoid damping behaved rather differently from the other modal parameters. Altitude also had an effect; if inputs were made to try to maintain altitude the damping fluctuate. If the aircraft was set to trim conditions and altitude allowed to drop, the damping would continue to increase. The maximum relative change in the phugoid damping was an increase of $41.6 \%$. Figure 76 shows the plot of how the phugoid damping changes with respect to the time in icing conditions, and altitude.

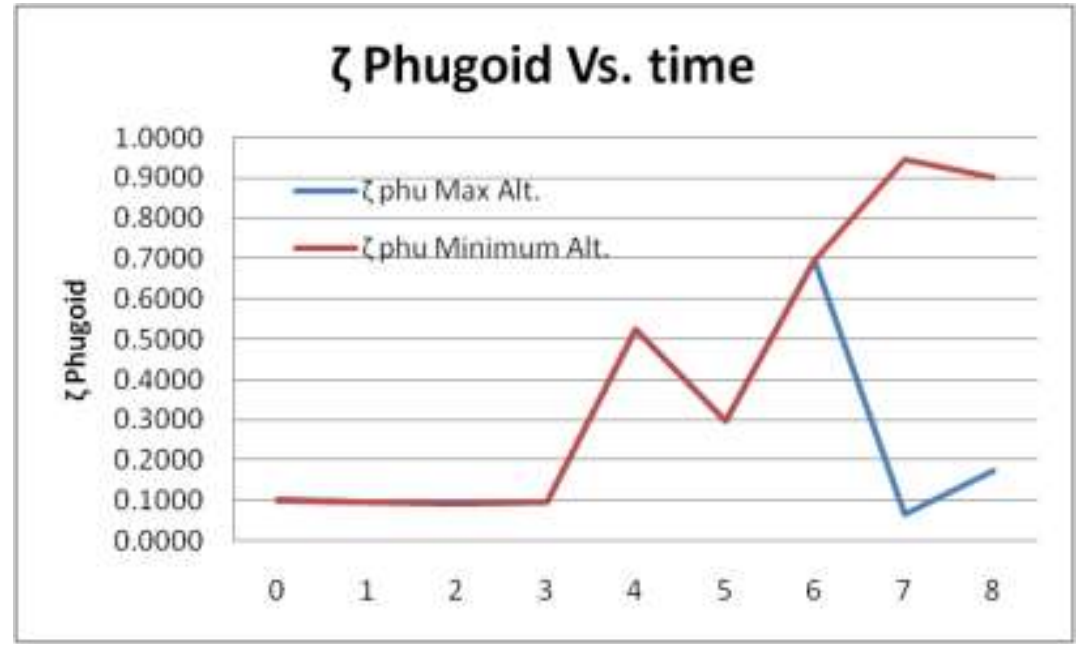

Figure 76: Changes in phugoid damping with time.

The longitudinal handling qualities requirements examine specifically the short period frequency, the angle of attack, and aircraft's load factor, n. Various frequencies, load factors, and angles of attack were taken from the same simulation data used to find the short period frequencies in the modal parameter analysis. Figure 77 was made in order to examine the effects of icing on the handling properties according to the military specifications. 


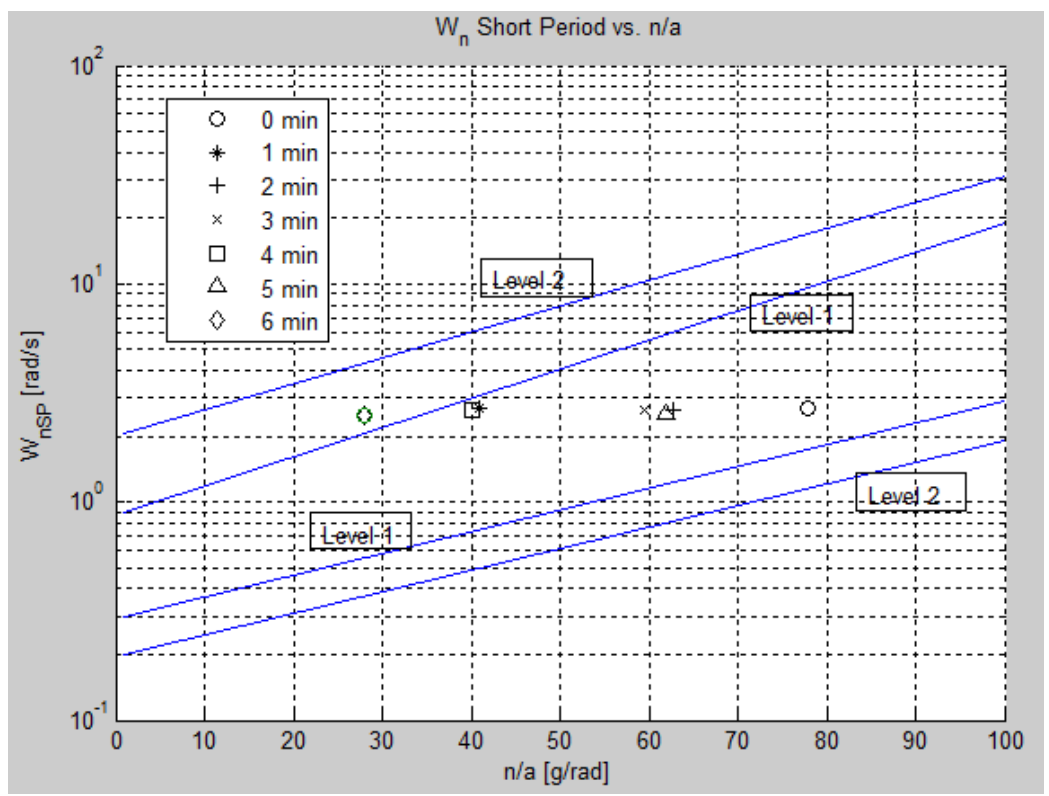

Figure 77: Plot of short period frequency vs. gravity force/angle of attack.

The plot shows that as the time in icing increases, the aircraft's position on the plot will move due to the changes in angle of attack and the changing short period frequency due to ice accretions. As the amount of icing increases, the aircraft's position gradually migrates toward the level 2 area, indicating that pilot workload increases and handling qualities degrade.

The aircraft's phugoid mode always meets the military specifications, even under icing conditions. For level 1 flight, the aircraft's phugoid damping must be at least 0.04 , and for level 2 must be at least 0 .

\subsubsection{Lateral Handling Qualities}

The Dutch roll mode parameters, and roll time constant are all discussed in this section. The easiest mode to see from the plots is the Dutch roll. It can be seen in either the roll or yaw rate response plots.

The Dutch roll natural frequency decreases as the time spent in icing conditions increases. By eight minutes in icing conditions the frequency of the Dutch roll has decreased by $3.44 \%$ making it the least affected by the icing conditions. Figure 78 shows the Dutch roll frequency with respect to the icing time.

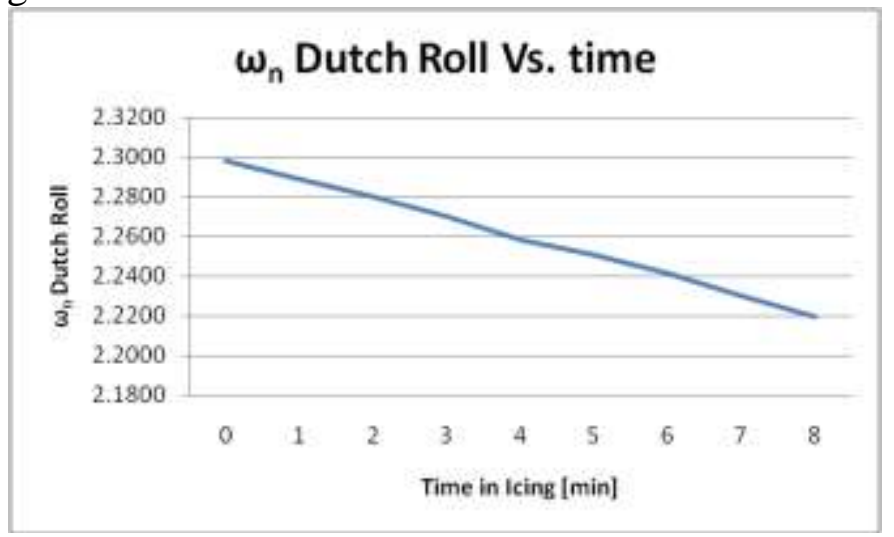

Figure 78: Changes in Dutch roll frequency with time. 
Figure 79 again shows the roll doublet response of the aircraft after six minutes within the icing conditions. At this point the Dutch roll frequency has been altered enough that it can be seen within the plot and shows the decrease in frequency. The times of the peaks of the nominal case are different from the time when the peaks of the icing conditions occur. The icing peaks occur slightly after the nominal case.

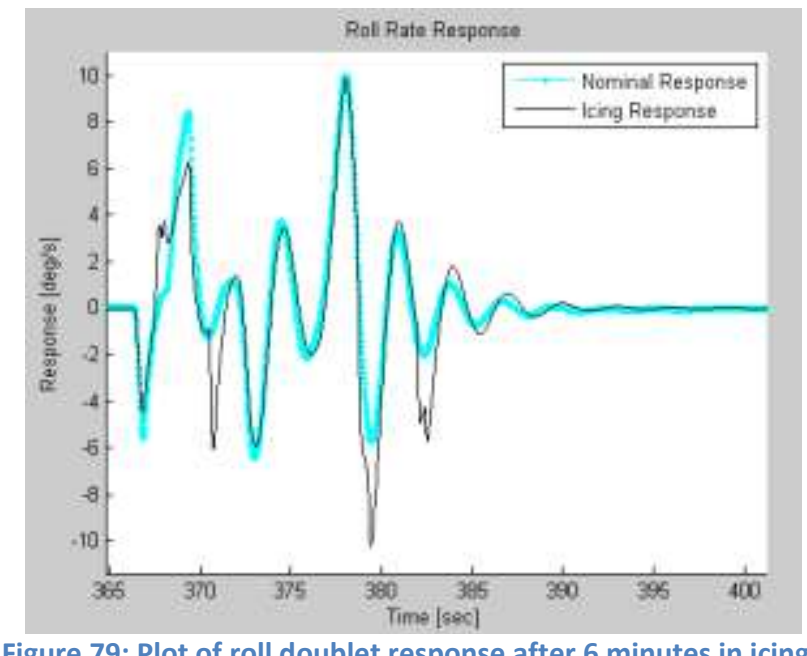

Also note that the peaks of the icing conditions are slightly higher in magnitude than those of the nominal case. This is due to the decreasing Dutch roll damping. After eight minutes in the icing conditions the reduction to Dutch roll damping is $27.17 \%$. Figure 80 shows the decreasing Dutch roll damping with respect to the time spent in icing conditions.

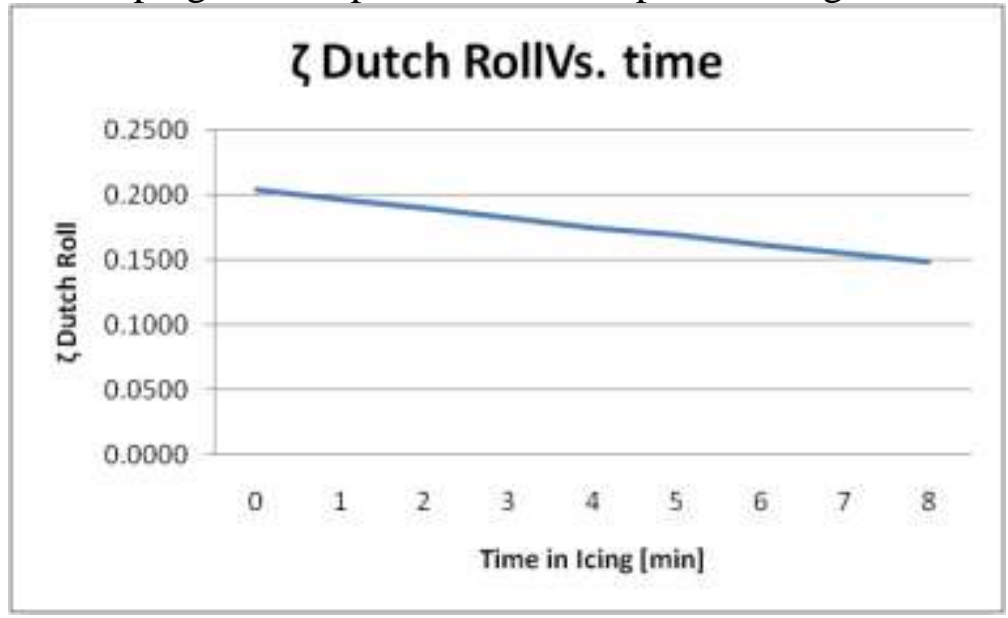

Figure 80: Changes in Dutch roll damping with time.

The time constant effects are hard to see within the response plots. The roll time constant is the amount of time it takes the aircraft to reach $63 \%$ of the steady state response to a step input. As time in icing conditions increased so did the aircraft's roll time constant. This means it takes the aircraft longer to respond to a roll command. After eight minutes in icing the roll time constant had increased by $12.32 \%$. Figure 81 shows how the aircraft's roll response alters with respect to the amount of time in icing conditions. 


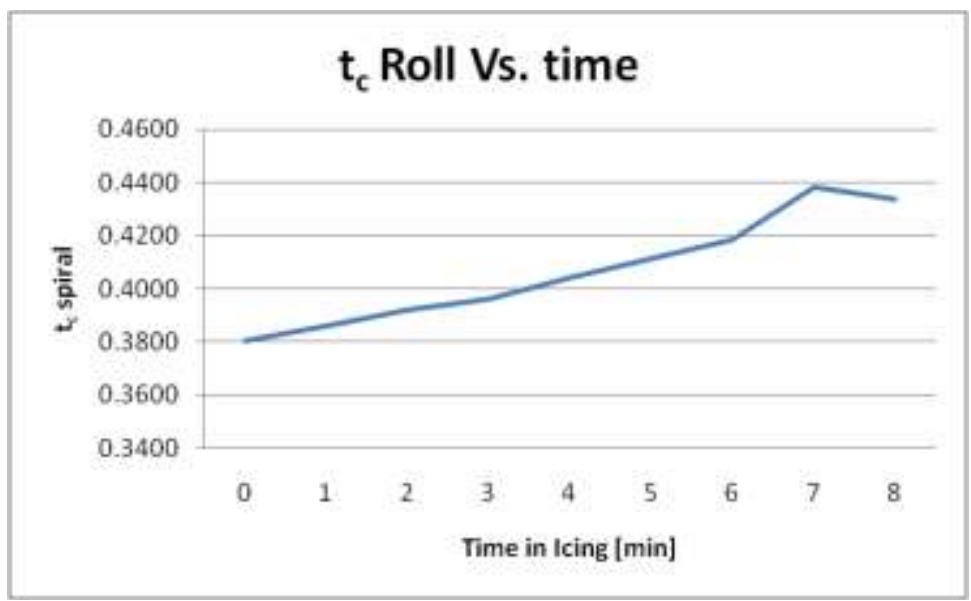

Figure 81: Effects of icing on roll time constant.

Figure 82 shows the change in the spiral time constant with respect to the increasing icing time. In the eight minutes of exposure, the spiral time constant has decreased by $36.07 \%$ or a time of about 41 seconds.

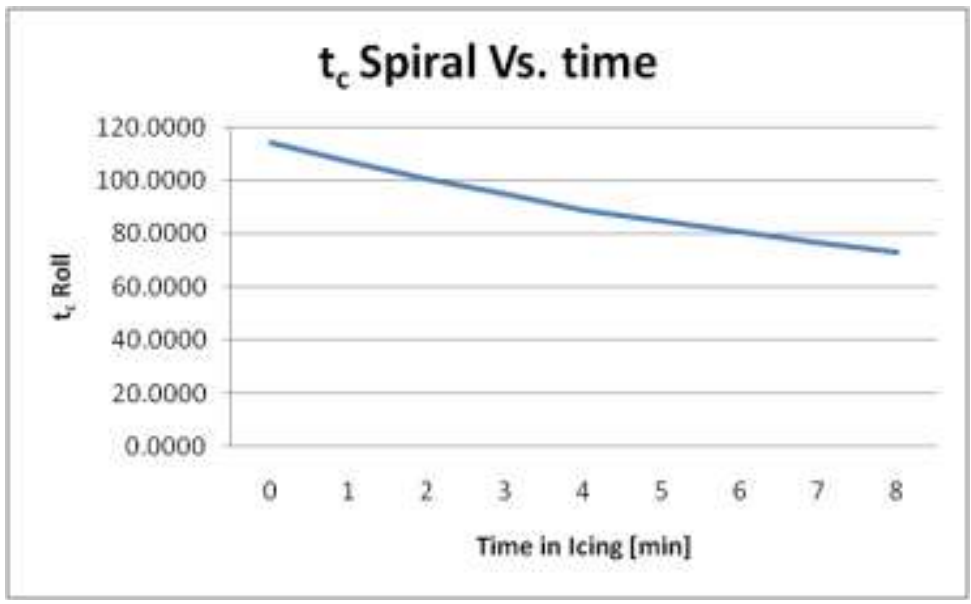

Figure 82: Effects of icing on spiral time constant.

Examining the handling properties of the lateral dynamics, show similar trends to those of the longitudinal phugoid mode are noticed. Although the general trends of both the natural frequency and the damping ratios are towards a degradation of the handling qualities, the aircraft's Dutch roll mode meets the military specifications, exceeding the imposed lower limits by a large margin. For category B, the aircraft must have a minimum Dutch roll damping of 0.08 and minimum frequency of $0.4 \mathrm{rad} / \mathrm{sec}$.

\subsection{Icing Effects on Performance}

\subsubsection{Trim Requirements for Horizontal Flight}

A further simulation was performed in order to find the various aircraft parameters required to maintain a symmetric steady level flight condition. Each simulation is three minutes in length for the current ice time. The time in icing is then manually set to the next minute. Beginning with normal conditions, the aircraft can remain at its default trim configuration. As each simulation is performed, and the time in icing increases, the trim conditions of the aircraft 
need to be changed to maintain the steady level flight conditions. The following table shows the parameters needed to maintain this condition.

Table 3: Required trim settings to maintain steady level flight.

\begin{tabular}{ccccc}
\hline $\begin{array}{c}\text { Ice Time } \\
\text { [min] }\end{array}$ & $\begin{array}{c}\text { Angle of } \\
\text { Attack [deg] }\end{array}$ & $\begin{array}{c}\text { Needed Elevator } \\
\text { Deflection [deg] }\end{array}$ & $\begin{array}{c}\text { Average Velocity } \\
\text { [m/s] }\end{array}$ & $\begin{array}{c}\text { Throttle } \\
\text { Position }\end{array}$ \\
\hline $\mathbf{0}$ & 0.8 & 1.79 & 123 & 0.72 \\
$\mathbf{1}$ & 0.9 & 1.79 & 120.5 & 0.8 \\
$\mathbf{2}$ & 1.1 & 1.65 & 119 & 0.94 \\
$\mathbf{3}$ & 1.37 & 1.42 & 113.5 & 1.00 \\
$\mathbf{4}$ & 2.0 & -2.08 & 102 & 1.00 \\
$\mathbf{5}$ & 2.4 & -2.25 & 95 & 1.00 \\
\hline
\end{tabular}

Up to three minutes in the icing conditions, the aircraft can maintain steady level flight quite adequately. After that point, the aircraft will lose altitude regardless of trim conditions. Increasing the aircraft angle of attack increases drag, further reducing the velocity. As such, a loop of increasing angle of attack to attempt to maintain altitude continues until stall conditions are reached. However, with the trim conditions mention above, the aircraft can maintain a steady descent. Figure 83 shows the aircraft altitude throughout the simulations and the steady rate of descent that it achieves.
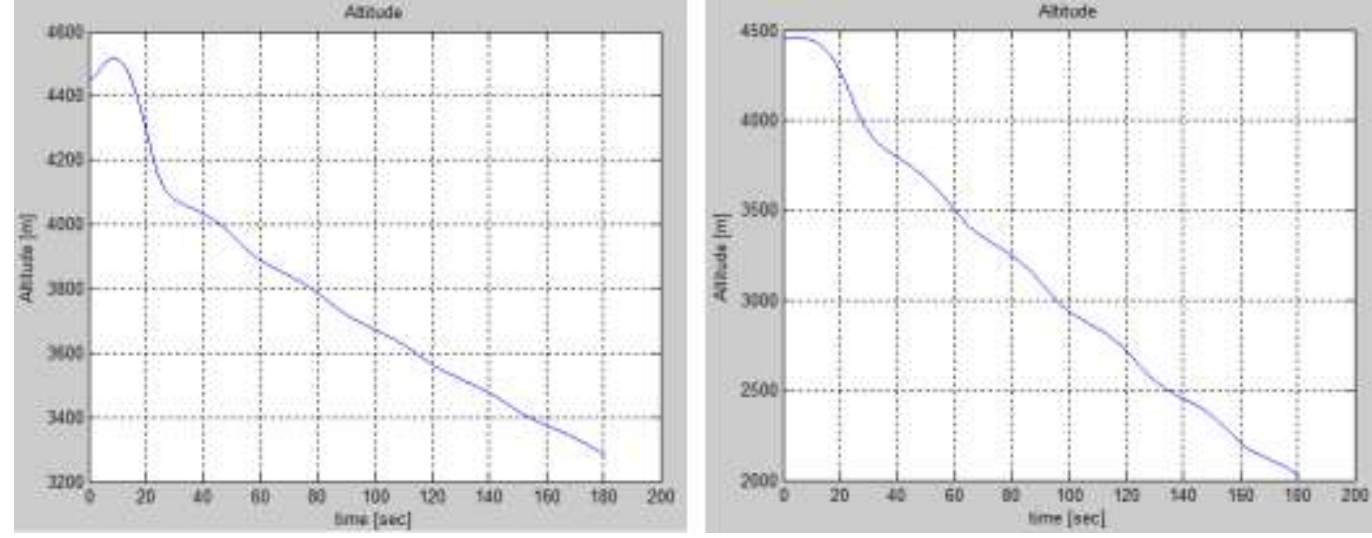

Figure 83: (Left) Altitude at four minutes in icing. (Right) Altitude at five minutes in icing.

\subsubsection{Coordinated Turn}

In order to further examine the effects of icing on the performance of the aircraft, simulations were performed that checked the parameters of the coordinated turn. This coordinated turn would be a full $360^{\circ}$ turn at a constant bank angle of $20^{\circ}$ and constant altitude and velocity. This simulation would be performed multiple times in a similar fashion to the first coordinated turn simulation, except the time spent in icing was manually set for each test. For each of the tests, the time spent in icing increases by one minute. Afterwards, the roll angle, average aileron deflection, average velocity, throttle position, and time taken to make the full turn are all examined.

Due to the aircraft's spiral time constant, once a roll input is introduced, the aircraft naturally tends to settle back to a steady level flight condition. Therefore it was necessary to have a constant aileron deflection to hold the aircraft at a desired bank angle. With a human pilot this becomes extremely difficult, so a proportional integral derivative (PID) controller was 
introduced to remove the human error factor. The desired bank angle is given to the controller as a step input with magnitude equal the bank angle in degrees. The controller then uses the standard PID architecture as well as the aircraft's roll rate information in order to hold the aircraft at the desired bank angle.

Further examination of the response of the controller reveals that the response of the controller varied slightly as the amount of ice increased. However, the overall differences between the responses were small, showing the robustness of the controller used. Figure 84 shows the aircraft's varying roll responses to the controller under different amounts of ice.

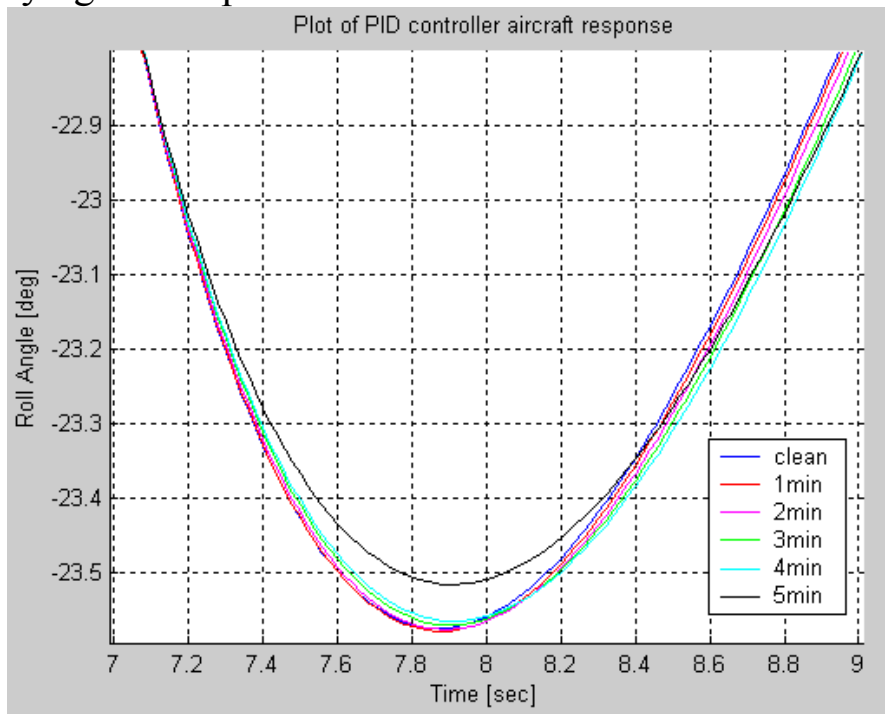

Figure 84: Aircraft roll angle under varying amounts of ice.

Several variables were tracked throughout the aircraft's turn: aircraft bank angle, required aileron for bank, average aileron deflection, average velocity, throttle position, and the time taken to complete the turn. The required aileron for bank is the amount of deflection required by the ailerons to make the aircraft roll $20^{\circ}$. The average aileron deflection is the amount of deflection required for the aircraft to maintain the $20^{\circ}$ bank angle.

The aircraft's velocity was greatly affected by the ice and had the greatest effect on the turning tests. Due to the dropping velocity, the turn radius decreases, thus the time for the aircraft to complete the turn also decreases. It was further found that as the amount of ice increases, the amount of aileron deflection needed to maintain the desired bank angle increases. Table 4 shows the results of the coordinated turn simulations. Note that the velocity can be roughly maintained up to 3 minutes in icing, through throttle increase. After 3 minutes in icing the throttle saturates.

Table 4: Coordinated turn data.

\begin{tabular}{cccccc}
\hline $\begin{array}{c}\text { Ice Time } \\
\text { [min] }\end{array}$ & $\begin{array}{c}\text { Bank Angle } \\
\text { [deg] }\end{array}$ & $\begin{array}{c}\text { Time for Turn } \\
\text { [sec] }\end{array}$ & $\begin{array}{c}\text { Needed Aileron } \\
\text { Deflection [deg] }\end{array}$ & $\begin{array}{c}\text { Average Velocity } \\
{[\mathbf{m} / \mathbf{s}]}\end{array}$ & $\begin{array}{c}\text { Throttle } \\
\text { Position }\end{array}$ \\
\hline $\mathbf{0}$ & -20.0003 & 239.26 & -0.0688 & 125.37 & 0.72 \\
$\mathbf{1}$ & -20.0003 & 238.5 & -0.0688 & 125.68 & 0.915 \\
$\mathbf{2}$ & -20.0003 & 232.3 & -0.0802 & 122.50 & 0.96 \\
$\mathbf{3}$ & -20.0002 & 225.93 & -0.0974 & 119.25 & 1.00 \\
$\mathbf{4}$ & -19.9999 & 218.514 & -0.1261 & 115.28 & 1.00 \\
$\mathbf{5}$ & -19.9996 & 211.63 & -0.1604 & 111.68 & 1.00 \\
\hline
\end{tabular}




\section{Chapter 7- Conclusions}

A simplified icing model for examining aircraft handling qualities and performance, based on the wind tunnel and literature data, has been successfully developed, implemented, and tested on a Class B aircraft. The behavior of the model at both nominal conditions and within the icing conditions is as expected. The nominal characteristics of the aircraft match those of a general business jet. The implemented alteration coefficients also replicate the experimental data and the aircraft demonstrates the characteristics associated with ice accretions, such as the reduction in lift and stall angle.

The integrated icing model provides a useful computational tool for analysis and study of icing conditions. The model has been successfully integrated in with the rest of the aircraft health management simulation package.

Effects of icing on handling qualities have been analyzed based on modal parameters and MIL-F-8785C specifications. It can be concluded that handling qualities degrade with increasing icing exposure. The largest relative changes in the aircraft modal parameters were exhibited by the damping of the phugoid and Dutch roll modes. The short period response of the aircraft was affected enough to change from level 1 to level 2 on the Cooper-Harper scale. However, overall the effects of icing on the handling qualities for the period of exposure considered appeared to be limited.

The effects of icing on the aircraft performance have been observed to be critical. The aircraft lift decreases as expected. The drag increases and requires an increase to throttle until it becomes saturated, around three minutes into simulation. By five minutes, with the continued reduction in aircraft velocity and lift, the aircraft can no longer maintain altitude and can easily reach stall conditions.

It should be noted that the effects of icing on the gravimetric characteristics (mass, inertias, and center of gravity location) were not considered. These effects are expected to have a potentially significant impact on handling qualities. Due to lack of experimental data, several other assumptions were made in developing this simplified icing model. The effects on the aircraft performance and on most of the handling qualities investigated appear to still be adequately captured by the simplified model. However, the trend of increasing short period damping with time in icing may be questionable and needs to be investigated in more depth. It is expected that considering mass effects will provide a more realistic trend for the parameter.

Availability of additional experimental data and future revisions of the model could provide students with the ability to simulate and experiment with a larger range of icing scenarios. With additional data, the model accuracy and capabilities could be improved. Through further revision and expansion of the model, students could also work with failure scenarios due to ice accretions. Some of the features could include; sensor icing, engine performance issues, stuck actuators due to the build-up of ice, or tail stall. 


\section{References}

1. AOPA Air Safety Foundation., "Safety Advisor Weather No. 1 - Aircraft Icing", www.aopa.org/asf/publications/sa11.pdf, 421 Aviation Way, Frederick, Maryland 21701, 2008.

2. Barnhart Billy. "CJ2 Icing Effects Simulator". Bihrle Applied Research, Inc. 400 Jericho Pike, Jericho, NY 11753. August 2007.

3. Barnhart Billy, Dickes Edward G., Gringras David R., Ratvasky Thomas P. "Simulation Model Development for Icing Effects Flight Training”. SAE 2002-01-1527. April 2002.

4. Bragg Michael B., Hutchison, T., Meret J., Oltman R., Pokhariyal D., "Effect of Ice Accretion on Aircraft Flight Dynamics," AIAA 2000-0360, Reno, NV. January 2000.

5. Bragg Michael B., Loth Eric. "Effects of Large-Droplet Ice Accretion on Airfoil and Wing Aerodynamics and Control". DOT/FAA/AR-00/14. University of Illinois at UrbanaChampaign Aeronautical and Astronautical Engineering, Urbana, IL 61801. March 2000.

6. B/E Aerospace. "De-Icing Systems". B/E Aerospace, Inc. Fenwick, WV, 26202. 2008.

7. Beamer F., Perhinschi M. G., Cunningham M., Davis J., "Development of a Simulation Environment to Support Aircraft Health Management Education", Proceedings of the AIAA Atmospheric Fligh Mechanics Conference, Portland, OR, August 2011.

8. CebeciTuncer, KafyekeFassi, "Aircraft Icing”, annurev.fluid.35.101101.161217, Annual Review Fluid Mech. Pg 11-21, 2003.

9. Civil Aviation Authority. "Aircraft Icing Handbook." Version 1. Lower Hutt, New Zealand. June 2000.

10. Cooper G.E., Harper R.P. (1969). "The Use of Pilot Ratings in the Evaluation of Aircraft Handling Qualities. NASA TN-D-5153. Moffett Field, CA: NASA Ames Research Center.

11. Cunningham Matthew, Perhinschi Mario. "A Simplified Icing Model for Simulation and Analysis of Dynamic Effects."AIAA Young Professional, Teacher, and Education Conference. Baltimore, Maryland. 4 November 2011.

12. Curry J, Liu G. "Assessment of Aircraft Icing Potential Using Satellite Data." Department of Meteorology, The Pennsylvania State University, University Park, Pennsylvania. October 1991.

13. David K, Gorham J, Kim S, Miller P, Minkus C. "Aeronautical Wind Tunnels Europe and Asia." Federal Research Division, Library of Congress, with NASA Aeronautics Research Mission Directorate, National Aeronautics and Space Administration. Page 93. Feb 2006.

14. Electronic Code of Federal Regulations. "Title 14 - Aeronautics and Space." Volume 2, Section 91.527 - "Operating in icing conditions." January 2011.

15. Etkin Bernard. "Dynamics of Flight Stability and Control”. Second Edition.John Wiley \& Sons. 1982. p.117.

16. "Federal Aviation Regulations" Wikipedia, the Free Encyclopedia. Wikimedia Foundation, Inc. 6 October 2011. Web. $27 \quad$ October 2011. http://en.wikipedia.org/wiki/Federal_Aviation_Regulations.

17. Fortin G, Laforte J, Beisswenger A. "Prediction of Ice Shapes on NACA0012 2D Airfoil," Anti-Icing Materials International Laboratory, Universite du Quebec a Chicoutimi, Quebec, Canada, SAE International 2003.

18. Gent R.W. "TRAJICE 2- A Combined Water Droplet Trajectory and Ice Accretion Prediction Program for Aerofoils," Royal Aircraft Establishment, RAE TR 90054, Farnborough, England, U.K., Nov. 1990. 
19. Goodrich M, Gorham J. "Wind Tunnels of the Western Hemisphere." Federal Research Division, Library of Congress, for the Aeronautics Research Mission Directorate, National Aeronautics and Space Administration. Page 117. June 2008.

20. Gouttebroze S, Saeed F, Paraschivoiu I. "CANICE - Capabilities and Current Status." EcolePolytechnique de Montreal, Departement de Genie Mecanique. CP 6079 Succ. Centre Ville, Montreal (Quebec, H3C 3A7, Canada. 2000

21. Gregorio Fabrizio De., Airoldi Maria, "PIV Investigation on Airfoil with Ice Accretions and Resulting Performance Degradation”, IEEE 0-7803-7022-8, Italy, 2001.

22. Habashi Wagdi G., "Newly formed research consortium explores ways to achieve optimal design of ice protection systems", ICAO Journal, Concordia University, Montreal, Quebec, Canada, October 1995.

23. Harper R.P., Cooper G.E., "Handling Qualities and Pilot Evaluation," Journal of Guidance, 9(5), 515-529, 1986.

24. Hedde T, Guffond D. “ONERA Three-Dimensional Icing Model” AIAA Journal ISSN 00011452. Vol. 33, page 1038-1045, 1995.

25. Huebsch, W.W. \&A.P. Rothmayer."Effects of Surface Ice Roughness on Dynamic Stall," AIAA Journal of Aircraft, Vol 39, Issue 6. Pages 945-953. December 2002.

26. Huebsch, W.W. \& A.P. Rothmayer. "Unsteady Navier-Stokes Simulation of Flow Past Surface Ice Geometrics," AIAA Paper 2000-0232, presented at the $38^{\text {th }}$ Aerospace Sciences Meeting, Reno, NV.

27. Irani E, Al-Khalil K."Calibration and Recent Upgrades to the Cox Icing Tunnel." American Institute of Aeronautics and Astronautics. September 2007.

28. LamptonAmanda,Valasek John, "Prediction of Icing Effects on the Coupled Dynamic Response of Light Airplanes". AIAA 2007-6484. AIAA Flight Mechanics Conference and Exhibit, Hilton Head, South Carolina, August 2007.

29. Lankford, Terry T. "Aircraft Icing: A Pilot's Guide". Mc-Graw Hill Companies Inc. 2000. p.41.

30. Lednicer David. "Airfoils of US and Canadian Aircraft". Analytical Methods, Inc. http://aerofiles.com/airfoils.html.

31. Levinson, L.H,Potapczuk, M.G, Mellor, P.A. "Software Development Processes Applied to Computational Icing Simulation.” NASA/TM-1999-208898 (AIAA Paper 99-0248), 1999.

32. NASA GRC Icing Branch. "In-Flight Icing Course Related Information." Aircrafticing.grc.nasa.gov/resources/related.html. October 2008. Last accessed March 2012.

33. Ogretim E, Huebsch W, Shinn A. "Aircraft Ice Accretion Prediction Based on Neural Networks". American Institute of Aeronautics and Astronautics. Journal of AircraftVol 43 Issue 1. 2006.

34. Paraschivoiu I, Gouttebroze S, and Saeed F, "CANICE-CapabilitiesandCurrent Status," NATO/RTO Workshop, Assessment of icing code prediction capabilities, at CIRA in Capua, Italy, Dec. 6-7, 2000.

35. Perhinschi M. G., Mullins S., Evans P., Napolitano E.R., "Computational Environment for the Development of an FAA Compliant Flight Simulator", Proceedings of the AIAA Modeling and Simulation Technologies Conference, Toronto, Canada, August 2010.

36. Perhinschi M. G., Napolitano M. R., "Teaching Aircraft Health Management- A SimulationBased Approach", Computers in Education Journal, vol. XVIIII, no.4, pp32-42, Oct-Dec, 2009. 
37. Potapcczuk Mark, "Review of the NATO/RTO Ice Accretion Code Evaluation Workshop", http://icingalliance.org/meetings/3-

D_Ice_Accretion_Code_Workshop_2010/documents/NATO_RTO_Potapczuk_080410_AIA A_Toronto.pdf, Toronto, On, Canada, August 4, 2010.

38. Ratvasky T.P, "Aircraft Icing and Its Effects On Performance and Handling", www.docstoc.com/docs/7232686/Tom-Ratvasky, NASA Glenn Research Center, Cleveland, Ohio 44135, December 2008.

39. Ratvasky T.P, Barnhart B.P., Lee S., "Current Methods for Modeling and Simulating Icing Effects on Aircraft Performance, Stability, and Control", NASA/TM- 2008-215453, NASA Glenn Research Center, Cleveland, Ohio 44135, December 2008.

40. Reveley Mary, Jones Sharon Monica. "Subsonic Aircraft Safety Icing Study". http://www.eng.morgan.edu/ cibac/events/Day2/IRAC/3SAS\%20Icing\%20Study\%20(Reveley_Jones)E7B3.pdf. October 2007.

41. Ritter Steve. "Aircraft Deicers". Chemical \& Engineering News. Volume 70, Number 1 CENEAR70 1 p.30, January 1, 2001.

42. Roskam Jan. "Aircraft Flight Dynamics and Automatic Flight Controls Part I". Dar corporation. 1440 Wakarusa Drive, Lawrence Kansas 66049. 2003. p. 438.

43. Schroeder B, Sarter N. "Supporting Decision-Making and Action Selection Under Time Pressure and Uncertainty: The Case of Inflight Icing." Institute for Ergonomics. The Ohio State University. Columbus, Oh.

44. Small Airplane Directorate, Federal Aviation Administration. "General Aviation Safety Challenges 2008 - Part 2.” 2008.

45. Strang Gilbert. "Introduction to Linear Algebra". Fourth Edition. Wellesley - Cambridge Press. 2009. p.287.

46. U.S. Military. "Military Specification. Flying Qualities of Piloted Airplanes." MILF_8785C. 5 November 1980.

47. VladimírHorák, ZdeněkChára, "In-Flight Ice Accretion Prediction Code". Incas Bulletin, Volume 2, Number 4. Pg 119-126, 2010.

48. White William J., "Advisory Circular- effect of Icing on Aircraft Control and Airplane Deice and Anti-ice Systems", U.S. Department of Transportation FAA, 95-51A, July 171996. 


\section{Appendix}

\section{A.1 User Manual}

The icing simulation model is a part of the WVU aircraft health management package. Please refer to the general aircraft health management package user manual for information on other types of simulation. The outlined process here will set up an icing simulation to use a flight stick for pilot inputs and icing effects on all surfaces of the aircraft including control surfaces. This will affect aircraft lift, drag, moment coefficient, lateral stability coefficients, and control coefficients.

Upon opening Matlab, the first step is to change the current working directory to the WVU Aircraft Health Management directory. By simply typing "start" in the command window, the Health Management portal is opened. Use the drop down box to select the Business Jet Icing option, as highlighted in Figure A-1.

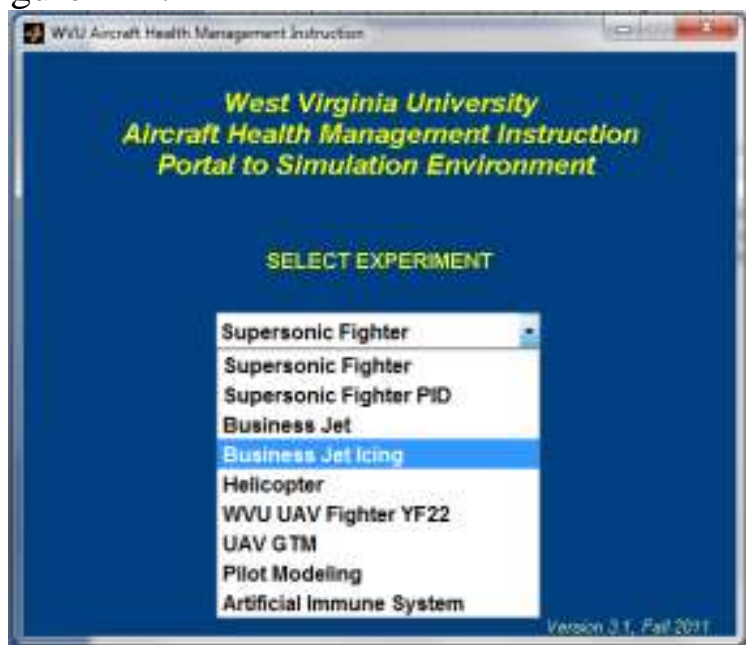

Figure A- 1: Health management portal window with Business Jet Icing highlighted.

Selecting this option and pressing the Continue button begins the setup of the icing simulation and brings up the Pilot Input Menu. This menu allows for the use of a flight stick, or selection of pre-recorded commands to be used with the simulation. Selecting the "All Joy-stick Generated" radio button allows for the use of a flight stick at any time to create pilot inputs. The configuration shown below will allow for pilot inputs.

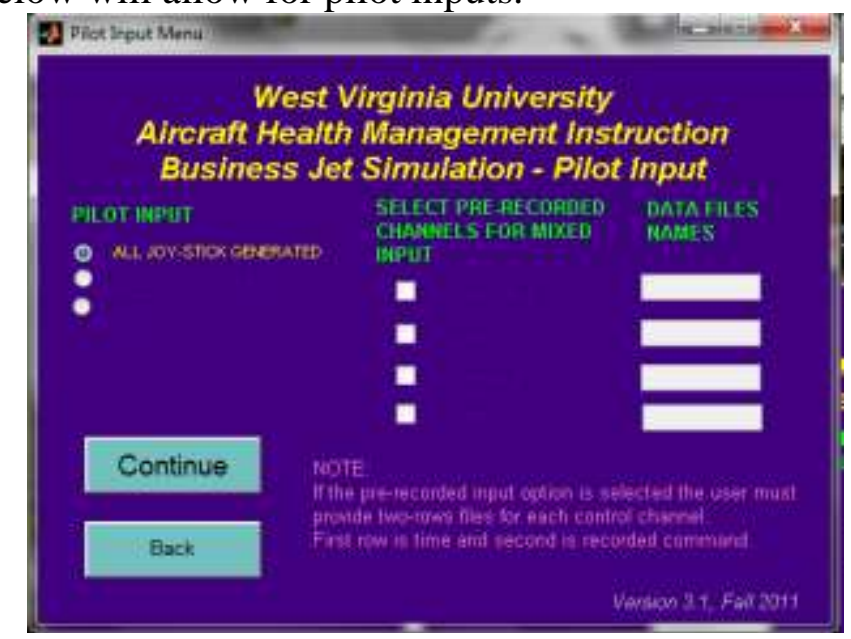

Figure A- 2: Pilot Input Menu set for joy-stick generated commands. 
Clicking continue brings up the icing selection menu. This menu is used to select which alteration coefficients are active in the icing model. For instance, if the box for "Icing affects only the lateral derivatives" is checked, then $k_{C_{l \beta}}, k_{C_{l P}}, k_{C_{n r}}$, and $k_{C_{n P}}$ will all change with respect to the time in icing. The remaining alteration coefficients will remain 1 . The check box at the bottom, "Check box to turn on icing of control surfaces," will enable the alteration coefficients for the control derivatives. By default the icing of control derivatives is off. Selecting the options as shown in Figure A-3 will enable icing effects on all available alteration coefficients.

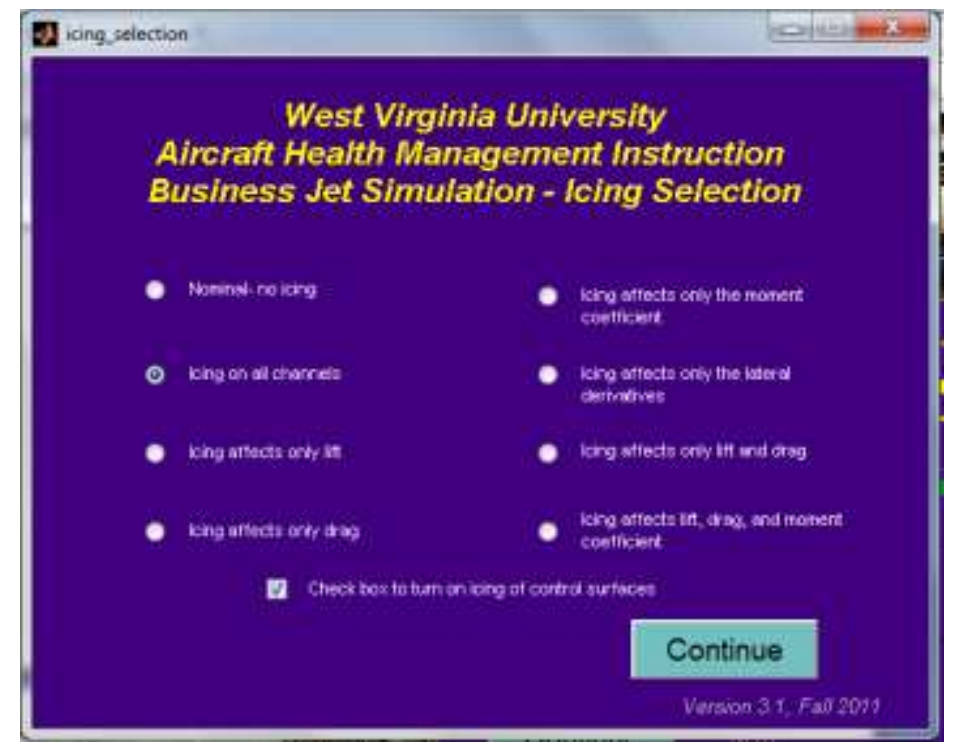

Figure A- 3: Icing Selection menu set to use all the alteration coefficients.

Pressing the continue button opens the Simulink model of the Business Jet Icing simulation and the ScopesFE menu. This menu is used to open a variety of scopes that are within Simulink. The button labeled Open FlightGear will open the FlightGear environment, which provides a 3dimensional visualization of the aircraft. At this stage the icing simulation is ready for use. 